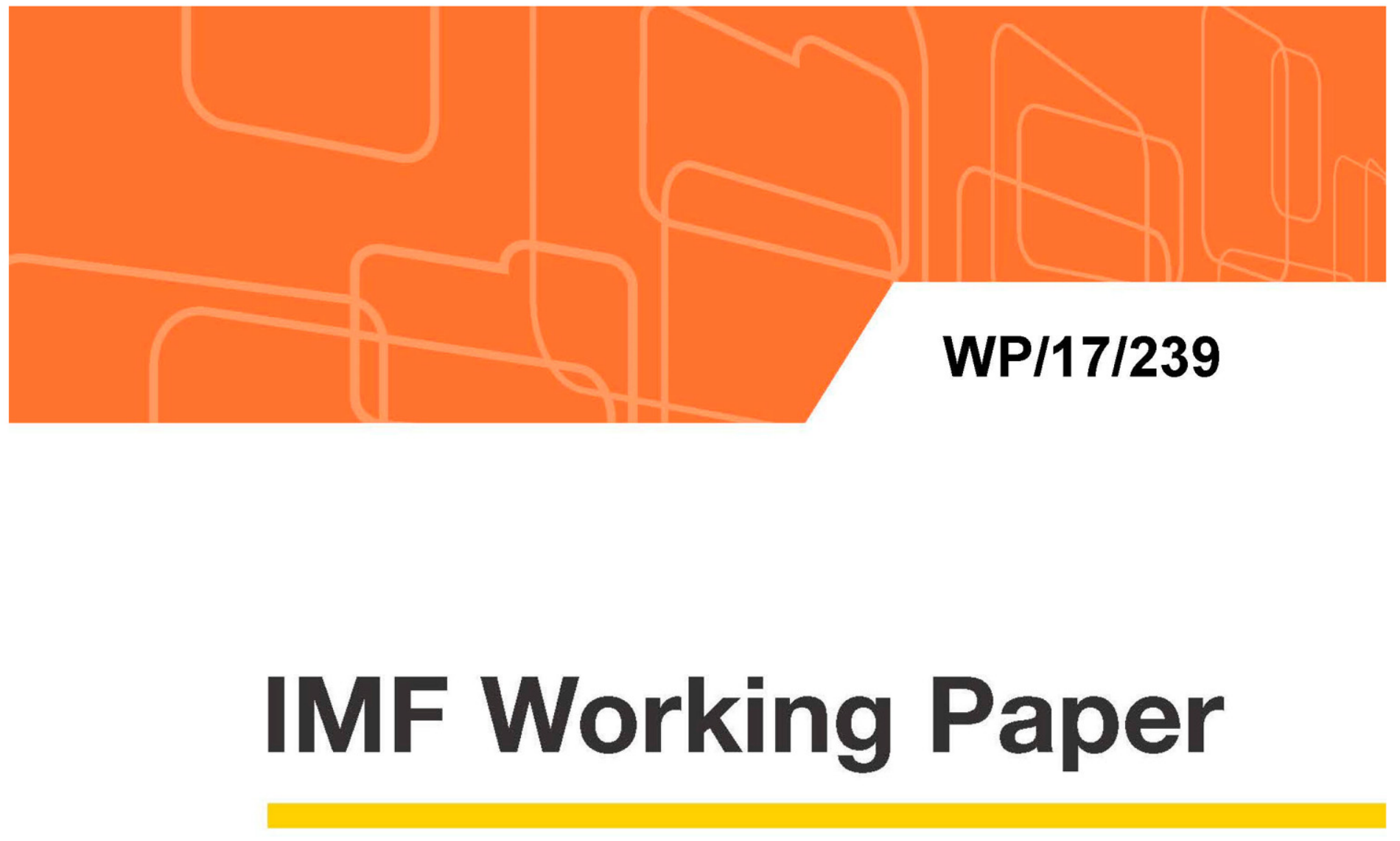

\title{
Global Trade and the Dollar
}

by Emine Boz, Gita Gopinath and Mikkel Plagborg-Møller

IMF Working Papers describe research in progress by the author(s) and are published to elicit comments and to encourage debate. The views expressed in IMF Working Papers are those of the author(s) and do not necessarily represent the views of the IMF, its Executive Board, or IMF management. 


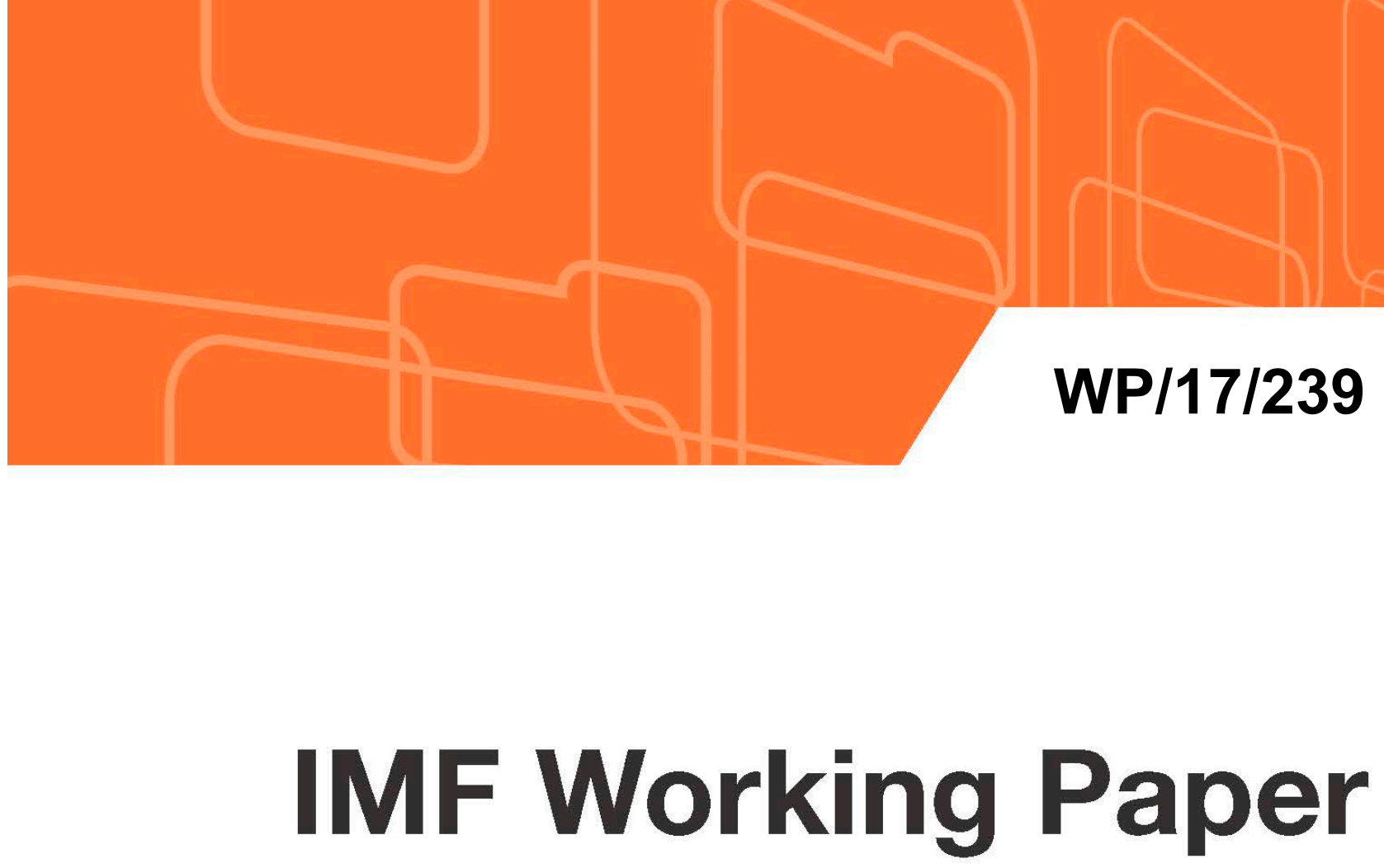

\section{Global Trade and the Dollar}

by Emine Boz, Gita Gopinath and Mikkel Plagborg-Møller

IMF Working Papers describe research in progress by the author(s) and are published to elicit comments and to encourage debate. The views expressed in IMF Working Papers are those of the author(s) and do not necessarily represent the views of the IMF, its Executive Board, or IMF management. 


\section{IMF Working Paper}

Research Department

\section{Global Trade and the Dollar ${ }^{1}$}

\section{Prepared by Emine Boz, Gita Gopinath and Mikkel Plagborg-Møller}

Authorized for distribution by Maurice Obstfeld

November 2017

\section{IMF Working Papers describe research in progress by the author(s) and are published to elicit comments and to encourage debate. The views expressed in IMF Working Papers are those of the author(s) and do not necessarily represent the views of the IMF, its Executive Board, or IMF management.}

We document that the U.S. dollar exchange rate drives global trade prices and volumes. Using a newly constructed data set of bilateral price and volume indices for more than 2,500 country pairs, we establish the following facts: 1) The dollar exchange rate quantitatively dominates the bilateral exchange rate in price pass-through and trade elasticity regressions. U.S. monetary policy induced dollar fluctuations have high pass-through into bilateral import prices. 2) Bilateral non-commodities terms of trade are essentially uncorrelated with bilateral exchange rates. 3) The strength of the U.S. dollar is a key predictor of rest-of-world aggregate trade volume and consumer/producer price inflation. A 1 percent U.S. dollar appreciation against all other currencies in the world predicts a $0.6-0.8$ percent decline within a year in the volume of total trade between countries in the rest of the world, controlling for the global business cycle. 4) Using a novel Bayesian semiparametric hierarchical panel data model, we estimate that the importing country's share of imports invoiced in dollars explains 15 percent of the variance of dollar pass-through/elasticity across country pairs. Our findings strongly support the dominant currency paradigm as opposed to the traditional Mundell-Fleming pricing paradigms.

JEL Classification Numbers: C11, C33, F14, F31

Keywords: Bayesian semiparametrics, bilateral trade, dominant currency, exchange rate passthrough, hierarchical Bayes, panel data, trade elasticity, U.S. dollar.

Authors’ E-Mail Addresses: eboz@imf.org; gopinath@harvard.edu; mikkelpm@princeton.edu

\footnotetext{
${ }^{1}$ We are grateful for comments from Isaiah Andrews, Gary Chamberlain, Michal Kolesár, Maury Obstfeld, Jonathan Ostry, and seminar participants at several venues. Evgenia Pugacheva provided excellent research assistance. Gopinath acknowledges that this material is based upon work supported by the NSF under Grant Number \#1628874. Any opinions, findings, and conclusions or recommendations expressed in this material are those of the author(s) and do not necessarily reflect the views of the NSF or the International Monetary Fund. All remaining errors are our own.
} 


\section{Introduction}

Exchange rate fluctuations impact a country's trade competitiveness, inflation, and output and therefore have important consequences for its welfare and economic policy. It is common practice to estimate this impact by examining the pass-through of bilateral or trade-weighted exchange rates into export and import prices and volumes. This practice follows naturally from the classic Mundell-Fleming paradigm of sticky prices and producer currency pricing whereby exporting firms infrequently change prices denominated in their home currency. According to this paradigm, the price an importing country faces when expressed in the importing country's currency fluctuates closely with the bilateral exchange rate. Accordingly, studies of exchange rate pass-through focus on trade-weighted or bilateral exchange rate changes (see Goldberg and Knetter (1997) and Burstein and Gopinath (2014) for surveys).

Recent evidence by Goldberg and Tille (2008) and Gopinath (2015) question the MundellFleming assumption of producer currency pricing, as the vast majority of trade is invoiced in a small number of "dominant currencies", with the U.S. dollar playing an outsize role. Accordingly Casas et al. (2016) develop a "dominant currency paradigm" where trade prices are sticky in dollars and demonstrate that the value of a country's currency relative to the dollar is a primary driver of a country's import prices and quantities regardless of where the good originates from, even at annual frequencies. They provide empirical evidence supporting these predictions using customs data for Colombia. However, no evidence exists on the the importance of dominant currencies for global trade. Such an analysis requires trade price and volume indices at the level of countrypairs, that excludes commodities, and covers many countries. This data is not readily available.

In this paper we contribute to the literature by first constructing annual trade price and volume data for country pairs broken down by commodities/noncommodities. Specifically, we construct harmonized annual bilateral import and export unit value and volume indices for 55 countries (yielding more than 2,500 dyads, i.e., trading pairs) from highly disaggregated UN Comtrade data starting as early as 1989 , depending on the country, and covering through 2015 . The countries in our sample comprise $91 \%$ of the world's total goods exports and imports in 2015.

We then employ this data, merged with currency invoicing data from Gopinath (2015), to examine the implications of the dominant currency paradigm for a large number of countries. In order to estimate the cross-sectional heterogeneity of pass-through and its relation to dollar invoicing, we employ a novel Bayesian semiparametric hierarchical panel data model.

Our empirical results reject the Mundell-Fleming benchmark in favor of the dominant currency paradigm by establishing the following facts: 1) The dollar exchange rate quantitatively dominates the bilateral exchange rate in price pass-through and trade elasticity regressions. U.S. 
monetary policy induced dollar fluctuations have high pass-through into bilateral import prices. 2) Bilateral non-commodities terms of trade are essentially uncorrelated with bilateral exchange rates. 3) The strength of the U.S. dollar is a key predictor of rest-of-world aggregate trade volume and consumer/producer price inflation. Specifically, a 1\% U.S. dollar appreciation against all other currencies in the world predicts a $0.6-0.8 \%$ decline within a year in the volume of total trade between countries in the rest of the world, holding constant various proxies for the global business cycle. 4) The importer's share of imports invoiced in dollars explains about $15 \%$ of the variance of dollar pass-through/elasticity across country pairs. These results derive from fixed effects panel regressions as well as a novel Bayesian semiparametric hierarchical panel data model. We now elaborate further on each of these findings.

First, we introduce the U.S. dollar exchange rate as an additional explanatory variable in price pass-through and trade elasticity regressions. In standard price pass-through regressions, we document that when country $j$ 's currency depreciates relative to country $i$ by $10 \%$, import prices in country $j$ for goods imported from country $i$ rise by $8 \%$, suggestive of close to complete passthrough at the one year horizon. However, adding the dollar to the regression knocks the coefficient on the bilateral exchange rate from 0.80 down to 0.32 in the case when exporter-reported prices are used, and from 0.76 to 0.16 when importer-reported prices are used. The coefficient on the dollar exchange rate of $0.66(0.78)$ dominates that of the bilateral exchange rate. This result cannot be attributed to the correlation of the dollar with the global business cycle, as we control for time fixed effects. Similarly, adding the dollar exchange rate to a bilateral volume forecasting regression knocks down the coefficient on the bilateral exchange rate by a substantial amount. The contemporaneous volume elasticity for the dollar exchange rate is around -0.20 across specifications and data sources, while the elasticity for the bilateral exchange rate is an order of magnitude smaller at -0.03 . We also show that the dollar's role as an invoicing currency is indeed special as it handily beats the explanatory power of the euro in price and volume regressions.

To evaluate the impact of U.S. monetary policy shocks on bilateral trade, we isolate daily dollar exchange rate changes on scheduled U.S. monetary policy announcement dates. As theory predicts, we document that a tightening of U.S. monetary policy is associated with a nominal appreciation of the dollar. Using only this subset of exchange rate changes in our regressions, we estimate a high pass-through of the dollar exchange rate into bilateral import prices. The impact of U.S. monetary shocks also significantly increases with the share of a country's imports invoiced in dollars.

Second, the previous finding that prices respond to the dollar exchange rate but not the bilateral exchange rate would imply that the terms of trade should not be sensitive to the bilateral 
exchange rate, in sharp contrast to the Mundell-Fleming paradigm. More generally, if bilateral trade is invoiced in a dominant currency (for some countries this could be the euro), we should obtain low sensitivity to bilateral exchange rate changes. We indeed find this to be the case. In a regression of changes in the bilateral non-commodities terms of trade on changes in the bilateral exchange rate and the bilateral relative producer price index (PPI), the contemporaneous coefficient on the exchange rate is indistinguishable from zero, with the $95 \%$ confidence interval equal to $[-0.013,0.037]$ for data reported by exporters, and $[-0.017,0.035]$ for data reported by importers. For comparison, the coefficient should be 1 under producer currency pricing and -1 under local currency pricing (i.e., pricing in the currency of the destination market), given fully rigid nominal prices.

Third, we demonstrate empirically that the strength of the U.S. dollar is a key predictor of restof-world trade volume and inflation, even controlling for measures of the global business cycle. We find that a $1 \%$ appreciation of the U.S. dollar relative to all other currencies is associated with a $0.6-0.8 \%$ contraction in rest-of-world (i.e., excluding the U.S. entirely) aggregate import volume within the year. Furthermore, countries with larger dollar import invoicing shares experience higher pass-through of the dollar exchange rate into consumer and producer price inflation. Whereas these findings are puzzling from the perspective of the traditional Mundell-Fleming model due to its emphasis on bilateral exchange rates, they emerge naturally in the dominant currency paradigm.

Fourth, we exploit our rich panel data set to show that the cross-dyad heterogeneity in passthrough coefficients is well explained by the propensity to invoice imports in dollars. We use the importer's country-level dollar invoicing share from Gopinath (2015) as a proxy for the invoicing share of bilateral imports. ${ }^{1}$ Standard panel regressions with interactions show that increasing the dollar invoicing share by 10 percentage points causes the contemporaneous dollar price pass-through to increase by 2.0-3.5 percentage points. Using a flexible hierarchical Bayesian framework to directly model pass-through heterogeneity, we estimate that the importer's dollar invoicing share explains $15 \%$ of the overall cross-dyad variance in dollar exchange rate passthrough into prices. We also find that the importer's dollar invoicing share affects the exchange rate elasticity of trade volumes. These findings confirm the quantitative importance of the global currency of invoicing, a key concept in the dominant currency paradigm.

The Bayesian estimation procedure we develop allows the data to speak flexibly about the extent and determinants of the cross-sectional heterogeneity of pass-through. We employ a ran-

\footnotetext{
${ }^{1}$ Casas et al. (2016) use customs data to calculate export invoicing shares for Colombia at the bilateral level and find small heterogeneity, implying that a country's average should serve as a good proxy for some countries.
} 
dom coefficients panel data model, where the distribution of the random coefficient on the dollar exchange rate is allowed to depend nonparametrically on the dollar invoicing share as well as unobserved determinants of pass-through heterogeneity. Unlike standard panel regressions that can be informative about the average pass-through and the statistical significance of the determinants of pass-through heterogeneity, the Bayesian approach allows us to quantify the overall cross-sectional heterogeneity of exchange rate pass-through/elasticities and the relation of this heterogeneity to dollar invoicing. The hierarchical aspect of the Bayesian inference procedure can be thought of as striking an optimal bias-variance balance between two extreme approaches: (1) constrained but precisely estimated panel regressions with cross-sectionally constant parameters and (2) unconstrained but noisily estimated dyad-by-dyad time series regressions. Despite the high dimensionality of our semiparametric model, posterior sampling is handled efficiently and robustly by the user-friendly open source software Stan (Stan Development Team, 2016).

Given the magnitudes of our results and the global coverage of our data, we conclude that the dominant currency paradigm is a more empirically relevant starting point than traditional modeling approaches when analyzing the international transmission of shocks and optimal monetary and exchange rate policy.

Literature review. Our exchange rate pass-through analysis appears to be among the first to exploit a globally representative data set on bilateral trade volumes in addition to values. This allows us to distinguish the effects of exchange rates on volumes and prices (more precisely, unit values) at the level of country pairs. We use the cross-sectional richness of our data set to investigate the determinants of differential pass-through, especially as it relates to currency of invoicing. Our analysis appears to be the first attempt in the literature at quantifying both the overall extent and the determinants of the heterogeneity of exchange rate pass-through and elasticity across trade dyads.

To our knowledge, the only other work that utilizes a similarly rich data set is Bussière et al. (2016), who analyze trade prices and quantities at the product level. The goal of that paper is to quantify the elasticity of prices and quantities to the bilateral exchange rate and check if MarshallLerner conditions hold. In contrast, our goal is to understand the prominence of dominant currencies in international trade by comparing the importance of dollar and bilateral exchange rates and by exploiting data on currency invoicing.

The remaining literature on exchange rate pass-through falls into two main camps. ${ }^{2}$ First,

\footnotetext{
${ }^{2}$ The trade gravity equation literature frequently uses extensive bilateral data sets, but the data is on trade values without distinguishing between prices and volumes (see the review by Head and Mayer, 2015).
} 
many papers have used unilateral/country-level time series, which limits the ability to analyze cross-sectional heterogeneity and necessitates the use of trade-weighted rather than truly bilateral exchange rates (e.g., Leigh et al., 2015). Second, a recent literature has estimated pass-through of bilateral exchange rates into product-level prices (as opposed to unit values), but these micro data sets are only available for a small number of countries (see the review by Burstein and Gopinath, 2014).

Our paper confirms that the findings of Casas et al. (2016) are relevant for the majority of world trade, and we establish additional channels of U.S. dollar dominance. Casas et al. (2016) model the dominant currency paradigm and test its implications for the dollar's role in pass-through regressions and for the terms of trade using product level data for Colombia. We depart from this paper by providing evidence for the dominant currency paradigm using newly constructed import and export price index data for 55 countries and over 2,500 country-pairs. Moreover, we relate the heterogeneity in pass-through estimates to the dollar invoicing shares of countries, estimate the impact of U.S. monetary policy shocks on bilateral import price pass-through, and demonstrate that the strength of the dollar is a key predictor of rest-of-world trade and consumer/producer price inflation.

The findings in this paper help shed light on the literature on producer (Obstfeld and Rogoff (1995), Corsetti and Pesenti (2001), Galí (2008)) versus local currency pricing (Betts and Devereux (2000), Devereux and Engel (2003), Engel (2011)). Corsetti et al. (2010) provide an in-depth analysis of both. By demonstrating that global trade data is less consistent with these frameworks than with dominant currency pricing, our results open up new avenues for research into the consequences and determinants of currency invoicing under sticky prices.

From a methodological perspective, our paper's contribution is to introduce a semiparametric Bayesian panel data model with cross-sectionally heterogeneous slope coefficients. Our specification of the cross-sectional distribution of slope coefficients relies on the Mixture of Gaussian Linear Regression nonparametric conditional density prior in Pati et al. (2013), who derive highlevel posterior concentration results. The MGLR prior extends the much-used Dirichlet Process Mixture density prior to conditional density estimation. ${ }^{3}$ Liu (2017) uses the MGLR prior specification but places it on the unit-specific panel intercepts (rather than slopes), and she focuses on forecasting rather than characterizing cross-sectional heterogeneity. Although our linear-inparameters specification is more restrictive than the frequentist non-parametric approaches of Evdokimov (2010) and Chernozhukov et al. (2013), our Bayesian framework facilitates visualization of the conditional pass-through distribution, uncertainty assessment, and model selection.

\footnotetext{
${ }^{3}$ Hirano (2002) imposes the DPM prior on the distribution of idiosyncratic errors in a panel data model.
} 
Outline. Section 2 discusses a simple conceptual framework that motivates our empirical analysis. Section 3 describes our data set of bilateral trade unit values and quantities, exchange rates, dollar invoicing shares, and U.S. monetary shocks. Section 4 presents panel regression evidence on the average pass-through from bilateral, dollar, and euro exchange rates (or monetary shocks) into prices, quantities, and terms of trade. In Section 5, we employ the Bayesian model to characterize the cross-sectional heterogeneity of dollar pass-through and its relation to invoicing shares. Section 6 shows that the strength of the U.S. dollar is a key predictor of rest-of-world trade volume and inflation. Section 7 concludes. Appendix A details the data set and Bayesian approach. Appendix B contains supplementary material on data, empirics, and numerical procedures.

\section{Conceptual framework}

In this section we provide a simple conceptual framework along the lines of Proposition 2 in Casas et al. (2016) to motivate the empirical analysis that follows. Define $p_{i j}$ to be the log price of goods exported from country $i$ to country $j$ measured in currency $j, e_{i j}$ to be the log bilateral exchange rate between country $i$ and country $j$ expressed as the price of currency $i$ in terms of currency $j$, and $e_{\$_{j}}$ to be the $\log$ price of a U.S. dollar in currency $j$. Suppose a fraction $\theta_{i}$ of these exports are invoiced in the producer's (country $i$ ) currency, a fraction $\theta_{j}$ in the local (destination country $j$ ) currency and a fraction $\theta_{u}$ in the dominant currency (dollar) with $\sum_{k \in\{i, j, u\}} \theta_{k}=1$. Import price inflation for country $j$ for goods originating from country $i$ is then

$$
\Delta p_{i j, t}=\theta_{j} \Delta p_{i j, t}^{j}+\theta_{i}\left[\Delta p_{i j, t}^{i}+\Delta e_{i j, t}\right]+\theta_{u}\left[\Delta p_{i j, t}^{u}+\Delta e_{u j, t}\right],
$$

where $p_{i j, t}^{k}$ stands for the price of goods imported by country $j$ from $i$ that are invoiced in the currency $k$. Under Calvo pricing we have, $\Delta p_{i j, t}^{k}=\left(1-\delta_{p}\right)\left(\bar{p}_{i j, t}^{k}-p_{i j, t-1}^{k}\right)$ where $\bar{p}_{i j, t}^{k}$ is the reset-price for $(i j)$ in currency $k$. Through substitution we can express import price inflation as

$$
\Delta p_{i j, t}=\theta_{i} \Delta e_{i j, t}+\theta_{u} \Delta e_{u j, t}+\left(1-\delta_{p}\right) \sum_{k} \theta_{k} \Delta \bar{p}_{i j, t}^{k}
$$

where $\Delta \bar{p}_{i j, t}^{k} \equiv \bar{p}_{i j, t}^{k}-p_{i j, t-1}^{k}$. In the very short run when $\delta_{p} \rightarrow 1$, we have the following benchmarks for the changes in import prices and the terms of trade (TOT). 
- In the case of producer currency pricing $(P C P), \theta_{i}=1$ and $\theta_{j}=\theta_{u}=0$,

$$
\begin{aligned}
\Delta p_{i j, t} & =1 \cdot \Delta e_{i j, t}+0 \cdot \Delta e_{u j, t}, \quad \Delta p_{j i, t}=-1 \cdot \Delta e_{i j, t}+0 \cdot \Delta e_{u j, t} \\
\text { tot }_{i j, t} & =\Delta p_{i j, t}-\left(\Delta p_{j i, t}+\Delta e_{i j, t}\right)=1 \cdot \Delta e_{i j, t} .
\end{aligned}
$$

- In the case of local currency pricing $(L C P), \theta_{j}=1$ and $\theta_{i}=\theta_{u}=0$,

$$
\begin{aligned}
& \Delta p_{i j, t}=0 \cdot \Delta e_{i j, t}+0 \cdot \Delta e_{u j, t} \quad \Delta p_{j i, t}=0 \cdot \Delta e_{i j, t}+0 \cdot \Delta e_{u j, t} \\
& \text { tot }_{i j, t}=\Delta p_{i j, t}-\left(\Delta p_{j i, t}+\Delta e_{i j, t}\right)=-1 \cdot \Delta e_{i j, t} .
\end{aligned}
$$

- In the case of dominant currency pricing $(D C P), \theta_{u}=1$ and $\theta_{i}=\theta_{j}=0$,

$$
\begin{aligned}
\Delta p_{i j, t} & =0 \cdot \Delta e_{i j, t}+1 \cdot \Delta e_{u j, t}, \quad \Delta p_{j i, t}=0 \cdot \Delta e_{i j, t}+1 \cdot \Delta e_{u i, t}, \\
t_{t o t} t_{i j, t} & =\Delta p_{i j, t}-\left(\Delta p_{j i, t}+\Delta e_{i j, t}\right)=0 \cdot \Delta e_{i j, t} .
\end{aligned}
$$

In summary, the predicted coefficients from a regression of (log) changes in import prices on (log) changes in bilateral and dollar exchange rates differ qualitatively across the $P C P, L C P$, and $D C P$ benchmarks, as do the implications for the terms of trade.

A primitive assumption of Keynesian environments is that prices are sticky in the currency of invoicing. This assumption is supported by direct measures of price stickiness for U.S. prices-atthe dock in Gopinath and Rigobon (2008) and for Irish prices-at-the dock in Fitzgerald and Haller (2013). Cravino (2017) provides indirect evidence of price stickiness using differential sensitivity of Chilean export prices invoiced in different currencies to exchange rate shocks, similar to the evidence in Gopinath et al. (2010).

At longer horizons, some prices do adjust and the predictions depend on the response of reset prices $\bar{p}_{i j, t}^{k}$ to changes in $e_{i j, t}$. With endogenous currency choice and Calvo timing, Gopinath et al. (2010) demonstrate that firms choose to price in currencies in which its reset price is most stable, i.e., its desired pass-through conditional on a price change is low. Consequently, even at longer (annual) horizons, we expect the divergent predictions across $P C P, L C P$, and $D C P$ to hold.

\section{Data}

The core of our data set consists of panel data on bilateral trade values and volumes from Comtrade. To this global data set we append macroeconomic country aggregates from the World 
Bank's World Development Indicators, financial variables from the Federal Reserve Bank of St. Louis's FRED database, and currency invoicing shares from Gopinath (2015). Finally, we construct an annual series of U.S. monetary policy induced exchange rate changes.

Comtrade. UN Comtrade provides detailed customs data for a large set of countries at HS 6digit product level with information about the USD value, quantity, and weight of imports and exports. This dataset makes it possible to compute volume changes over time for each product, and use the value data to infer unit values. Once unit values are calculated, we compute Laspeyres, Paasche and Fisher indices, both in their fixed base and chained forms to aggregate up from the product level. We do various aggregations, the main one being across products we classify as commodities and one for noncommodities. Given the inherent difficulty in drawing a line between commodities and noncommodities, we define commodities fairly broadly as HS chapters 1-27 and 72-83 which comprise animal, vegetable, food, mineral, and metal products. We use chained Fisher indices in the analysis that follows, except where noted. ${ }^{4}$

We conduct this exercise at annual frequency, and for exporter and importer reported data separately. Coverage of Comtrade at annual frequency over time and across countries is good. The longest time span of the data is 1989-2015, although the coverage varies by dyad. Appendix A.1 breaks down the coverage by country. In 2015, the 55 countries in our sample are responsible for $91.2 \%$ and $91.5 \%$ of the value of world goods imports and exports, respectively, as recorded in Comtrade. For each reporting country, we construct indices for both imports and exports. This gives us two sets of numbers for each bilateral trade flow, one as reported by the importer and one as reported by the exporter, and allows us to do robustness checks by comparing our empirical results across the two sets.

The biggest challenge for constructing price and volume indices using customs data is the so-called unit value bias, as argued by Silver (2007). Unit values, calculated simply by dividing observed values by quantities, are not actual prices. Even at the narrowly defined product categories at 6-digit product level, there is likely to be a wide range of products whose prices may not be moving proportionately. The implication is that if there are shifts in quantities traded within the narrowly defined product categories, unit values would be influenced even when there may not be any price movement. This creates a bias that the employed methodology takes a stab at correcting for by eliminating products whose unit values have a variance higher than a threshold and hence are more likely to suffer from the unit value bias.

\footnotetext{
${ }^{4}$ The Fisher price index satisfies a number of tests laid out in index number theory and is flexible enough to provide a good proxy for a large set of functional forms (Gaulier et al., 2008; IMF, 2009).
} 
Another challenge that arises from using Comtrade data is related to the use of different HS vintages over time. HS classification is updated about every five years to ensure that the available codings accurately reflect the variety of products being traded. This involves introducing codes for new products, eliminating the old ones, and often regrouping existing products. While concordances are readily available to facilitate the matching of HS codes across different HS vintages, this process inevitably leads to a loss of information, especially in the case of data on quantities, because the mapping of products across vintages is rarely one-to-one. To get around this problem, for the years in which there is a transition to a new HS vintage, we compute the indices twice, once under the old vintage (using concordances) and once under the new one. This way, only these transition years would be effected by the loss of information due to matching across vintages. After that year, we switch to working with the new vintage. This method not only minimizes the loss of information but also allows us to include new products in the construction of the indices. Boz and Cerutti (2017) provide further details of this method, including the strategy for dealing with outliers and missing values, and a comparison with a similar dataset constructed by Gaulier et al. (2008).

In the final stage, we compare our unit value indices to those provided by the BLS for the U.S., the only country, to our knowledge, that collects import price indices based on price surveys by origin. As shown in Appendix B.1, this comparison for the U.S. suggests that working with unit values is acceptable, as the growth rates of the two series are broadly aligned for most trading partners. Additionally, Boz and Cerutti (2017) find favorable results when comparing countrylevel indices with those from the WTO and IMF World Economic Outlook.

Currency invoicing share. For currency invoicing shares we use the data set constructed by Gopinath (2015). The export and import invoicing share for a country is a simple average of the respective shares for the years in which it is reported over the period 1999-2014. For all countries the invoicing shares tend to be fairly stable over time. Appendix A.1 lists the USD and euro import invoicing share for the 39 countries in our sample with available invoicing data.

U.S. monetary shocks. We compute currency-specific annual U.S. monetary policy induced exchange rate changes by summing across daily exchange rate changes on U.S. Federal Open Market Committee (FOMC) announcement dates. We use the scheduled FOMC announcement dates for 1990-2004 from Gürkaynak et al. (2005), supplemented with dates for 2005-2013 from Nakamura and Steinsson (2016), as well as dates for 2014-2015 from the FOMC meeting calendar on the website of the Board of Governors. There are a total of 219 scheduled announcement dates from 1990-2015. On each of these dates, we compute the daily log change (relative to the previous 
weekday) in the exchange rate vis-à-vis the U.S. dollar for each country in the Comtrade sample. Daily exchange rate series were obtained from FactSet (close mid price). ${ }^{5}$ To obtain an annual series for each country, we compute the unweighted sum of the log exchange rate changes on FOMC dates in a given year.

Country-level and global macro data. We use the World Bank's World Development Indicators (WDI) database as the source for annual average exchange rates and macroeconomic data for the world and for the countries in our sample. We obtain the WTI oil price, 1-year Treasury bill rate, and VIX from the St. Louis Fed's FRED database. See Appendix A.1 for details.

\section{Bilateral pass-through, terms of trade, and the dollar}

In this section we show that our global trade dataset is consistent with the dominant currency paradigm: The U.S. dollar plays an outsize role in driving international trade prices and quantities. We run fixed effects panel regressions at the dyad (country pair) level with exchange rates as the independent variable, and either prices, terms of trade, or volumes as the dependent variables. In all cases we find that bilateral (importer vs. exporter) exchange rates matter substantially less than the exchange rate vis-à-vis the U.S. dollar. The effects of the dollar are stronger when the importing country has a higher fraction of trade invoiced in dollars. The pass-through of the subset of dollar exchange rate fluctuations that are due to U.S. monetary policy actions is high. Finally, we show that the dollar's quantitative dominance holds up in specifications that control also for the euro exchange rate.

All specifications below rely on Comtrade series that use Fisher price indices, data for noncommodities goods only, and the preferred imputation and outlier truncation technique of Boz and Cerutti (2017). In Appendix B.2 we show that our results are robust to alternative choices.

\subsection{Exchange rate pass-through into prices}

We first examine the pass-through of bilateral and dollar exchange rates to bilateral trade price indices. Define $p_{i j}$ to be the $\log$ price of goods exported from country $i$ to country $j$ measured in currency $j, e_{i j}$ to be the $\log$ bilateral exchange rate between country $i$ and country $j$ expressed as the price of currency $i$ in terms of currency $j$, and $e_{{ }_{\$}}$ to be the log price of a U.S. dollar in

\footnotetext{
${ }^{5}$ FactSet corrects exchange rates for redenomination and currency substitution. We only use data on FOMC dates.
} 
currency $j$. We estimate the following specifications,

$$
\begin{gathered}
\Delta p_{i j, t}=\lambda_{i j}+\delta_{t}+\sum_{k=0}^{2} \alpha_{k} \Delta e_{i j, t-k}+\theta^{\prime} X_{i, t}+\varepsilon_{i j, t} \\
\Delta p_{i j, t}=\lambda_{i j}+\delta_{t}+\sum_{k=0}^{2} \alpha_{k} \Delta e_{i j, t-k}+\sum_{k=0}^{2} \beta_{k} \Delta e_{\$ j, t-k}+\theta^{\prime} X_{i, t}+\varepsilon_{i j, t} \\
\Delta p_{i j, t}=\lambda_{i j}+\delta_{t}+\sum_{k=0}^{2} \alpha_{k} \Delta e_{i j, t-k}+\sum_{k=0}^{2} \eta_{k} \Delta e_{i j, t-k} \times S_{j} \\
+\sum_{k=0}^{2} \beta_{k} \Delta e_{\$ j, t-k}+\sum_{k=0}^{2} \psi_{k} \Delta e_{\$ j, t-k} \times S_{j}+\theta^{\prime} X_{i, t}+\varepsilon_{i j, t}
\end{gathered}
$$

where $\lambda_{i j}$ and $\delta_{t}$ are dyadic and time fixed effects, respectively. $X_{i, t}$ are other controls, namely the change in the log producer price index of the exporting country $i$ measured in currency $i$ (and two lags).

For reference, we first consider the specification without the dollar exchange rate as an explanatory variable. Regression Eq. (1) is a standard pass-through regression where bilateral import prices are regressed on bilateral exchange rates. The estimates from such a regression are reported in columns (1) and (4) of Table 1. Column (1) uses import prices of country $j$ originating from country $i$ as reported by country $i$, and column (4) uses prices reported by country $j$. Under perfect construction, these two should be the same, but that is not the case in practice. However, we obtain similar estimates for pass-through. According to these estimates, when country $j$ 's currency depreciates relative to country $i$ by $10 \%$, import prices in country $j$ rise by $8 \%$, suggestive of close to complete pass-through at the one year horizon. ${ }^{6}$ The second and third lags are economically less important.

Our main result in this section establishes the dominance of the dollar over bilateral exchange rates in predicting trade price movements. Columns (2) and (5) report estimates from regression Eq. (2). As is evident, including the dollar exchange rate sharply reduces the relevance of the bilateral exchange rate. It knocks the coefficient on the bilateral exchange rate from 0.80 down to 0.32 in the case when exporter-reported prices are used, and from 0.76 to 0.16 when importerreported prices are used. Instead, almost all of the effect is absorbed by the dollar exchange

\footnotetext{
${ }^{6}$ With year fixed effects this should be interpreted as fluctuations in excess of world annual fluctuations.
} 
EXCHANGE RATE PASS-THROUGH INTO PRICES

\begin{tabular}{|c|c|c|c|c|c|c|}
\hline VARIABLES & $\begin{array}{c}(1) \\
\text { export } \\
\Delta p_{i j, t}\end{array}$ & $\begin{array}{c}(2) \\
\text { export } \\
\Delta p_{i j, t} \\
\end{array}$ & $\begin{array}{c}(3) \\
\text { export } \\
\Delta p_{i j, t}\end{array}$ & $\begin{array}{c}(4) \\
\text { import } \\
\Delta p_{i j, t}\end{array}$ & $\begin{array}{c}(5) \\
\text { import } \\
\Delta p_{i j, t}\end{array}$ & $\begin{array}{c}(6) \\
\text { import } \\
\Delta p_{i j, t}\end{array}$ \\
\hline$\Delta e_{i j, t}$ & $\begin{array}{l}0.801^{* * *} \\
(0.0113)\end{array}$ & $\begin{array}{l}0.315^{* * *} \\
(0.0127)\end{array}$ & $\begin{array}{l}0.318^{* * *} \\
(0.0177)\end{array}$ & $\begin{array}{l}0.757^{* * *} \\
(0.0132)\end{array}$ & $\begin{array}{l}0.164^{* * *} \\
(0.0126)\end{array}$ & $\begin{array}{l}0.209^{* * *} \\
(0.0169)\end{array}$ \\
\hline$\Delta e_{i j, t-1}$ & $\begin{array}{l}0.0762^{* * *} \\
(0.00675)\end{array}$ & $\begin{array}{l}0.115^{* * *} \\
(0.0133)\end{array}$ & $\begin{array}{l}0.126^{* * *} \\
(0.0206)\end{array}$ & $\begin{array}{l}0.0674^{* * *} \\
(0.00818)\end{array}$ & $\begin{array}{c}0.0521^{* * *} \\
(0.0123)\end{array}$ & $\begin{array}{l}0.0270^{*} \\
(0.0154)\end{array}$ \\
\hline$\Delta e_{i j, t-2}$ & $\begin{array}{c}0.0113^{* *} \\
(0.00489)\end{array}$ & $\begin{array}{c}-0.0656^{* * *} \\
(0.0114)\end{array}$ & $\begin{array}{c}-0.0863^{* * *} \\
(0.0147)\end{array}$ & $\begin{array}{l}0.0306^{* * *} \\
(0.00608)\end{array}$ & $\begin{array}{c}-0.0727^{* * *} \\
(0.0127)\end{array}$ & $\begin{array}{c}-0.0721^{* * *} \\
(0.0167)\end{array}$ \\
\hline$\Delta e_{i j, t} \times S_{j}$ & & & $\begin{array}{l}-0.0152 \\
(0.0230)\end{array}$ & & & $\begin{array}{c}-0.0841^{* * *} \\
(0.0240)\end{array}$ \\
\hline$\Delta e_{i j, t-1} \times S_{j}$ & & & $\begin{array}{l}-0.0156 \\
(0.0260)\end{array}$ & & & $\begin{array}{c}0.0319 \\
(0.0232)\end{array}$ \\
\hline$\Delta e_{i j, t-2} \times S_{j}$ & & & $\begin{array}{c}0.0205 \\
(0.0156)\end{array}$ & & & $\begin{array}{c}-0.000922 \\
(0.0164)\end{array}$ \\
\hline$\Delta e_{\$ j, t}$ & & $\begin{array}{l}0.656^{* * *} \\
(0.0142)\end{array}$ & $\begin{array}{l}0.522^{* * *} \\
(0.0274)\end{array}$ & & $\begin{array}{l}0.781^{* * *} \\
(0.0143)\end{array}$ & $\begin{array}{l}0.565^{* * *} \\
(0.0283)\end{array}$ \\
\hline$\Delta e_{\$ j, t-1}$ & & $\begin{array}{c}-0.128^{* * *} \\
(0.0146)\end{array}$ & $\begin{array}{c}-0.118^{* * *} \\
(0.0290)\end{array}$ & & $\begin{array}{c}-0.0737^{* * *} \\
(0.0157)\end{array}$ & $\begin{array}{c}0.0844^{* * *} \\
(0.0276)\end{array}$ \\
\hline$\Delta e_{\$ j, t-2}$ & & $\begin{array}{c}0.0857^{* * *} \\
(0.0124)\end{array}$ & $\begin{array}{l}0.143^{* * *} \\
(0.0227)\end{array}$ & & $\begin{array}{l}0.104^{* * *} \\
(0.0146)\end{array}$ & $\begin{array}{l}0.117^{* * *} \\
(0.0259)\end{array}$ \\
\hline$\Delta e_{\$ j, t} \times S_{j}$ & & & $\begin{array}{l}0.196^{* * *} \\
(0.0320)\end{array}$ & & & $\begin{array}{l}0.348^{* * *} \\
(0.0326)\end{array}$ \\
\hline$\Delta e_{\$ j, t-1} \times S_{j}$ & & & $\begin{array}{l}-0.0145 \\
(0.0353)\end{array}$ & & & $\begin{array}{c}-0.185^{* * *} \\
(0.0358)\end{array}$ \\
\hline$\Delta e_{\$ j, t-2} \times S_{j}$ & & & $\begin{array}{c}-0.0716^{* * *} \\
(0.0261)\end{array}$ & & & $\begin{array}{l}-0.0495^{*} \\
(0.0290)\end{array}$ \\
\hline Exp. PPI & yes & yes & yes & yes & yes & yes \\
\hline Time FE & yes & yes & yes & yes & yes & yes \\
\hline R-squared & 0.411 & 0.447 & 0.507 & 0.356 & 0.398 & 0.515 \\
\hline Observations & 45,945 & 45,945 & 33,291 & 46,820 & 46,820 & 34,513 \\
\hline Dyads & 2,611 & 2,611 & 1,867 & 2,647 & 2,647 & 1,900 \\
\hline
\end{tabular}

Table 1: The first (resp., last) three columns use Comtrade data reported by exporting (resp., importing) countries. S.e. clustered by dyad. ${ }^{* * *} \mathrm{p}<0.01,{ }^{* *} \mathrm{p}<0.05,{ }^{*} \mathrm{p}<0.1$. 
rate. $^{7}$ Notice that, due to our inclusion of time fixed effects, the apparent dominance of the dollar cannot be an artifact of special conditions that may apply in times when the dollar appreciates or depreciates against all other currencies, for example due to global recessions or flight to safety in asset markets. Appendix B.2 shows that our results are robust to the choice of time sample.

The cross-dyad heterogeneity in pass-through coefficients is related to the propensity to invoice imports in dollars. Columns (3) and (6) interact the dollar and bilateral exchange rates with the share of invoicing in dollars at the importer country level, as in regression Eq. (3). Notice that we do not have data on the fraction of bilateral trade invoiced in dollars, so we use the importer's country-level share as a proxy. As expected, the import invoicing share plays an economically and statistically significant role for the dollar pass-through. Depending on whether we use prices reported by exporters or importers, the regression results indicate that increasing the dollar invoicing share by 10 percentage points causes the contemporaneous dollar pass-through to increase by $2.0-3.5$ percentage points. In Section 5 below we further quantify the importance of the dollar invoicing share for explaining the cross-sectional variation in pass-through.

Figs. 1 and 2 depict the regression results visually in the form of impulse response functions. Fig. 1 shows the impulse responses of the bilateral import price level. The top row uses exporter reported data, the bottom row importer reported data. The left column shows the bilateral passthrough in the specifications without the dollar exchange rate, while the right column compares the bilateral and dollar pass-throughs in specifications with both exchange rates. Fig. 2 illustrates the pass-through heterogeneity as a function of the invoicing share $S_{j}$, as implied by the regression specifications with interactions. The figure focuses on three representative countries: Switzerland $\left(S_{j}=0.13\right)$, Turkey $\left(S_{j}=0.59\right)$, and Argentina $\left(S_{j}=0.88\right)$. Although Fig. 2 suggests that dollar pass-through is high even for low dollar invoicing shares, this particular finding appears to be an artifact of using country-level dollar invoicing shares rather than bilateral shares. If we weight the pass-through regression by trade value shares, giving higher weight to dyads that are responsible for a larger share of the importer's total imports, the bilateral pass-through is estimated to exceed the dollar pass-through when the dollar invoicing share is low (e.g., $S_{j}=0.13$ ).

\footnotetext{
${ }^{7}$ While the exporter- and importer-reported data sets disagree somewhat about the level of bilateral pass-through, the dollar pass-through is consistent across data sets. The dollar pass-through dominates in both data sets. The World Bank views importer-reported data as more reliable since imports generate tariff revenues (World Bank, 2010), see also Feenstra et al. (2005).
} 
AVERAGE PRICE PASS-THROUGH

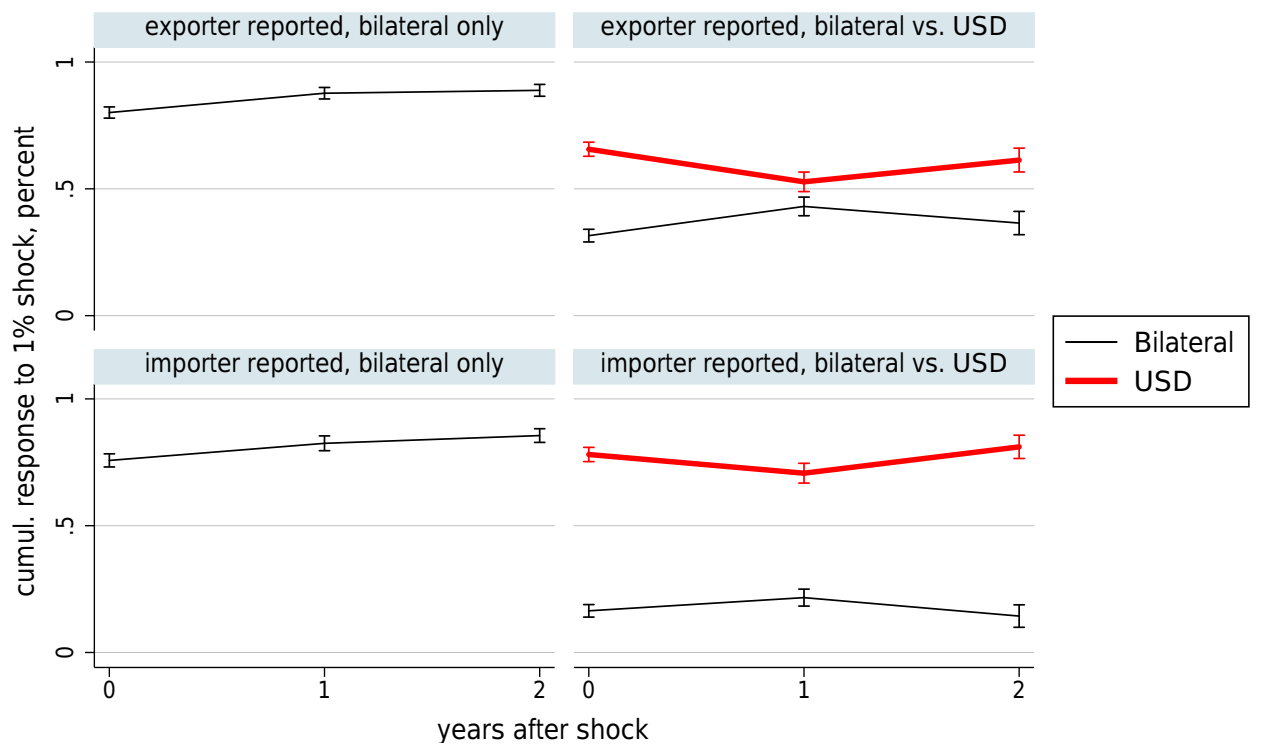

Figure 1: Impulse responses of bilateral price level to bilateral $e_{i j, t}$ and USD $e_{\$ j, t}$ exchange rates. Based on the regressions in Table 1 without interactions. Top row: exporter reported data, bottom row: importer reported. Left column: specifications (1) and (4), right column: specifications (2) and (5). Error bars: 95\% confidence intervals, clustering by dyad.

Price PASS-THROUGH AS A FUNCTION OF INVOICING SHARE

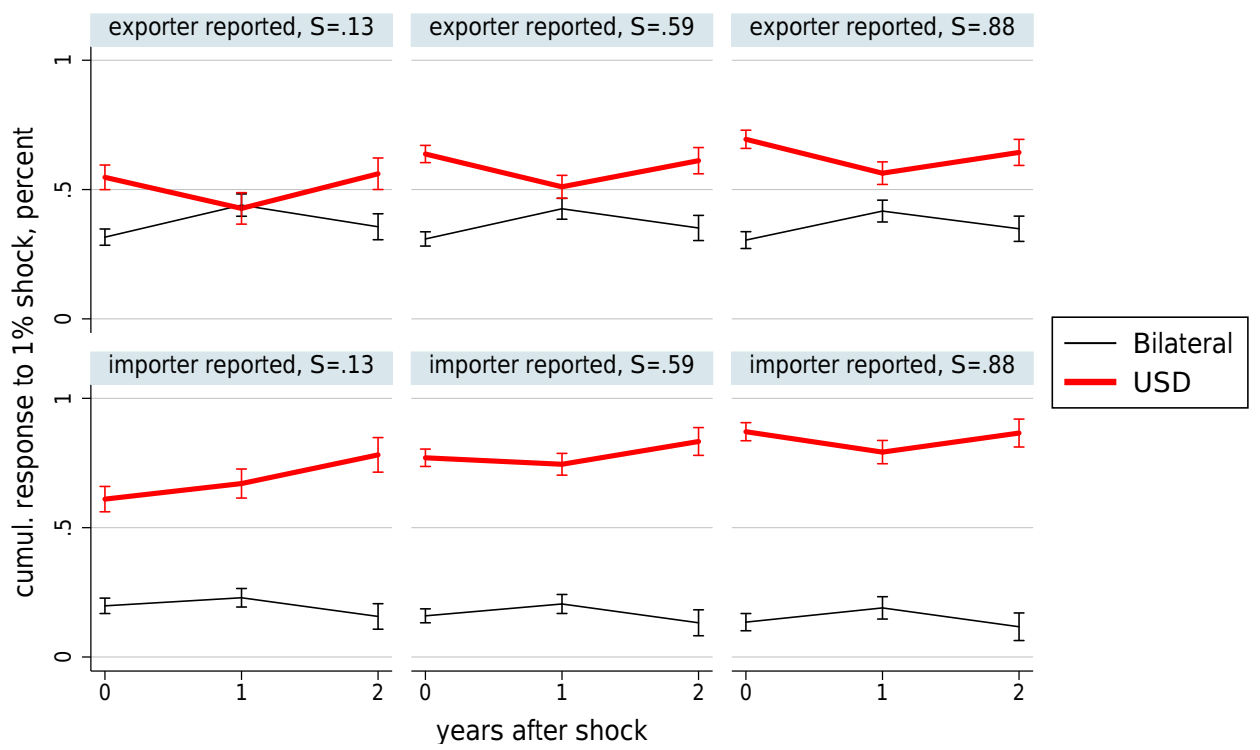

Figure 2: Impulse responses of bilateral price level to bilateral $e_{i j, t}$ and USD $e_{\$ j, t}$ exchange rates, as a function of importer's dollar invoicing share $S_{j}$. Based on regression specifications (3) and (6) in Table 1 with interactions. Top row: exporter reported data, bottom row: importer reported. Error bars: 95\% confidence intervals, clustering by dyad. 


\subsection{Terms of trade and exchange rates}

The previously established fact that prices respond to the dollar exchange rate but not the bilateral exchange rate implies that the terms of trade should not respond to the bilateral exchange rate. We now test this hypothesis directly in our data by relating bilateral terms of trade to bilateral exchange rates. In this subsection, a cross-sectional unit is defined to be an unordered country pair, so that all trade flows between two countries $i$ and $j$ are associated with the cross-sectional unit $\{i, j\}$. Define the bilateral $\log$ terms of trade $t_{i j}=p_{i j}-p_{j i}-e_{i j}$, a unitless quantity (i.e., export and import price indices are measured in the same currency). Moreover, let $p p i_{i j}$ denote the $\log$ ratio of PPI in country $i$ divided by PPI in country $j$, with indices expressed in the same currency.

We consider the following regressions:

$$
\begin{gathered}
\Delta \text { tot }_{i j, t}=\lambda_{i j}+\delta_{t}+\sum_{k=0}^{2} \alpha_{k} \Delta e_{i j, t-k}+\varepsilon_{i j, t}, \\
\Delta t_{o t} t_{i j, t}=\lambda_{i j}+\delta_{t}+\sum_{k=0}^{2} \alpha_{k} \Delta e_{i j, t-k}+\sum_{k=0}^{2} \beta_{k} \Delta p p i_{i j, t-k}+\varepsilon_{i j, t},
\end{gathered}
$$

where $\lambda_{i j}$ and $\delta_{t}$ are dyadic and time fixed effects. Regression Eq. (4) relates the growth rate of the bilateral terms of trade to the growth rate of the bilateral nominal exchange rate (and two lags). As discussed in Section 2, if exporting firms set prices in their local currencies (producer currency pricing, PCP) and prices are sticky, the contemporaneous exchange rate coefficient $\alpha_{0}$ should equal 1. On the other hand, if exporting firms set prices in the destination currency (local currency pricing, LCP) and prices are sticky, the contemporaneous exchange rate coefficient should be -1 . However, if most prices are invoiced in U.S. dollars and are sticky in nominal terms, the coefficients $\alpha_{k}$ should be close to zero. Regression Eq. (5) controls for lags 0-2 of the growth rate of the ratio of PPI in the two countries, since firms' optimal reset prices should fluctuate with domestic cost conditions.

In line with the dominant currency paradigm, we find that bilateral exchange rates are virtually uncorrelated with bilateral terms of trade. The results of the panel regressions are shown in Table 2. If we do not control for relative PPI, the regression results indicate that the contemporaneous effect of the exchange rate on the terms of trade is negative, in direct contradiction of PCP. While the negative sign is consistent with LCP, the magnitude is not, as the $95 \%$ confidence interval equals $[-0.11,-0.07]$ for data reported by exporters, and $[-0.05,-0.02]$ for data 
TERMS OF TRADE AND EXCHANGE RATES

\begin{tabular}{|c|c|c|c|c|}
\hline VARIABLES & $\begin{array}{c}(1) \\
\text { export } \\
\Delta t_{o t} t_{i j, t}\end{array}$ & $\begin{array}{c}(2) \\
\text { export } \\
\Delta t_{o t} t_{i j, t}\end{array}$ & $\begin{array}{c}(3) \\
\text { import } \\
\Delta \text { tot }_{i j, t}\end{array}$ & $\begin{array}{c}(4) \\
\text { import } \\
\Delta \text { tot }_{i j, t}\end{array}$ \\
\hline$\Delta e_{i j, t}$ & $\begin{array}{c}-0.0881^{* * *} \\
(0.00941)\end{array}$ & $\begin{array}{c}0.0121 \\
(0.0127)\end{array}$ & $\begin{array}{c}-0.0369^{* * *} \\
(0.00863)\end{array}$ & $\begin{array}{l}0.00938 \\
(0.0130)\end{array}$ \\
\hline$\Delta e_{i j, t-1}$ & $\begin{array}{c}0.0157 \\
(0.0102)\end{array}$ & $\begin{array}{l}-0.0126 \\
(0.0169)\end{array}$ & $\begin{array}{c}0.0447^{* * *} \\
(0.0104)\end{array}$ & $\begin{array}{c}-0.0167 \\
(0.0157)\end{array}$ \\
\hline$\Delta e_{i j, t-2}$ & $\begin{array}{l}0.0269^{* * *} \\
(0.00875)\end{array}$ & $\begin{array}{r}-0.00807 \\
(0.0105)\end{array}$ & $\begin{array}{c}0.00174 \\
(0.00788)\end{array}$ & $\begin{array}{c}0.00710 \\
(0.00877)\end{array}$ \\
\hline$\Delta p p i_{i j, t}$ & & $\begin{array}{l}0.239^{* * *} \\
(0.0246)\end{array}$ & & $\begin{array}{c}0.0340 \\
(0.0260)\end{array}$ \\
\hline$\Delta p p i_{i j, t-1}$ & & $\begin{array}{l}0.0605^{* *} \\
(0.0257)\end{array}$ & & $\begin{array}{c}-0.131^{* * *} \\
(0.0263)\end{array}$ \\
\hline$\Delta p p i_{i j, t-2}$ & & $\begin{array}{c}-0.0687^{* * *} \\
(0.0195)\end{array}$ & & $\begin{array}{c}-0.0511^{* *} \\
(0.0212)\end{array}$ \\
\hline Time FE & yes & yes & yes & yes \\
\hline R-squared & 0.007 & 0.015 & 0.008 & 0.011 \\
\hline Observations & 22,928 & 18,757 & 24,270 & 19,847 \\
\hline Dyads & 1,322 & 1,172 & 1,347 & 1,200 \\
\hline
\end{tabular}

Table 2: The first (resp., last) two columns use Comtrade data reported by exporting (resp., importing) countries. S.e. clustered by dyad. The number of dyads is about half that in Table 1 since here the two ordered country tuples $(i, j)$ and $(j, i)$ are collapsed into one cross-sectional unit $\{i, j\} .{ }^{* * *} \mathrm{p}<0.01,{ }^{* *}$ $\mathrm{p}<0.05,{ }^{*} \mathrm{p}<0.1$.

reported by importers. ${ }^{8}$ The coefficients on the first and second lags have opposite sign of the contemporaneous coefficient but are very small in magnitude. When controlling for relative PPI, the point estimates of the coefficients on the bilateral exchange rate shrink further toward zero, and confidence intervals on these coefficients remain narrow. Hence, the results lend strong support to the prediction of the dominant currency paradigm: Terms of trade are unresponsive to bilateral exchange rates.

\footnotetext{
${ }^{8}$ Attenuation bias is not a worry in this context, since the explanatory variables of interest (exchange rates) are precisely measured, except perhaps for time aggregation issues at the annual frequency.
} 


\subsection{Trade volume elasticity}

Having demonstrated the outsize role of the U.S. dollar in determining international prices, we now show that the dollar also dominates the bilateral exchange rate when predicting bilateral trade volumes.

Table 3 shows the results from panel regressions of trade volume on bilateral and dollar exchange rates. Let $y_{i j}$ denote the log volume of goods exported from country $i$ to country $j$. Our volume regressions take the same form as in the price pass-through regressions Eqs. (1) to (3), except that the dependent variable is now the log growth rate $\Delta y_{i j, t}$ of bilateral trade volumes, and the extra controls $X_{j, t}$ (here indexed by $j$ rather than $i$ ) consist of the log growth rate of real GDP (and two lags) for the importing country $j$. These regressions do not capture structural demand elasticity parameters, since we do not attempt to control for all relevant relative prices, and the importer's GDP growth is an imperfect proxy for the level of import demand. In particular, our results will invariably conflate expenditure switching and shifts in aggregate import demand (for example due to valuation effects on net foreign assets). We view these regressions as predictive relationships that may inform future structural estimation exercises. Nevertheless, we will refer to the coefficients on exchange rates as "trade elasticities" for simplicity.

The volume regressions underline the dominant role played by the U.S. dollar. As in the case of the price pass-through regressions, adding the dollar exchange rate to the volume regressions knocks down the coefficient on the bilateral exchange rate by a substantial amount. The contemporaneous elasticity for the dollar exchange rate is around -0.2 across specifications and data sources, while the elasticity for the bilateral exchange rate is an order of magnitude smaller. The data point to an interesting reversal in the years following the contemporaneous effect, whereby import volumes tend to increase one year after a ceteris paribus depreciation of the importer currency rate vis-à-vis the dollar. We discuss these lag dynamics below. Unlike the price pass-through regressions, the interactions of exchange rate changes with the importer's dollar invoicing share are mostly imprecisely estimated here.

Fig. 3 visually depicts the regression results in the form of impulse responses. The figure shows the response of the level of bilateral trade volume to exchange rate shocks. The right column shows results from regression specifications with both bilateral and dollar exchange rates. It is apparent from the figure that the dollar exchange rate has a much more negative impact effect than the bilateral exchange rate. Yet, the figure also shows that the effect of either exchange rate on the level is essentially neutral at horizons of 1-2 years, due to the negative lagged terms in Table 3. One potential explanation is that the ratio of import prices and domestic prices adjust with a lag to exchange rate changes, implying that a year after the initial shock, relative prices 
TRADE ELASTICITY WITH RESPECT TO EXCHANGE RATE

\begin{tabular}{|c|c|c|c|c|c|c|}
\hline VARIABLES & $\begin{array}{c}(1) \\
\text { export } \\
\Delta y_{i j, t} \\
\end{array}$ & $\begin{array}{c}(2) \\
\text { export } \\
\Delta y_{i j, t}\end{array}$ & $\begin{array}{c}(3) \\
\text { export } \\
\Delta y_{i j, t}\end{array}$ & $\begin{array}{c}(4) \\
\text { import } \\
\Delta y_{i j, t}\end{array}$ & $\begin{array}{c}(5) \\
\text { import } \\
\Delta y_{i j, t}\end{array}$ & $\begin{array}{c}(6) \\
\text { import } \\
\Delta y_{i j, t}\end{array}$ \\
\hline$\Delta e_{i j, t}$ & $\begin{array}{c}-0.148^{* * *} \\
(0.0148)\end{array}$ & $\begin{array}{c}-0.0384^{* *} \\
(0.0180)\end{array}$ & $\begin{array}{c}0.0171 \\
(0.0403)\end{array}$ & $\begin{array}{c}-0.119^{* * *} \\
(0.0139)\end{array}$ & $\begin{array}{l}-0.0310^{*} \\
(0.0160)\end{array}$ & $\begin{array}{l}-0.0765 \\
(0.0403)\end{array}$ \\
\hline$\Delta e_{i j, t-1}$ & $\begin{array}{c}0.0755^{* * *} \\
(0.0148)\end{array}$ & $\begin{array}{l}0.00728 \\
(0.0198)\end{array}$ & $\begin{array}{l}-0.0682 \\
(0.0485)\end{array}$ & $\begin{array}{c}0.0757^{* * *} \\
(0.0126)\end{array}$ & $\begin{array}{c}-0.00245 \\
(0.0165)\end{array}$ & $\begin{array}{l}0.00742 \\
(0.0354)\end{array}$ \\
\hline$\Delta e_{i j, t-2}$ & $\begin{array}{c}0.0416^{* * *} \\
(0.0102)\end{array}$ & $\begin{array}{c}0.0128 \\
(0.0141)\end{array}$ & $\begin{array}{c}0.0495 \\
(0.0311)\end{array}$ & $\begin{array}{l}0.0393^{* * *} \\
(0.00919)\end{array}$ & $\begin{array}{l}0.0235^{* *} \\
(0.0115)\end{array}$ & $\begin{array}{l}0.00410 \\
(0.0241)\end{array}$ \\
\hline$\Delta e_{i j, t} \times S_{j}$ & & & $\begin{array}{l}-0.0606 \\
(0.0655)\end{array}$ & & & $\begin{array}{c}0.118^{*} \\
(0.0684)\end{array}$ \\
\hline$\Delta e_{i j, t-1} \times S_{j}$ & & & $\begin{array}{c}0.0976 \\
(0.0746)\end{array}$ & & & $\begin{array}{l}-0.0433 \\
(0.0640)\end{array}$ \\
\hline$\Delta e_{i j, t-2} \times S_{j}$ & & & $\begin{array}{l}-0.0441 \\
(0.0494)\end{array}$ & & & $\begin{array}{c}0.0419 \\
(0.0428)\end{array}$ \\
\hline$\Delta e_{\$ j, t}$ & & $\begin{array}{c}-0.237^{* * *} \\
(0.0294)\end{array}$ & $\begin{array}{c}-0.188^{* * *} \\
(0.0587)\end{array}$ & & $\begin{array}{c}-0.186^{* * *} \\
(0.0250)\end{array}$ & $\begin{array}{l}-0.140^{* *} \\
(0.0600)\end{array}$ \\
\hline$\Delta e_{\$ j, t-1}$ & & $\begin{array}{l}0.148^{* * *} \\
(0.0278)\end{array}$ & $\begin{array}{l}0.359^{* * *} \\
(0.0666)\end{array}$ & & $\begin{array}{l}0.168^{* * *} \\
(0.0248)\end{array}$ & $\begin{array}{l}0.221^{* * *} \\
(0.0635)\end{array}$ \\
\hline$\Delta e_{\$ j, t-2}$ & & $\begin{array}{c}0.0542^{* * *} \\
(0.0201)\end{array}$ & $\begin{array}{l}-0.114^{* *} \\
(0.0580)\end{array}$ & & $\begin{array}{c}0.0365^{*} \\
(0.0198)\end{array}$ & $\begin{array}{c}0.111^{* *} \\
(0.0525)\end{array}$ \\
\hline$\Delta e_{\$ j, t} \times S_{j}$ & & & $\begin{array}{l}-0.0104 \\
(0.0906)\end{array}$ & & & $\begin{array}{c}-0.0903 \\
(0.0871)\end{array}$ \\
\hline$\Delta e_{\$ j, t-1} \times S_{j}$ & & & $\begin{array}{c}-0.244^{* *} \\
(0.100)\end{array}$ & & & $\begin{array}{l}-0.0465 \\
(0.0922)\end{array}$ \\
\hline$\Delta e_{\$ j, t-2} \times S_{j}$ & & & $\begin{array}{c}0.192^{* *} \\
(0.0797)\end{array}$ & & & $\begin{array}{l}-0.0952 \\
(0.0706)\end{array}$ \\
\hline Imp. GDP & yes & yes & yes & yes & yes & yes \\
\hline Time FE & yes & yes & yes & yes & yes & yes \\
\hline R-squared & 0.073 & 0.075 & 0.084 & 0.069 & 0.071 & 0.074 \\
\hline Observations & 50,761 & 50,761 & 36,757 & 52,272 & 52,272 & 38,582 \\
\hline Dyads & 2,773 & 2,773 & 1,982 & 2,807 & 2,807 & 2,014 \\
\hline
\end{tabular}

Table 3: The first (resp., last) three columns use Comtrade data reported by exporting (resp., importing) countries. S.e. clustered by dyad. ${ }^{* * *} \mathrm{p}<0.01,{ }^{* *} \mathrm{p}<0.05,{ }^{*} \mathrm{p}<0.1$. 
Average trade ElASticity

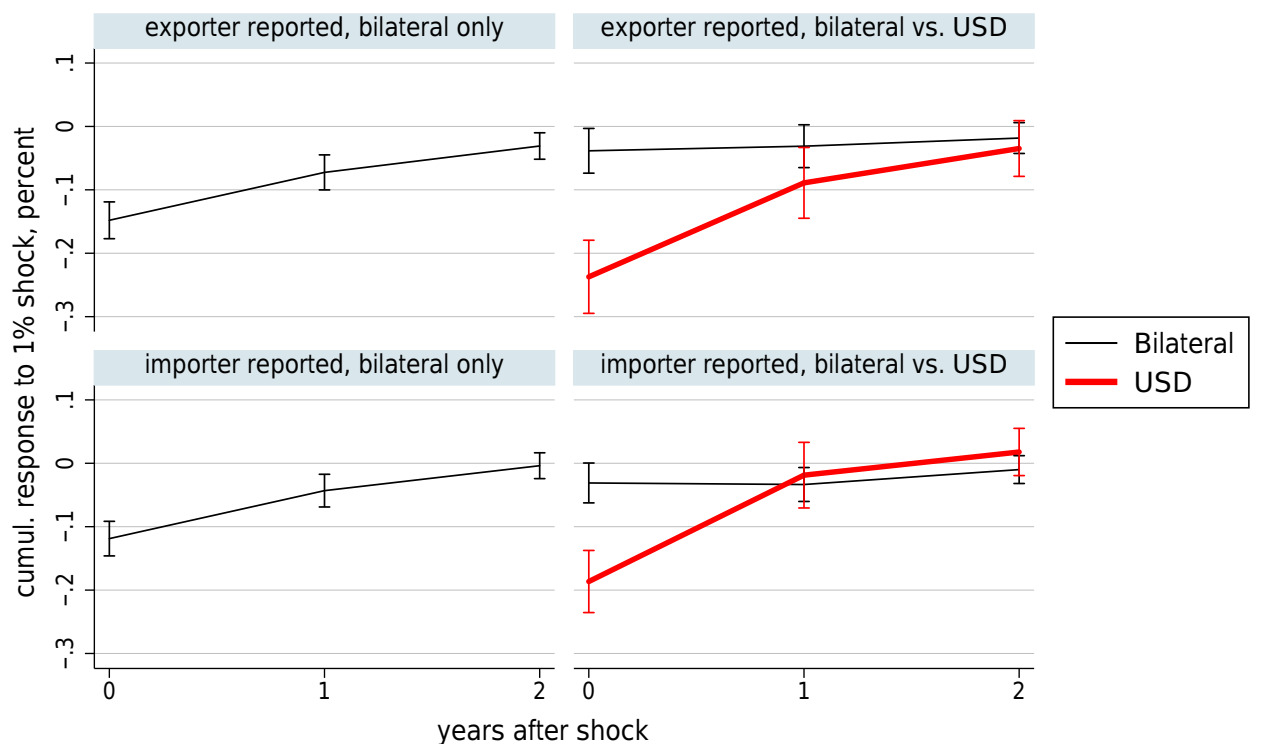

Figure 3: Impulse responses of bilateral volume to bilateral $e_{i j, t}$ and USD $e_{\$ j, t}$ exchange rates. Based on regressions in Table 3 without interactions. Top row: exporter reported data, bottom row: importer reported. Left column: specifications (1) and (4), right column: specifications (2) and (5). Error bars: $95 \%$ confidence intervals, clustering by dyad.

\section{TRADE ELASTICITY AS A FUNCTION OF INVOICING SHARE}

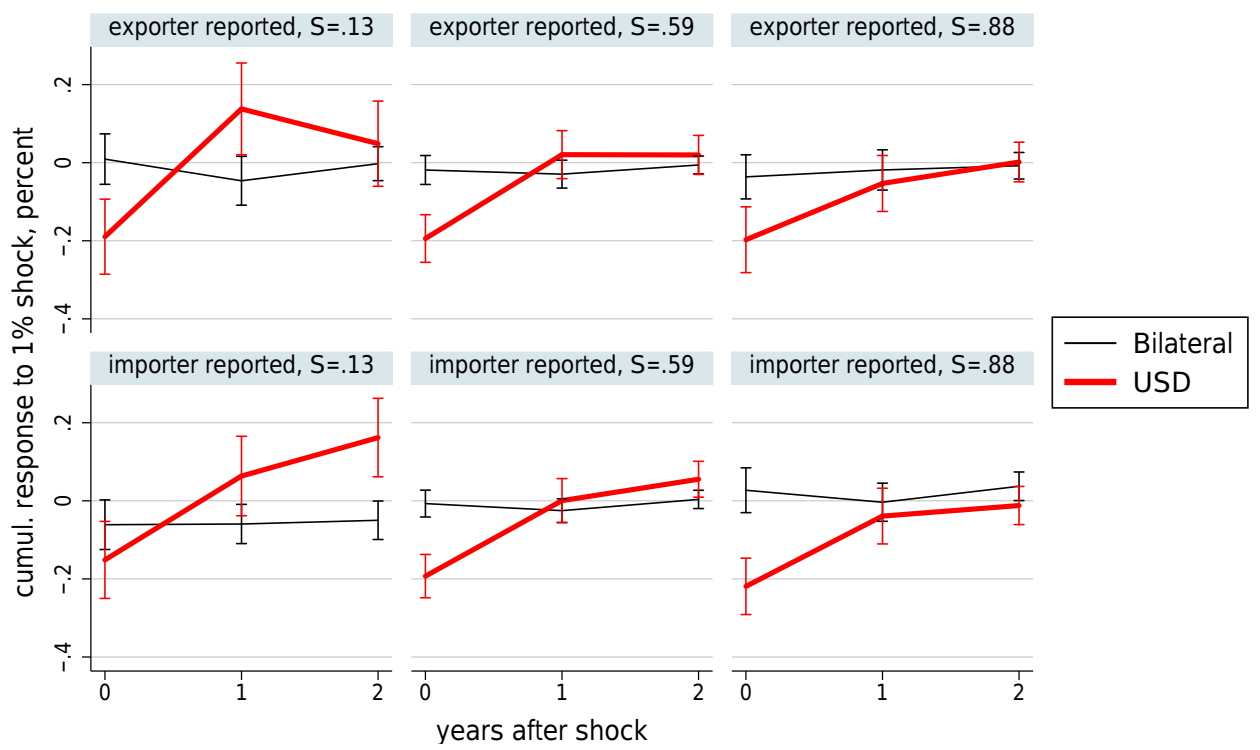

Figure 4: Impulse responses of bilateral volume to bilateral $e_{i j, t}$ and USD $e_{\$ j, t}$ exchange rates, as a function of importer's dollar invoicing share $S_{j}$. Based on regression specifications (3) and (6) in Table 1 with interactions. Top row: exporter reported data, bottom row: importer reported. Error bars: 95\% confidence intervals, clustering by dyad. 
faced by consumers are mostly unchanged compared to the period before the shock. However, we show in Appendix B.2 that this particular finding is driven by the early years in our sample, as results on the 2002-2015 subsample point toward a large, permanent negative effect of dollar appreciations on the volume of bilateral trade.

Fig. 4 illustrates the trade elasticity heterogeneity as a function of the dollar invoicing share, similar to Fig. 2. The point estimates of the impulse responses point toward an association between higher dollar invoicing shares and more negative trade elasticities, but the confidence intervals are wider than in our earlier price pass-through regressions. Section 5 provides further quantitative evidence on trade elasticity heterogeneity and its determinants.

\subsection{Effects of U.S. monetary policy shocks}

We now directly estimate the effects of U.S. monetary policy induced exchange rate changes on bilateral trade. The dominant role played by the dollar in our earlier price and volume regressions suggests that U.S. monetary policy actions that cause the dollar to fluctuate could have large spillover effects on international trade prices and volumes. In this section we directly measure the impulse responses with respect to U.S. monetary shocks.

As described in Section 3, for each country we construct an annual measure of U.S. monetary policy induced exchange rate fluctuations by summing daily log exchange rate changes on dates with scheduled FOMC announcements. Let $z_{j, t}$ be the sum of these daily log changes in year $t$ for country $j$, where the exchange rate is measured in units of country $j$ currency per U.S. dollar. The use of daily exchange rate changes on FOMC announcement dates allows for a specific interpretation of the shocks $z_{j, t}$, whereas the overall exchange rate change $\Delta e_{\$ j, t}$ arguably is an amalgam of the effects of several distinct shocks. However, we do not claim that $z_{j, t}$ is solely driven by U.S. monetary policy actions, or that all fluctuations in $z_{j, t}$ are necessarily "surprises". Because we are interested in a large number of currencies for a sample going back to 1990, we cannot use high-frequency intra-day data as in Andersen et al. (2003), Gürkaynak et al. (2005), and Nakamura and Steinsson (2016), for example.

Daily and annual data are consistent with our interpretation of the U.S. monetary shock series. U.S. monetary tightenings are associated with appreciations of the dollar against the currencies in our sample: The daily correlation of log exchange rate changes (across all currencies) and changes in the U.S. 1-year Treasury bill rate is 0.064 on FOMC dates in the period 1990-2007 (i.e., excluding the zero lower bound period). The standard deviation of daily log exchange rate changes across all currencies is $0.72 \%$ on FOMC dates; it is $0.92 \%$ across all days in the $1990-2015$ sample. The standard deviation of the annual (i.e., summed) monetary shock series $z_{j, t}$ is $2.6 \%$, 
compared to an annual standard deviation of $31.6 \%$ for overall log exchange rate changes $\Delta e_{\$ j, t}$ on the same 1990-2015 sample. The annual correlation of $z_{j, t}$ and $\Delta e_{\$ j, t}$ is 0.17 . We conclude that our monetary shock series captures a small but nontrivial fraction of shocks to exchange rates vis-à-vis the dollar.

We measure the effect of U.S. monetary policy actions on bilateral trade prices using panel fixed effects regressions as in Eqs. (1) to (3) in Section 4.1, except here we replace raw exchange rate changes with our U.S. monetary shock series. Specifically, we replace the log change in the bilateral exchange rate $\Delta e_{i j, t}$ with the U.S. monetary policy induced change in the bilateral exchange rate, $z_{j, t}-z_{i, t}$, and we replace the log change in the dollar exchange rate $\Delta e_{\$ j, t}$ with the dollar exchange rate shock $z_{j, t}$. We include lags $0-6$ of the exchange rate shocks on the righthand side of our regression specifications, as our results below suggest that the pass-through of U.S. monetary shocks is more gradual than the pass-through of raw exchange rate changes. We continue to control for dyad and time fixed effects, as well as lags $0-2$ of exporter PPI log growth.

Fig. 5 shows that the average pass-through of U.S. monetary policy induced exchange rate changes into bilateral import prices is high in the long run. The figure depicts the impulse response functions of the bilateral price level to shocks. ${ }^{9}$ The left column is based on specifications with only shocks $z_{j, t}-z_{i, t}$ to the bilateral exchange rate, while the right column is based on specifications that add shocks $z_{j, t}$ to the dollar exchange rate. We split the results by exporter (top row) and importer (bottom row) reported data. The impact effect of shocks to both bilateral and dollar exchange rates is about 0.3. However, in specifications with both bilateral and dollar exchange rate shocks, the dollar pass-through rises to about $0.6-1.0$ in years $4-6$, depending on specification, whereas the bilateral pass-through is negligible in the long run.

Fig. 6 shows that the pass-through of shocks to the dollar exchange rate is strongly positively associated with the importer's dollar invoicing share $S_{j}$. As in Section 4.1, we report impulse response functions for low, medium, and high levels of dollar invoicing, where the point estimates and confidence intervals are computed from regressions with interactions. The association between pass-through and dollar invoicing is even stronger for the U.S. monetary policy induced shocks than for the overall exchange rate changes analyzed in Section 4.1. While the estimated long-run pass-through of shocks to the dollar exchange rate is close to zero for a country like Switzerland with $S_{j}=0.13$, it is about 2.0-3.5 for a country like Argentina with $S_{j}=0.88$, depending on specification. These magnitudes are not directly comparable with the pass-through magnitudes in Section 4.1, since a $1 \%$ monetary shock $z_{j, t}$ represents a much rarer occurrence

\footnotetext{
${ }^{9}$ For brevity, we do not report to underlying regression results in table form. These results are available from the authors upon request.
} 


\section{AVERAGE PRICE PASS-THROUGH FROM U.S. MONETARY SHOCKS}

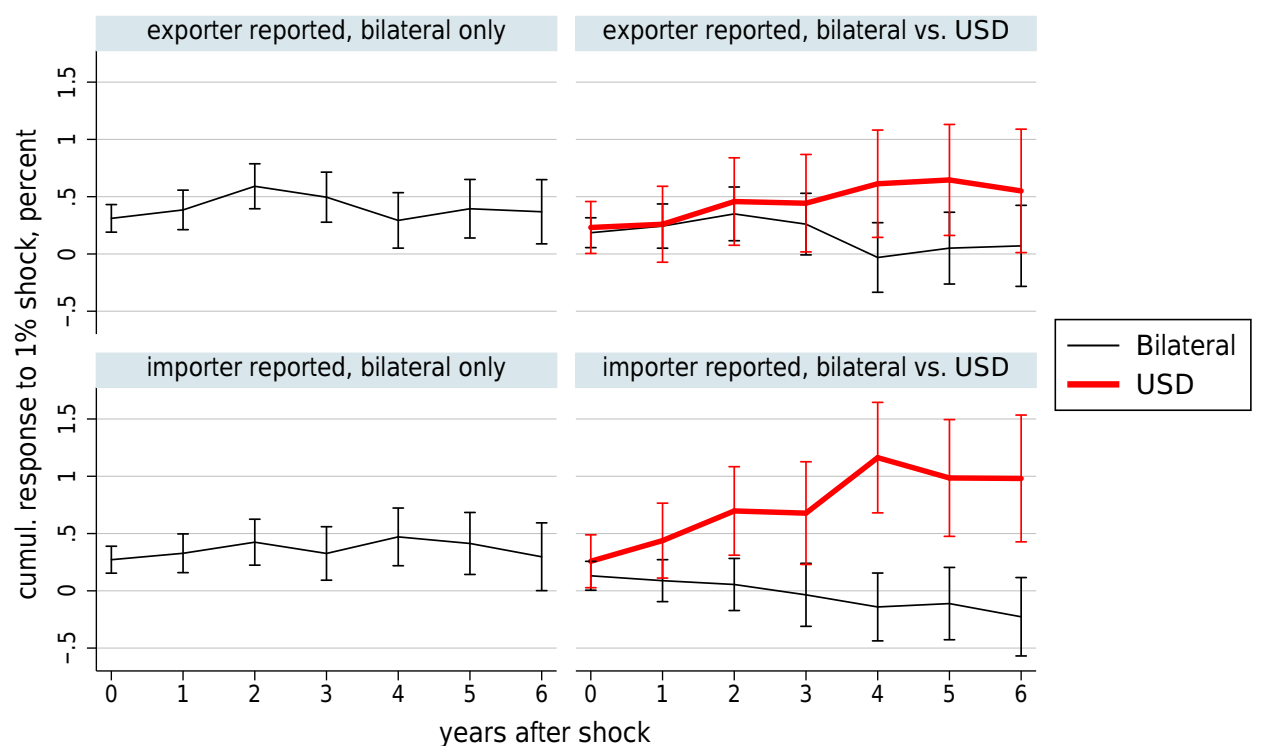

Figure 5: Impulse responses of bilateral price level to bilateral $z_{j, t}-z_{i, t}$ and USD $z_{j, t}$ U.S. monetary policy induced exchange rate shocks. Based on regression specifications without interactions. Top row: exporter reported data, bottom row: importer reported. Left column: specifications with only bilateral shock, right column: specifications with bilateral and USD shocks. Error bars: 95\% confidence intervals, clustering by dyad.

\section{PRICE PASS-THROUGH FROM U.S. MONETARY SHOCKS GIVEN INVOICING SHARE}

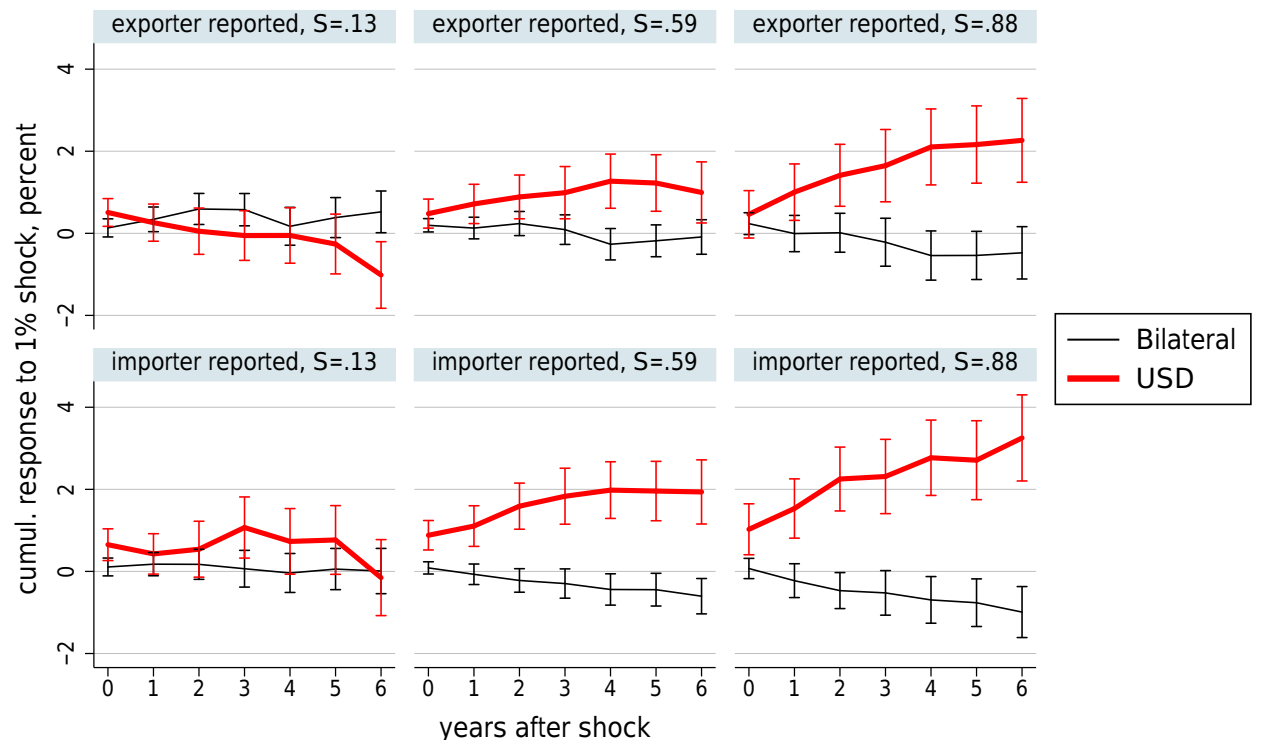

Figure 6: Impulse responses of bilateral price level to bilateral $z_{j, t}-z_{i, t}$ and USD $z_{j, t}$ U.S. monetary policy induced exchange rate shocks, as a function of importer's dollar invoicing share $S_{j}$. Based on regression specifications with interactions. Top row: exporter reported data, bottom row: importer reported. Error bars: 95\% confidence intervals, clustering by dyad. 
than a $1 \%$ appreciation of the dollar exchange rate $e_{\$ j, t}$, as discussed above.

Unlike for price pass-through, regressions of trade volumes on U.S. monetary shocks yield very noisy results. This is a consequence of relatively low $R^{2}$ values for volume regressions, which we also found in Section 4.3, coupled with the limited variation in measured monetary shocks relative to the variation in overall exchange rates. We therefore refrain from reporting volume regression results here. It is an interesting topic for future research to develop more comprehensive (and thus more volatile) measures of U.S. monetary policy shocks that can be related directly to trade volumes.

\subsection{The dollar versus the euro}

We conclude this section by comparing the explanatory power of the dollar exchange rate with that of the euro. We show that the dollar dominates both the bilateral exchange rate and the euro in regression specifications that include all three exchange rates.

The preceding panel regressions do not directly imply that the U.S. dollar is a uniquely important vehicle currency. In our regression specifications without interactions, we would have obtained exactly the same coefficient estimates if we had used the euro exchange rate, say, in place of the dollar exchange rate, since we control for time fixed effects. Nevertheless, our specifications with interactions indicated that the dollar may play a special role. Now we directly compare the explanatory power of the dollar against that of the euro in panel regressions that do not control for time fixed effects but instead control for observed global real and financial variables.

To measure bilateral price pass-through from the dollar and the euro, we run panel regressions of the form

$$
\Delta p_{i j, t}=\lambda_{i j}+\sum_{k=0}^{2} \alpha_{k} \Delta e_{i j, t-k}+\sum_{k=0}^{2} \beta_{k} \Delta e_{\$ j, t-k}+\sum_{k=0}^{2} \xi_{k} \Delta e_{€_{j, t-k}}+\theta^{\prime} X_{i j, t}+\varepsilon_{i j, t}
$$

where $e_{€ j, t}$ denotes the log euro exchange rate in units of currency $j$ per euro. Notice that we omit time fixed effects, as is necessary to identify $\beta_{k}$ and $\xi_{k}$ separately. In addition to lags $0-2$ of exporter PPI log growth, the controls $X_{i j, t}$ consist of the contemporaneous values of global real GDP growth, global GDP deflator inflation, global export volume growth, growth in the WTI oil price deflated by the global GDP deflator, and the log VIX. The time sample for regressions in this subsection is 2002-2015 due to the introduction of the euro in 1999 and our use of lagged exchange rate changes. 


\section{Price PASS-THROUGH FROM DOLLAR AND EURO EXCHANGE RATES}

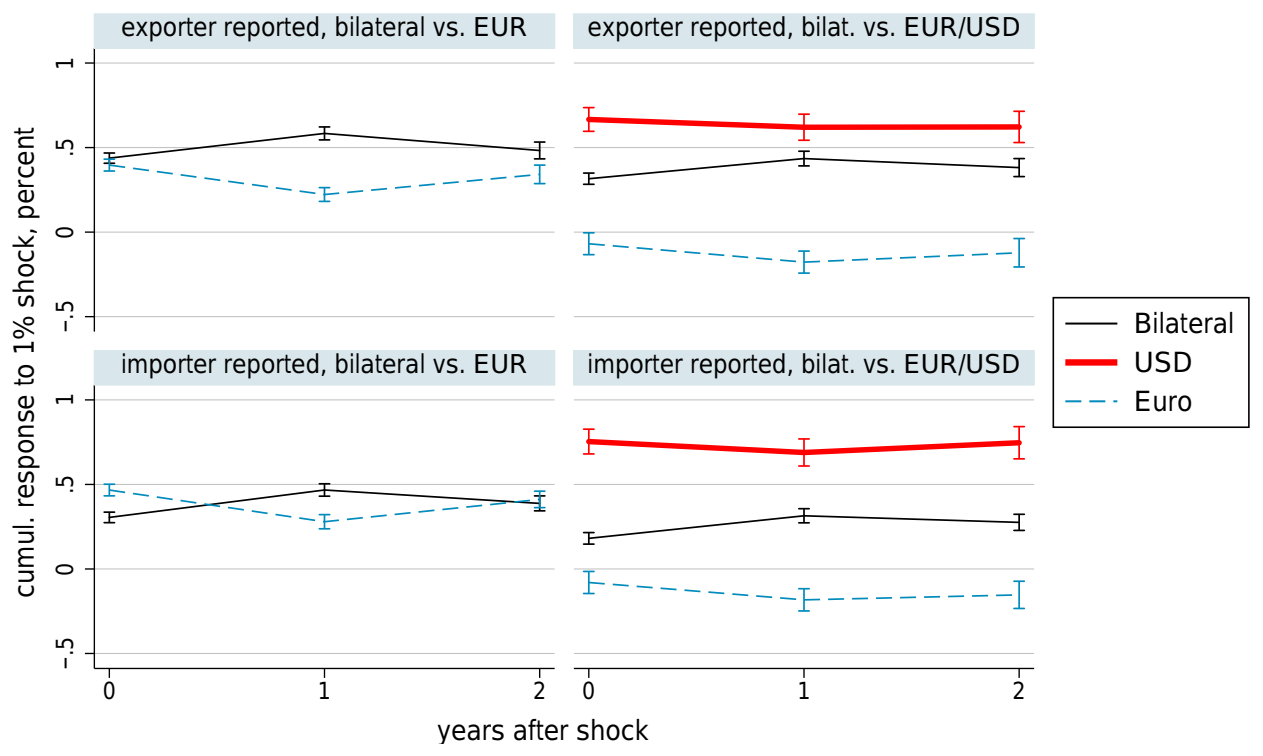

Figure 7: Impulse responses of bilateral price level to bilateral $e_{i j, t}$, USD $e_{\$ j, t}$, and euro $e_{€ j, t}$ exchange rates. Based on regressions in Table 6, Appendix B.2. Top row: exporter reported data, bottom row: importer reported. Left column: specifications with only bilateral and euro ER, right column: specifications adding USD. Error bars: 95\% confidence intervals, clustering by dyad.

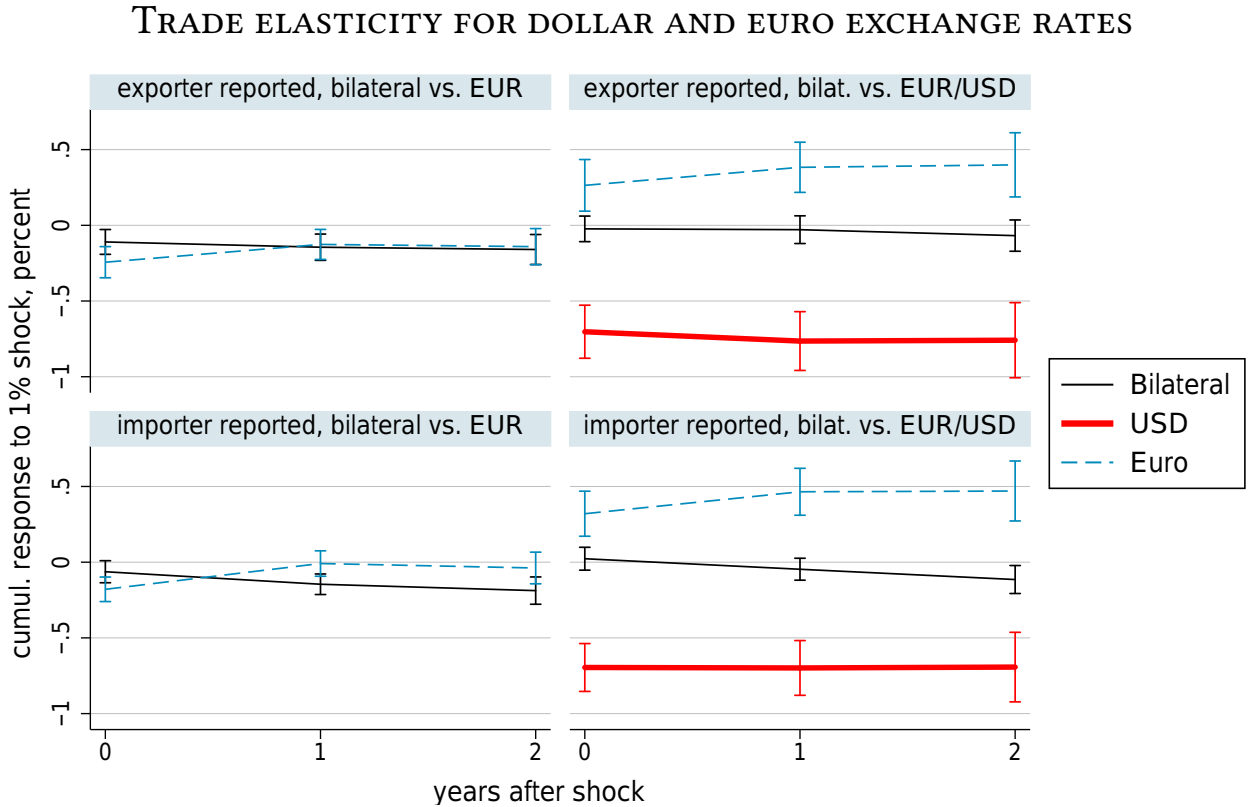

Figure 8: Impulse responses of bilateral volume to bilateral $e_{i j, t}$, USD $e_{\$ j, t}$, and euro $e_{€ j, t}$ exchange rates. Based on regressions in Table 7, Appendix B.2. Top row: exporter reported data, bottom row: importer reported. Left column: specifications with bilateral and euro ER, right column: specifications adding USD. Error bars: 95\% confidence intervals, clustering by dyad. 
Fig. 7 shows that the euro pass-through into prices is negligible on average, while the dollar pass-through remains high when we control for the euro. The figure displays the regression results in the form of impulse responses of the bilateral price level; corresponding regression tables are available in Appendix B.2. We split by exporter (top) and importer (bottom) reported data. The left column shows results for specifications that do not include the dollar exchange rate, i.e., restricting $\beta_{k}=0$ in Eq. (6). The right column displays estimates of bilateral, dollar, and euro pass-through from regressions with all three exchange rates. In the latter specifications, the dollar pass-through is quantitatively much larger than the euro pass-through; indeed, the results are close to those of Section 4.1 where we did not consider the euro at all. The euro pass-through is quantitatively small at all horizons, and it is in fact estimated to be slightly negative. The difference between the dollar and euro pass-through is statistically significant at conventional significance levels. In Appendix B.2 we show through regressions with interactions that the importer's dollar and euro invoicing shares help explain the heterogeneity in pass-through.

Similarly, we find that the dollar exchange rate has the largest predictive power for trade volumes. We run panel regressions similar to Eq. (6), except with volume growth $\Delta y_{i j, t}$ on the left-hand side, and we replace exporter PPI with lags 0-2 of importer real GDP growth in the list of controls $X_{i j, t}$. Fig. 8 shows impulse responses of the level of bilateral trade volume to the bilateral, dollar, and euro exchange rates. The dollar exchange rate is the only one of the three that has a quantitatively large negative association with trade volumes. ${ }^{10}$ Curiously, the trade elasticity of the euro exchange rate is estimated to be positive both in the short and long run, although the confidence intervals are consistent with economically small magnitudes. ${ }^{11}$ The difference between the dollar and euro trade elasticities is significant at conventional significance levels.

\section{Determinants of pass-through heterogeneity}

In this section we show that the cross-dyad variation in exchange rate price pass-through and trade elasticity is well explained by the U.S. dollar's dominance as invoicing currency. The theoretical framework underlying the dominant currency paradigm predicts that pass-through from bilateral exchange rates to prices or quantities should vary across countries, depending on the

\footnotetext{
${ }^{10}$ The different long-run level effect of the dollar in Figs. 3 and 8 is due to the difference in time sample, as discussed in Appendix B.2.

${ }^{11}$ It is an interesting topic for future research to investigate whether the positive predictive effect of euro appreciations on bilateral import volume can be ascribed to valuation effects on net foreign assets that shift the overall level of import demand.
} 
share of imports invoiced in U.S. dollars. The panel regressions in the previous section indicate that this interaction effect is statistically and economically significant for price pass-through. In this section we directly estimate how important the interaction effect is relative to unobserved factors affecting the cross-sectional heterogeneity of price pass-through and trade elasticities.

\subsection{Bayesian model of pass-through heterogeneity}

We employ a Bayesian hierarchical panel data model with cross-sectionally varying slopes. This model optimally exploits the geographical and temporal richness of our data set. By explicitly modeling the cross-sectional heterogeneity of pass-through, we are able to quantify how much of this heterogeneity can be explained by the share of trade invoiced in U.S. dollars (for brevity, here we use the term "pass-through" to describe the relationship between exchange rates and prices or quantities). Such questions cannot be answered by linear panel models with interactions, as these common-coefficients panel models are unable to quantify the overall cross-sectional heterogeneity of pass-through. We use a hierarchical Bayes framework with a nonparametric specification for the distribution of pass-through coefficients conditional on the dollar invoicing share. We demonstrate the ease of sampling from the posterior distribution by exploiting the flexible and user-friendly Bayesian software package Stan.

The hierarchical approach lets the data determine how much pass-through varies across trade dyads. ${ }^{12}$ This approach can roughly be thought of as striking a balance between two extreme but standard econometric methods. In one extreme, we could run dyad-by-dyad time series regressions to determine dyad-specific pass-through coefficients. However, these pass-through estimates would be highly noisy due to the availability of on average about 20 annual data points per dyad, especially given the need to control for other covariates. In the other extreme, we could run constant-coefficient panel regressions as in Section 4. While these are informative about average pass-through as well as interaction terms, they are useless for estimating the extent and nature of the overall cross-sectional heterogeneity of pass-through. Our hierarchical Bayes approach models this heterogeneity directly and flexibly, allowing the entire panel data set to inform the estimates of the distribution of pass-through as well as individual pass-through coefficients. Being a fully Bayesian method, uncertainty assessment and model selection is straight-forward.

\footnotetext{
${ }^{12} \mathrm{At}$ an abstract level, hierarchical Bayes methods treat certain prior parameters as unknown model parameters, which themselves are endowed with prior distributions that get updated by the data. This approach is similar to "empirical Bayes" or classical "random effects" methods, which in effect estimate the prior distribution (here: the distribution of pass-through coefficients) from the data.
} 
Model. The outcome equation of the model is a linear panel data model with dyad and time fixed effects, except some of the coefficients are allowed to vary across dyads:

$$
Y_{i j, t}=\lambda_{i j}+\delta_{t}+\gamma_{i j}^{\prime} R_{i j, t}+\theta^{\prime} X_{i j, t}+\varepsilon_{i j, t}
$$

In our applications, the outcome $Y_{i j, t}$ will be price or quantity log growth, while the covariates $R_{i j, t}$ with cross-sectionally varying coefficients $\gamma_{i j}$ will be the contemporaneous log growth rates of the bilateral and U.S. dollar exchange rates, $R_{i j, t}=\left(\Delta e_{i j, t}, \Delta e_{\$ j, t}\right)^{\prime}$. The covariates $X_{i j, t}$ with cross-sectionally constant coefficients $\theta$ include lags of the exchange rates as well as the other exogenous controls used in Section $4 .{ }^{13}$ We impose a standard random effects assumption on the dyad-specific effects, $\lambda_{i j} \sim N\left(\alpha, \tau^{2}\right)$ (i.i.d. across dyads), and assume Gaussian errors $\varepsilon_{i j, t} \sim$ $N\left(0, \sigma^{2}\right)$ (i.i.d. across dyads and time). ${ }^{14}$ We place independent diffuse half-Cauchy priors on $\tau$ and $\sigma$ and independent diffuse Cauchy priors on the intercept $\alpha$, the time fixed effects $\delta_{t}$, and the cross-sectionally constant coefficients $\theta$. See Appendix A.2.1 for details on the prior.

To economize on the number of parameters, we impose the assumption that the sum of the pass-through coefficients on the bilateral and dollar exchange rates is constant across dyads: $\gamma_{i j, 1}+\gamma_{i j, 2}=\bar{\gamma}$ for all $(i, j)$. This restriction is motivated by the institutional fact that, in most countries in our sample, trade that is not invoiced in dollars is instead invoiced in local currency, so dyads with high dollar pass-through should exhibit low bilateral pass-through, and vice versa. The restriction on the vector $\gamma_{i j}$ implies that the outcome equation can be written

$$
Y_{i j, t}=\lambda_{i j}+\delta_{t}+\gamma_{i j, 1}\left(\Delta e_{\$ j, t}-\Delta e_{i j, t}\right)+\bar{\gamma} \Delta e_{i j, t}+\theta^{\prime} X_{i j, t}+\varepsilon_{i j, t}
$$

This restricted outcome equation can be written in the general form (7), with $\gamma_{i j}$ a scalar, $R_{i j, t}=$ $\Delta e_{\$ j, t}-\Delta e_{i j, t}$, and subsuming the term $\bar{\gamma} \Delta e_{i j, t}$ in the covariate terms $\theta^{\prime} X_{i j, t}$. We assume this notation in the following.

A key part of the model is the cross-sectional distribution of dollar pass-through conditional on the dollar invoicing share. We continue to denote the importer's observed dollar invoicing share by $S_{j}$. For maximal flexibility, we use a nonparametric specification of the conditional dollar pass-through distribution $\gamma_{i j} \mid S_{j}$, while letting the hyperparameters of the prior be updated by

\footnotetext{
${ }^{13}$ All probability statements in this section are conditional on the covariates $R_{i j, t}$ and $X_{i j, t}$. In particular, we assume strict exogeneity of all covariates, and $\gamma_{i j}$ is independent of $X_{i j, t}$ conditional on $R_{i j, t}$.

${ }^{14}$ In the panel regressions in Section 4 we do not find evidence of economically significant serial correlation in the idiosyncratic errors. Identification of the full distribution of random slopes in linear panel data models is only possible under a priori restrictions on the persistence of the idiosyncratic regressions errors (Chamberlain, 1992; Arellano and Bonhomme, 2012).
} 
the data. Specifically, we follow Pati et al. (2013) and Liu (2017) and assume that, conditional on the importer's dollar invoicing share, the dollar pass-through coefficient is drawn from a Mixture of Gaussian Linear Regressions (MGLR):

$$
\left(\gamma_{i j} \mid S_{j}\right) \sim\left\{\begin{array}{rr}
N\left(\mu_{0,1}+\mu_{1,1} S_{j}, \omega_{1}^{2}\right) & \text { with prob. } \pi_{1}\left(S_{j}\right), \\
N\left(\mu_{0,2}+\mu_{1,2} S_{j}, \omega_{2}^{2}\right) & \text { with prob. } \pi_{2}\left(S_{j}\right), \\
\vdots & \\
N\left(\mu_{0, K}+\mu_{1, K} S_{j}, \omega_{K}^{2}\right) & \text { with prob. } \pi_{K}\left(S_{j}\right),
\end{array}\right.
$$

independent across dyads $(i, j)$. Thus, the dollar pass-through $\gamma_{i j}$ is drawn from one of $K$ normal distributions, each with possibly different mean and variance parameters. The priors on the hyperparameters $\mu_{0, k}, \mu_{1, k}$, and $\omega_{k}$ are described in Appendix A.2.1. The mixture probabilities $\pi_{k}\left(S_{j}\right)$ are allowed to depend flexibly on the dollar share. We adopt the "probit stick-breaking" specification of Pati et al. (2013),

$$
\pi_{k}(s)= \begin{cases}\Phi\left(\zeta_{k}(s)\right) \prod_{j=1}^{k-1}\left(1-\Phi\left(\zeta_{j}(s)\right)\right) & \text { for } k=1, \ldots, K-1, \\ 1-\sum_{j=1}^{K-1} \pi_{j}(s) & \text { for } k=K, \quad s \in[0,1]\end{cases}
$$

where $\Phi(\cdot)$ is the standard normal CDF. As in Liu (2017), we place independent nonparametric Gaussian process priors on the functions $\zeta_{k}(\cdot)$ for $k=1, \ldots, K-1$. See Appendix A.2.1.

The nonparametric prior on the cross-sectionally varying dollar pass-through coefficients allows the data to speak flexibly about our key question of interest, the extent to which the dollar invoicing share can explain pass-through heterogeneity. MGLR priors, as defined above, can accommodate a wide variety of shapes of the conditional density of $\gamma_{i j} \mid S_{j}$, including heavy-tailed, skewed, and multimodal conditional distributions. Since the mixture probabilities $\pi_{k}\left(S_{j}\right)$ depend on $S_{j}$, the functional form of the conditional distribution is allowed to change as the dollar invoicing share $S_{j}$ varies. In particular, we do not impose that the distribution of $\gamma_{i j}$ shifts linearly with $S_{j}{ }^{15}$ Pati et al. (2013) show that, if $K=\infty$, MGLR priors yield posterior consistency in nonparametric conditional density estimation problems under weak assumptions. We instead allow the data to inform us about the choice of the number $K$ of mixture components, using the Bayesian Leave-One-Out (LOO) cross-validation model selection criterion of Gelfand et al. (1992) and Vehtari et al. (2017), cf. Appendix A.2.2.

\footnotetext{
${ }^{15}$ It is only the distribution conditional on a mixture component $k$ that is assumed to shift linearly.
} 
Posterior sampling. We use the Bayesian statistics software package Stan to draw from the posterior distribution of the model parameters (Stan Development Team, 2016). Stan produces samples from the posterior using the No U-Turn Sampler of Hoffman and Gelman (2014), a variant of the Markov Chain Monte Carlo (MCMC) procedure Hamiltonian Monte Carlo (Neal, 2011). From an applied user's perspective, Stan has the advantage that it only requires the probability model to be specified in "natural" mathematical language (like the equations above). The software then automatically computes the posterior density and tunes the MCMC procedure. Stan achieves robust and rapid mixing in our high-dimensional hierarchical model, without requiring priors to be conjugate. Appendix B.3 details the performance of the MCMC routine.

\subsection{Results: price pass-through}

We find that the importer's share of dollar invoicing explains a substantial fraction of the heterogeneity in dollar pass-through into prices, confirming a key channel in the dominant currency paradigm. Below we summarize the most important features of the posterior distribution for our purposes, while Appendix B.4.1 provides additional details on other parameters.

Our empirical specification broadly follows Section 4. In terms of the general Bayesian model in Eq. (7), we set $Y_{i j, t}=\Delta p_{i j, t}$. As extra covariates in $X_{i j, t}$, we use the exporter's log PPI growth and one lag each of log PPI growth, bilateral exchange rate log growth, and dollar exchange rate log growth (second lags were found to be unimportant in Section 4). Here we focus on results that use Comtrade data reported by importers, for the reasons discussed in Section 4.1. We remove a few dyads whose data have gaps in the middle of the sample. Since we require data on the importer's dollar invoicing share, our final sample consists of 1856 dyads for a total of 35,398 observations (average of 19.1 years per dyad).

Our preferred specification uses $K=2$ mixture components for the conditional distribution of dollar pass-through coefficients given the dollar invoicing share. The LOO model selection criterion indicates strong support for $K \geq 2$ against $K=1$, but the criterion is mostly flat for $K=2,3, \ldots, 8$. Because the posterior summaries below are virtually unchanged across these values of $K$, we prefer to show results for the more parsimonious model $K=2$ here. Appendix B.4.2 provides results for the richer $K=8$ specification.

Fig. 9 shows that a higher importer (country-aggregate) dollar invoicing share is associated with a rightward shift in the cross-sectional density of dollar pass-through. The figure focuses on three invoicing shares: a low one (Switzerland), a medium one (Turkey), and a high one (Argentina). While the cross-sectional heterogeneity in pass-through is large, there is a noticeable overall rightward shift in dollar pass-through when going from a low- $S_{j}$ country to a high- $S_{j}$ 


\section{DENSITY OF DOLLAR PRICE PASS-THROUGH GIVEN DOLLAR INVOICING SHARE}
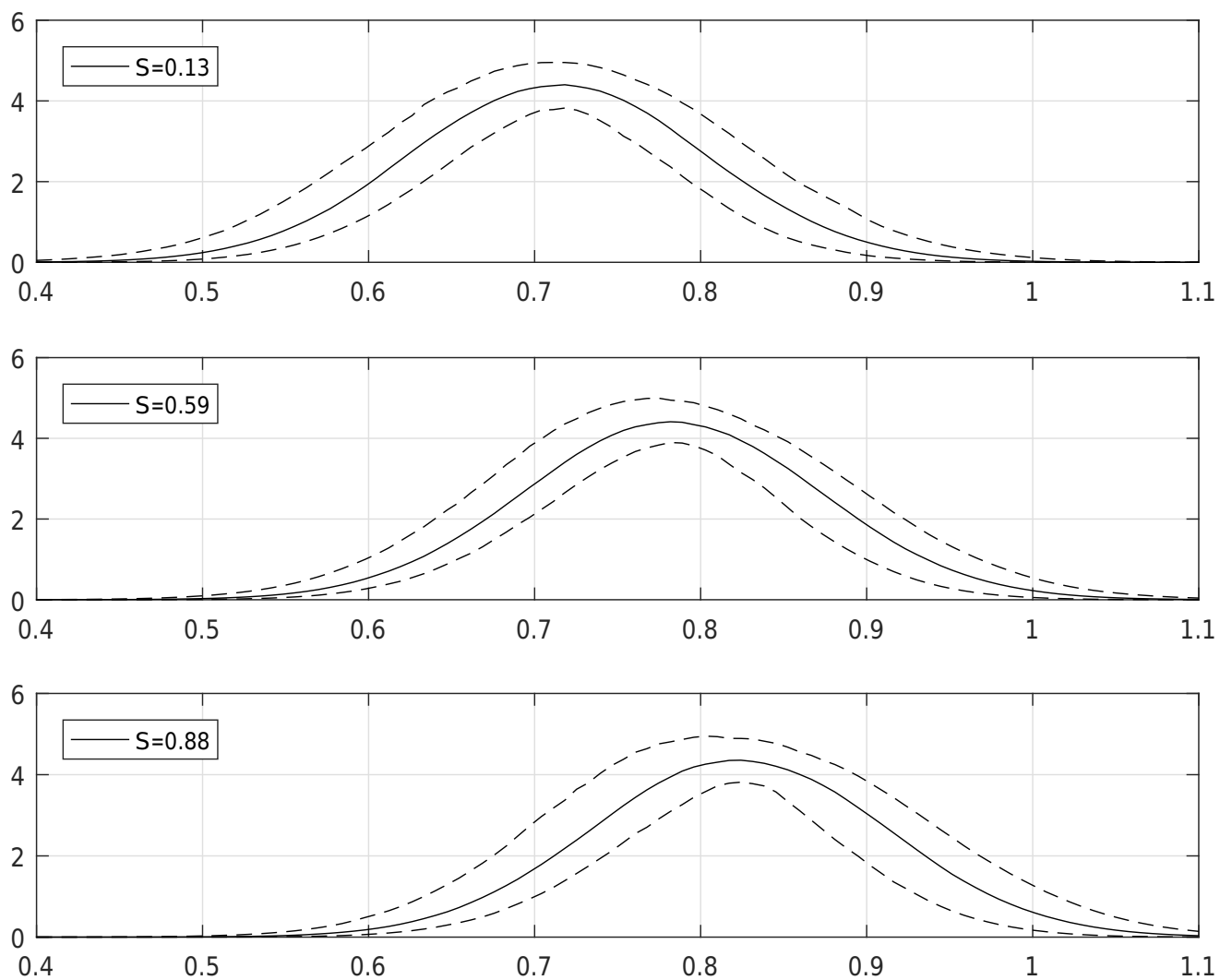

Figure 9: Model-implied conditional density $f\left(\gamma_{i j} \mid S_{j}\right)$ plotted at the dollar import invoicing shares $S_{j}$ of Switzerland (top), Turkey (middle), and Argentina (bottom). Solid lines are posterior medians, dashed lines are $95 \%$ pointwise equal-tailed posterior credible intervals.

country. Based on posterior median estimates, the mode of the $\gamma_{i j}$ distribution shifts by about 0.10 when the dollar invoicing share increases from Switzerland to Argentina levels. This is a substantial shift when compared to the estimated cross-dyad interquartile range of $\gamma_{i j}$ of 0.13 (see below). ${ }^{16}$

Fig. 10 plots the posterior conditional mean and standard deviation of the conditional distribution $\gamma_{i j} \mid S_{j}$ across all observed values of $S_{j}$. The figure confirms that the three conditional densities plotted in Fig. 9 are representative of the entire observed distribution of $S_{j}$ values. Although not assumed $a$ priori by our model, the conditional mean $E\left[\gamma_{i j} \mid S_{j}\right]$ appears approximately linear, with a slope that is broadly consistent with the linear model with interactions in Section 4 . The conditional standard deviation appears to be fairly constant across $S_{j}$ values, although the pos-

\footnotetext{
${ }^{16}$ Recall that our data set is limited to using country-level dollar invoicing shares for the importer, $S_{j}$, as opposed to the ideal of dyad-specific invoicing shares. We conjecture that the quantitative importance of the importer's countrylevel dollar invoicing share provides a lower bound on the importance of the (unobserved) dyad-level invoicing share.
} 


\section{CONDITIONAL MEAN AND STANDARD DEVIATION OF DOLLAR PRICE PASS-THROUGH}
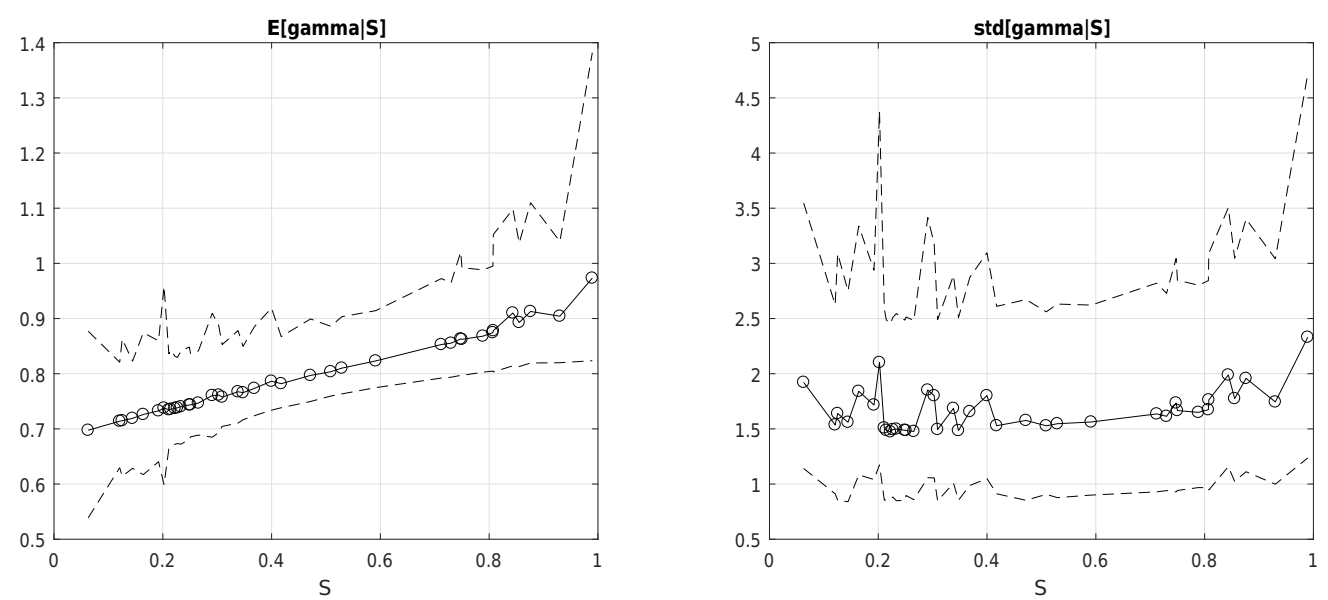

Figure 10: Model-implied conditional mean (left) and standard deviation (right) of $\gamma_{i j}$ given $S_{j}$. Solid lines are posterior medians, dashed lines are $95 \%$ pointwise equal-tailed posterior credible intervals. Circles indicate observed $S_{j}$ values.

SAMPLE DISTRIBUTION OF DOLLAR PRICE PASS-THROUGH
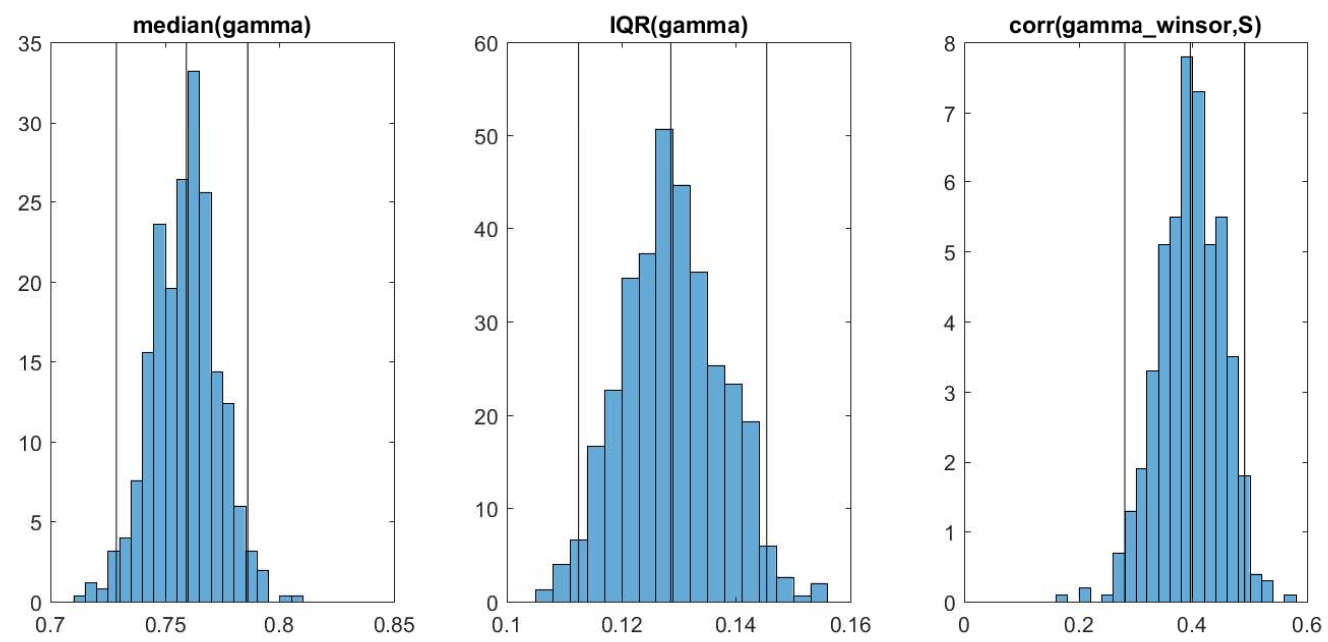

Figure 11: Histogram of posterior draws of the sample median of $\gamma_{i j}$ (left), the sample interquartile range of $\gamma_{i j}$ (middle), and winsorized correlation of $\gamma_{i j}$ and $S_{j}$ (right). That is, for each posterior draw, we compute the sample median, IQR, and winsorized correlation across the 1856 dyads in our sample. Vertical lines mark the 2.5, 50, and 97.5 posterior percentiles. 
terior uncertainty is large. However, the conditional distributions are heavy-tailed, as evidenced by the fact that the LOO criterion strongly prefers the $K=2$ mixture model to the $K=1$ model with normally distributed heterogeneity.

Fig. 11 provides further evidence that dollar pass-through is high on average but highly heterogeneous, and about $15 \%$ of the cross-dyad variance of dollar pass-through is explained by the importer's dollar invoicing share. The figure shows histograms of the posterior draws of the cross-dyad median and interquartile range (IQR) of $\gamma_{i j}$ for the 1856 dyads in the sample. The median dollar pass-through is consistent with the panel regressions in Section 4 (median median 0.76), but there is substantial heterogeneity in pass-through across dyads (median IQR 0.13), a fact we would not have been able to establish using standard linear panel regressions. The figure also plots the histogram of posterior draws of the cross-sectional correlation coefficient of $\gamma_{i j}$ and $S_{j}$, after winsorizing $\gamma_{i j}$ by $5 \%$ in each tail to reduce the influence of outlier dyads. There is a clear positive correlation (median correlation 0.39), again demonstrating that dyads with high dollar pass-through also tend to have a high importer dollar invoicing share. By squaring the correlation, we obtain the $R^{2}$ value in a cross-dyad regression of (winsorized) dollar pass-through on the importer's dollar invoicing share. The posterior median indicates that the importer's dollar invoicing share explains $15 \%$ of the cross-dyad variance in dollar pass-through, with $95 \%$ equaltailed posterior credible interval [7.1\%, 24.6\%]. Thus, knowledge of the importer's country-level dollar invoicing share substantially improves the ability to explain cross-dyad heterogeneity in price pass-through, as predicted by the dominant currency paradigm.

\subsection{Results: trade elasticity}

Similar to the price pass-through results, we find that the cross-dyad heterogeneity of the elasticity of trade quantities with respect to the dollar exchange rate is related to the dollar invoicing share. However, the results in this subsection generally come attached with higher posterior uncertainty. Appendix B.4.1 provides additional results on parameters not highlighted below.

Our empirical specification again follows Section 4. We set $Y_{i j, t}=\Delta y_{i j, t}$ in Eq. (7). We control for one lag of bilateral and dollar exchange rates, as well as the contemporaneous value and lag of importer log real GDP growth. The sample of dyad-year observations is the same as for the price pass-through results.

We report results for $K=4$ mixture components. The LOO model selection criterion strongly favors $K=3,4,5$ against either $K \leq 2$ or $K=6,7,8 . K=4$ has a slightly higher LOO score than $K=3,5$. However, we remark again that the results presented below are little changed across specifications with $K \geq 3$. We report results for $K=8$ in Appendix B.4.2. 


\section{DENSITY OF DOLLAR TRADE ELASTICITY GIVEN DOLLAR INVOICING SHARE}
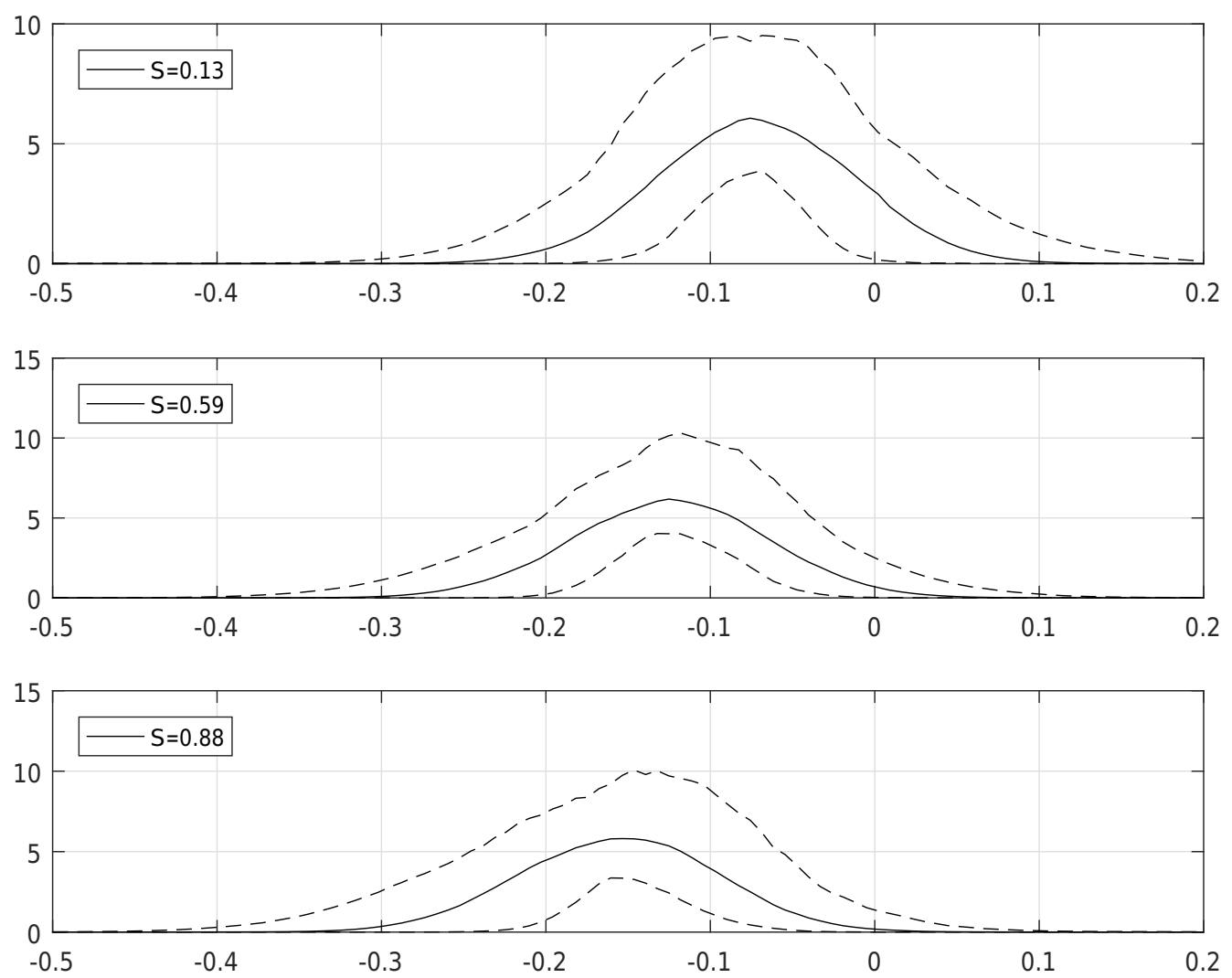

Figure 12: See caption for Fig. 9.

CONDITIONAL MEAN AND STANDARD DEVIATION OF DOLLAR TRADE ELASTICITY
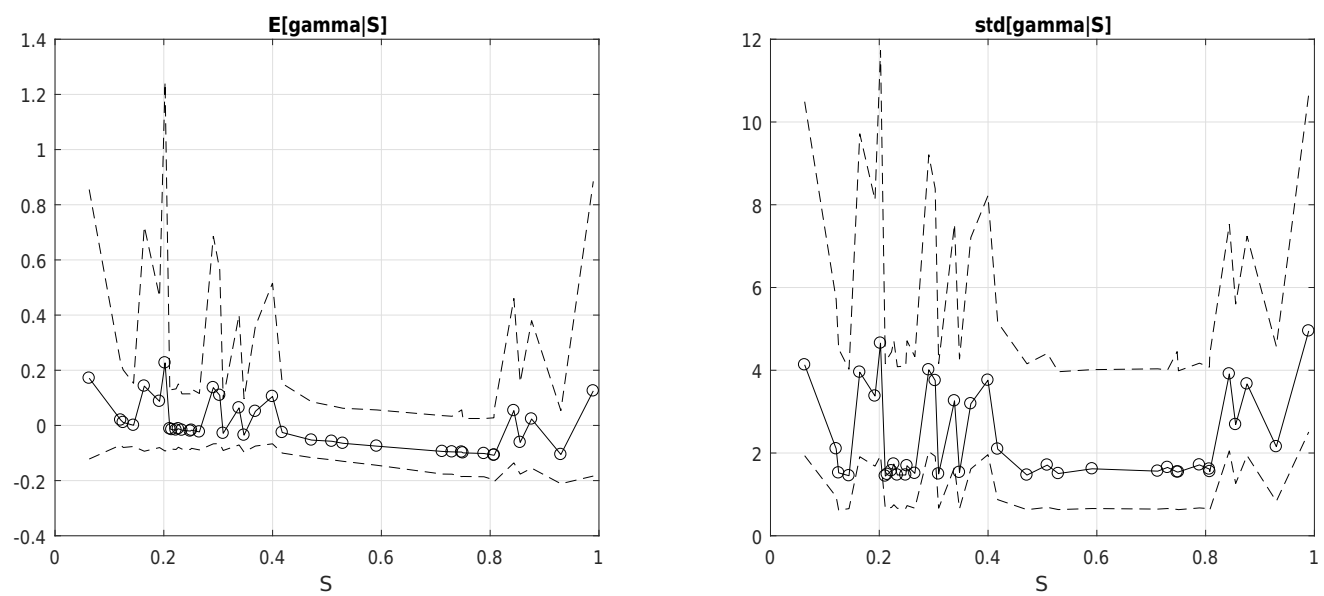

Figure 13: See caption for Fig. 10. 

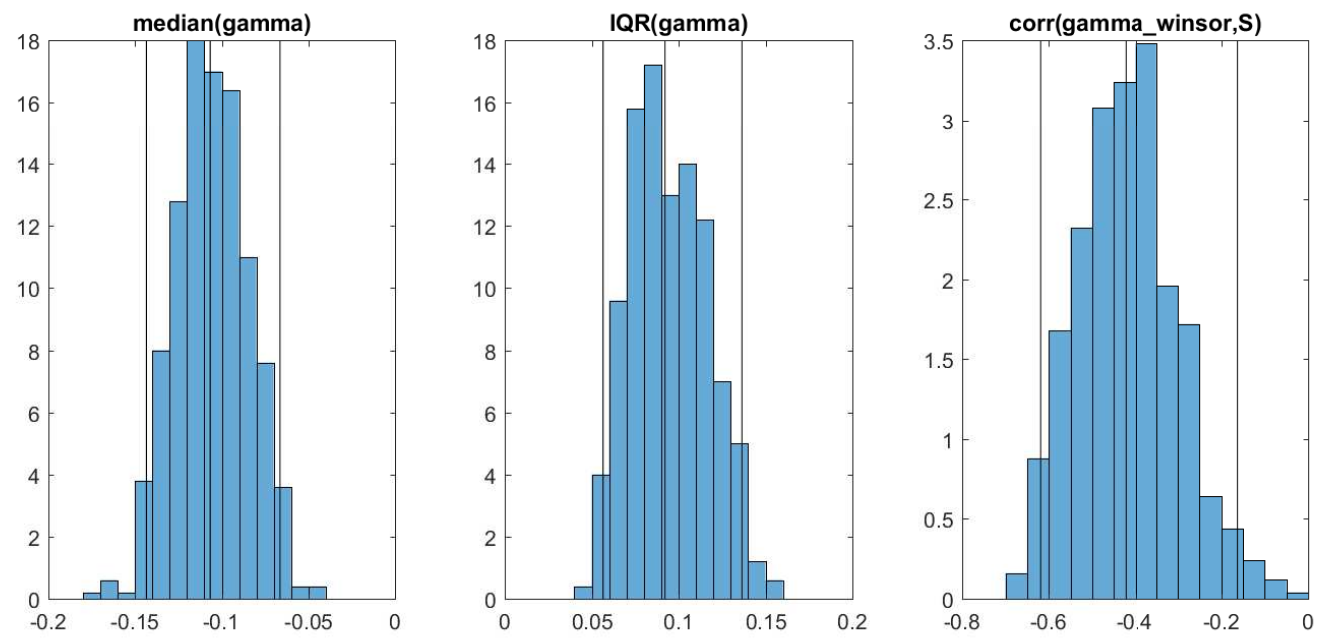

Figure 14: See caption for Fig. 11.

Fig. 12 shows that the conditional density of the dollar trade elasticity (expected to be a negative number, as also estimated in Section 4) shifts leftward when the importer's country-level dollar invoicing share increases. That is, the higher the dollar invoicing share, the larger in magnitude is the dollar trade elasticity, on average. Notice, however, that the credible bands are much wider here than for the price pass-through results. This is consistent with the larger standard errors on the interaction terms in the trade elasticity panel regressions in Section 4. Fig. 13 shows the conditional mean and standard deviation. While the posterior medians indicate that the conditional mean function is downward-sloping over most of the range of $S_{j}$, the function is estimated with substantial uncertainty.

Fig. 14 summarizes the posterior of the sample distribution of $\gamma_{i j}$. The median $\gamma_{i j}$ is in line with the panel regression results in Section 4 (median median -0.11), but the heterogeneity is substantial (median IQR 0.09). Again we find a strong (here: negative, as expected) correlation between $\gamma_{i j}$ and $S_{j}$ (median correlation -0.41), after winsorizing $\gamma_{i j}$ at $5 \%$ in each tail. Thus, trade elasticities with respect to the dollar are highly heterogeneous, but dyads with the largestin-magnitude dollar elasticities tend to be the dyads with the highest importer dollar invoicing share. The 95\% equal-tailed posterior credible interval for the $R^{2}$ in a cross-dyad regression of (winsorized) dollar elasticity on the importer's dollar invoicing share is [2.6\%, 34.0\%]. 


\section{Aggregate implications of dominant currency pricing}

Finally, we show that the dominant currency paradigm has important implications for how the strength of the U.S. dollar affects aggregate trade volume and inflation in the rest of the world.

\subsection{Effect of U.S. dollar on rest-of-world trade}

Underscoring the quantitative significance of the dominant currency paradigm, we argue that the U.S. dollar has substantial predictive power for aggregate trade among countries in the rest of the world. That is, the dollar is important for predicting global trade, even when excluding countries' direct trade with the U.S. Specifically, a 1\% U.S. dollar appreciation against all other currencies in the world predicts a $0.6-0.8 \%$ decline within a year in the volume of total trade between countries in the rest of the world, holding constant various proxies for the global business cycle.

We measure the elasticity of rest-of-world trade volume to the U.S. dollar by aggregating up from our richest bilateral panel regression specification in Section 4. This produces informative results that exploit our panel data set, unlike a simple annual time series regression of global trade on an effective dollar exchange rate index. Consider the following regression model with bilateral, dollar, and euro exchange rates, as well as interactions with dollar and euro import invoicing shares:

$$
\begin{aligned}
\Delta y_{i j, t}= & \sum_{k=0}^{2}\left(\alpha_{k}+\eta_{k}\left(1-S_{j}-S_{j}^{€}\right)\right) \Delta e_{i j, t-k} \\
& +\sum_{k=0}^{2}\left(\beta_{k}+\psi_{k} S_{j}\right) \Delta e_{\$ j, t-k} \\
& +\sum_{k=0}^{2}\left(\xi_{k}+\vartheta_{k} S_{j}^{€}\right) \Delta e_{€ j, t-k} \\
& +\lambda_{i j}+\theta^{\prime} X_{i j, t}+\varepsilon_{i j, t} .
\end{aligned}
$$

Here $S_{j}$ and $S_{j}^{€}$ are the importer's country-level dollar and euro invoicing shares, respectively, while $\lambda_{i j}$ is a dyad fixed effect. Because we are interested in the effect of a dollar appreciation against all other currencies, we do not control for time fixed effects. Instead, we control for the same proxies for the global business cycle as in Section 4.5. Coefficient estimates for the above panel regression on the post-2002 (post-euro) sample are given in Appendix B.2.

The outcome of interest to us here is the response of rest-of-world (i.e., ex-U.S.) aggregate trade volume to a $1 \%$ appreciation of the U.S. dollar relative to all other currencies, holding constant the global business cycle. Let $w_{j}$ denote country $j$ 's total non-commodity import value from all coun- 
tries except the U.S. in some reference year, normalized so that $\sum_{j \neq \mathrm{US}} w_{j}=1 .{ }^{17}$ We conceptualize the rest-of-world aggregate trade bundle as a Cobb-Douglas aggregate of individual-country (gross) imports with weights $w_{j}$. According to the bilateral interactive regression model (9), the ceteris paribus effect of a $1 \%$ dollar appreciation on $\sum_{j \neq \mathrm{US}} w_{j} \Delta y_{i j, t}$, the weighted rest-of-world imports from destination $i$, is given by

$$
\sum_{j \neq \mathrm{US}} w_{j}\left(\beta_{k}+\psi_{k} S_{j}\right)=\beta_{k}+\psi_{k} \sum_{j \neq \mathrm{US}} w_{j} S_{j}
$$

$k$ years after the appreciation, for each import destination $i$ other than the U.S. Thus, to measure the response of rest-of-world aggregate imports to a dollar appreciation, we simply have to compute the impulse response of trade volume for an importer $j$ whose U.S. dollar invoicing share happens to equal $\sum_{j \neq \mathrm{US}} w_{j} S_{j}$, the weighted average dollar invoicing share, computed using our ex-U.S. import value weights $w_{j}$. In practice, $w_{j}$ depends on the year in which import values are measured, but Appendix B.2 shows that the weighted average $\sum_{j \neq \mathrm{Us}} w_{j} S_{j}$ fluctuates tightly around a mean of 0.40 in the 2002-2015 sample, so we use the 0.40 value for our exercise.

Fig. 15 shows that rest-of-world aggregate import volume contracts markedly following an appreciation of the dollar against all other currencies. A $1 \%$ ceteris paribus dollar appreciation leads to a $0.6-0.8 \%$ contraction in rest-of-world trade volume within the year (depending on whether exporter or importer reported data is used), and this contractionary effect persists out to two years. While our regression specification cannot be interpreted structurally, the magnitude of the predictive effect underscores the importance of taking the dominant currency paradigm into account. In contrast, the Mundell-Fleming framework leaves no role for the strength of the U.S. dollar to influence trade volumes among countries in the rest of the world.

\subsection{Spillovers from U.S. dollar to foreign inflation}

Our results imply that fluctuations in the strength of the U.S. dollar, for example those caused by U.S. monetary policy actions, have spillover effects on foreign inflation. We have shown that the U.S. dollar exchange rate passes strongly through to bilateral import prices measured in the importer's currency, especially for countries whose imports are heavily invoiced in dollars. Given a non-negligible import content in consumption, this implies that U.S. dollar movements will directly affect foreign CPI inflation, as discussed by Gopinath (2015). Moreover, if foreign firms behave in a monopolistically competitive way, foreign producer prices will react to changes in foreign import prices, although perhaps with a lag. Hence, the direct effect of U.S. dollar move-

\footnotetext{
17"All countries" refers to the world aggregate in Comtrade, not only the countries in our regression sample.
} 
RESPONSE OF REST-OF-WORLD AGGREGATE TRADE TO USD APPRECIATION, 2002-2015

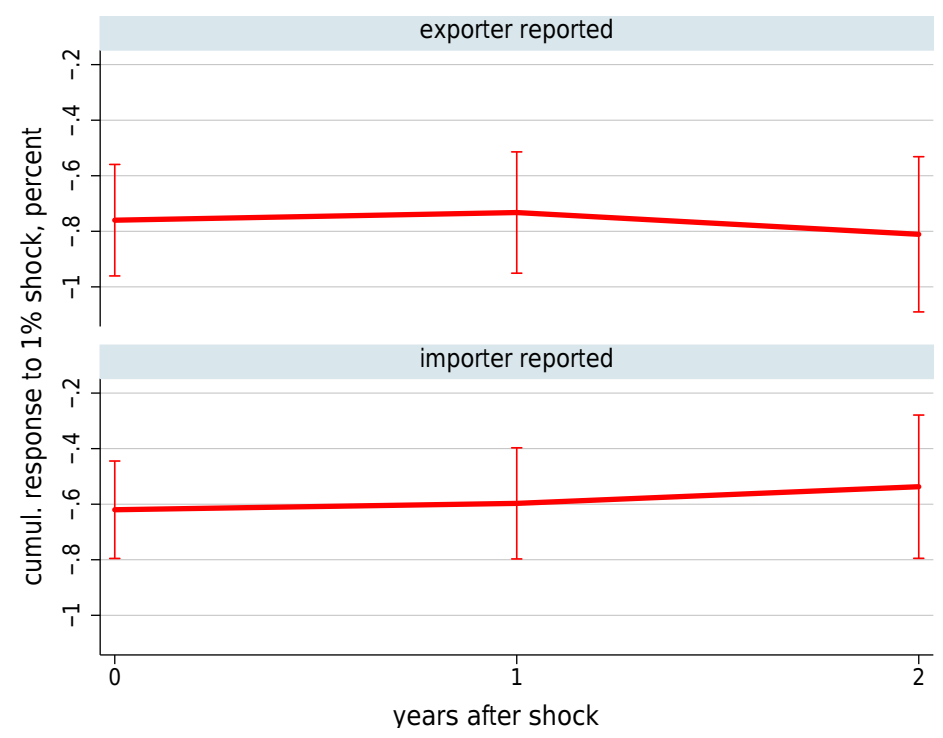

Figure 15: Impulse responses of rest-of-world aggregate trade volume to a 1\% U.S. dollar appreciation against all other currencies, holding constant all other exchange rates and the global business cycle. Based on regressions in Table 7, Appendix B.2. Top row: exporter reported data, bottom row: importer reported. Error bars: 95\% confidence intervals, clustering by dyad.

ments on foreign CPI inflation may be amplified by endogenous producer responses.

We now provide direct country-level regression evidence on the effects of the U.S. dollar exchange rate on foreign consumer and producer prices. Gopinath (2015) computed back-of-theenvelope estimates of these spillovers based on estimated country-level import price pass-through and the import content of consumption. We instead directly regress countries' CPI or PPI on the dollar exchange rate. Additionally, we investigate the interaction of the dollar exchange rate and the dollar import invoicing share.

Specifically, we consider the country-level panel regression

$$
\Delta c p i_{j, t}=\lambda_{j}+\delta_{t}+\sum_{k=0}^{2} \beta_{k} \Delta e_{\$ j, t-k}+\sum_{k=0}^{2} \psi_{k} \Delta e_{\$ j, t-k} \times S_{j}+\varepsilon_{j, t},
$$

where $\Delta c p i_{j, t}$ is the change in the log CPI in the currency of country $j$, and $\lambda_{j}$ and $\delta_{t}$ are country and year fixed effects. We also consider specifications with $\Delta p p i_{j, t}$ on the left-hand side, as well as specifications restricting $\psi_{k}=0$ for all $k$. We focus attention on the post-2002 (post-euro) sample, since full-sample regression results are unduly influenced by a handful of countries' high- 
Dollar EXCHANGE RATE PASS-THROUGH INTO FOREIGN CPI AND PPI, 2002-2015

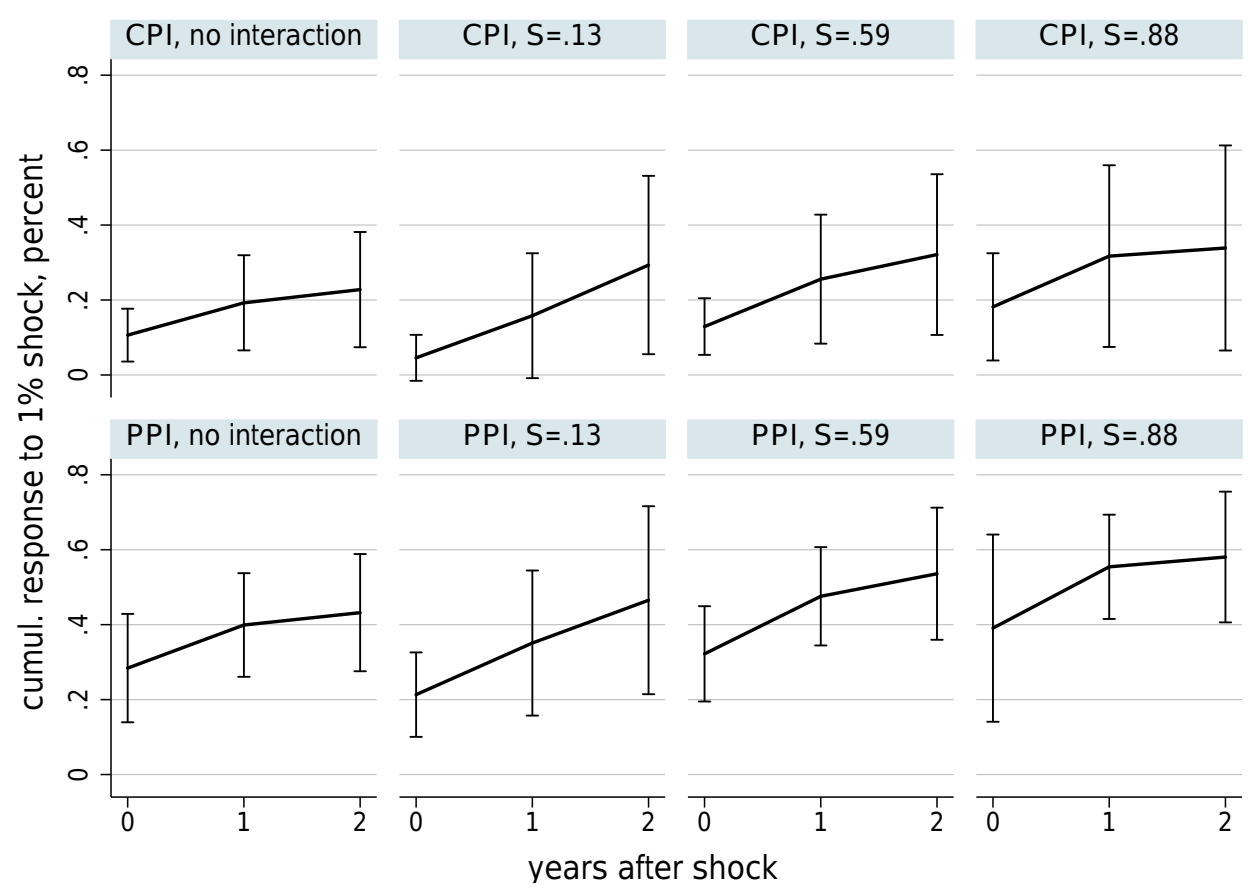

Figure 16: Impulse responses of country-level consumer and producer price indices to the dollar exchange rate $e_{\$ j, t}$. Based on regressions in Table 8, Appendix B.2. Top row: CPI, bottom row: PPI. Column 1: specifications without interactions, columns 2-4: specifications with interactions evaluated at different dollar invoicing shares $S_{j}$. Error bars: $95 \%$ confidence intervals, clustering by country and applying smallsample "LZ2-BM" adjustment in Imbens and Kolesár (2016).

inflation/high-depreciation episodes in the 1990s. ${ }^{18}$ We apply small-sample corrections to the clustered confidence intervals, as recommended by Imbens and Kolesár (2016). See Appendix B.2 for details and regression tables.

Fig. 16 displays the impulse response function of the CPI or PPI level to a $1 \%$ depreciation of the local currency vis-à-vis the dollar. The top row shows results for CPI pass-through, and the bottom row PPI pass-through. The first column shows the average impulse responses, corresponding to a regression specification without interactions, i.e., $\psi_{k}=0$ in Eq. (10). The average pass-through of the dollar into CPI (resp., PPI) is $11 \%$ (resp., 28\%) within the year, rising to a cumulative pass-through of $23 \%$ (resp., 43\%) after two years. The remaining three columns in Fig. 16, which are based on the specification with interactions, show that the dollar pass-through is larger for countries that have a substantial fraction of imports invoiced in dollars. Although the confidence intervals are wide due to the small number of country clusters, the regression table

\footnotetext{
${ }^{18}$ The results are very similar if we use the full 1992-2015 sample but drop country-year observations for which the arithmetic CPI inflation rate exceeds $30 \%$ annually ( $0.26 \log$ inflation rate).
} 
in Appendix B.2 shows that the contemporaneous interaction term is statistically significant at the $10 \%$ level for both the CPI and PPI specifications, and also at the $5 \%$ level for the CPI specification. Hence, it appears that countries which invoice more in dollars experience higher dollar pass-through into consumer and producer prices. We caution, though, that the magnitude of the pass-through is imprecisely estimated when controlling for country and time fixed effects.

Point estimates for analogous specifications with U.S. monetary policy induced exchange rate fluctuations are consistent with the patterns documented above for raw exchange rate passthrough. However, the variation in the monetary policy series $z_{j, t}$ is insufficient to deliver informative confidence statements. The regression table is presented in Appendix B.2.

\section{Conclusion}

To understand the impact of exchange rate fluctuations on trade, the practice is to regress import/export prices and volumes on bilateral or trade-weighted exchange rates. When viewed through the lens of the Mundell-Fleming paradigm where prices are assumed to be sticky in the producer's currency, this is the appropriate regression specification.

However, using newly constructed trade price and volume indices for over 2500 country pairs, we document that the relevant predictor for bilateral trade prices and volumes is not the bilateral exchange rate but the dollar exchange rate, even where the U.S. is on neither side of the trade transaction. A $1 \%$ U.S. dollar appreciation against all other currencies in the world predicts a 0.6-0.8\% decline within a year in the volume of total trade between countries in the rest of the world, controlling for the global business cycle. We also demonstrate that the impact of the dollar exchange rate is increasing in the fraction of a country's trade that is invoiced in dollars. We estimate that the importing country's share of imports invoiced in dollars explains $15 \%$ of the variance of dollar pass-through/elasticity across country pairs. These findings strongly support the dominant currency paradigm as the empirically relevant framework for understanding the international transmission of shocks and for policy analysis.

On a methodological note, our Bayesian analysis demonstrates the ease with which rich hierarchical econometric models can be estimated with the user-friendly open source software Stan. We expect that semiparametric hierarchical panel data analysis will prove useful also in other empirical settings where understanding cross-sectional heterogeneity is of primary importance. 


\section{A Appendix}

\section{A.1 Data}

Here we provide further details on the Comtrade, WDI, and FRED data.

Comtrade country summary statistics. Table 4 lists summary statistics on the number of observations for the 55 countries in our merged Comtrade/WDI dataset. The table also lists the share of imports invoiced in U.S. dollars and euros for the 39 countries for which we observe these measures (cf. Gopinath, 2015).

World Development Indicator data. The exchange rate is the World Bank's "alternative conversion factor" series (PA.NUS.ATLS), which corrects for redenominations and currency substitution, and is measured as an annual average of daily rates. Producer prices are given by the wholesale price index (FP.WPI.TOTL). Real GDP is measured at market prices in constant U.S. dollars (NY.GDP.MKTP.KD). The GDP deflator is given by the ratio of nominal GDP (NY.GDP.MKTP.CD) and real GDP. Consumer prices are constructed from CPI inflation rates (FP.CPI.TOTL.ZG), or if inflation is not available, CPI levels (FP.CPI.TOTL). We use data for 1989-2015 only.

FRED data. We obtain the WTI oil price (POILWTIUSDA), VIX (VIXCLS), and 1-year Treasury bill rate (DTB1YR) from the St. Louis Fed's FRED database. Annual series are averages of daily indices.

\section{A.2 Bayesian analysis: priors and model selection}

\section{A.2.1 Hyper-priors}

Here we describe the remaining parts of the prior not specified in the main text. We incorporate time fixed effects $\delta_{t}$ by adding $T-1$ dummies in the covariate vector $X_{t}$, so the parameter vector $\theta$ includes these parameters. We impose the following priors, all mutually independent:

$$
\begin{gathered}
\alpha \sim \operatorname{Cauchy}(0,5), \quad \theta_{j} \sim \operatorname{Cauchy}(0,5), \\
\sigma \sim \operatorname{HalfCauchy}(0,1), \quad \tau \sim \operatorname{HalfCauchy}(0,1) .
\end{gathered}
$$

Cauchy $(0, a)$ is the centered Cauchy distribution with interquartile range $2 a$. HalfCauchy $(0, a)$ is the restriction of the $\operatorname{Cauchy}(0, a)$ distribution to the positive real line. Since the units of our 


\section{COUNTRY SUMMARY STATISTICS}

\begin{tabular}{|c|c|c|c|c|c|c|}
\hline \multirow[b]{2}{*}{ Country } & \multicolumn{2}{|c|}{ As exporter } & \multicolumn{4}{|c|}{ As importer } \\
\hline & \#dyads & $\operatorname{avg} T$ & \#dyads & $\operatorname{avg} T$ & $\operatorname{Inv} S^{\$}$ & $\operatorname{Inv} S^{€}$ \\
\hline \multicolumn{7}{|l|}{ Africa } \\
\hline Algeria & 20 & 14.2 & 49 & 21.1 & & 0.49 \\
\hline Egypt & 54 & 20.4 & 52 & 21.6 & & \\
\hline South Africa & 54 & 15.0 & 53 & 14.7 & & \\
\hline \multicolumn{7}{|l|}{ Americas } \\
\hline Argentina & 54 & 21.8 & 52 & 21.8 & 0.88 & 0.08 \\
\hline Brazil & 54 & 24.2 & 53 & 23.1 & 0.84 & 0.11 \\
\hline Canada & 54 & 24.4 & 54 & 24.1 & 0.75 & 0.05 \\
\hline Chile & 52 & 20.9 & 50 & 22.0 & & \\
\hline Colombia & 53 & 19.5 & 52 & 21.4 & 0.99 & 0.00 \\
\hline Mexico & 54 & 23.4 & 52 & 23.3 & & \\
\hline United States & 54 & 24.0 & 54 & 23.5 & 0.93 & 0.02 \\
\hline Venezuela & 21 & 10.9 & 48 & 19.9 & & \\
\hline \multicolumn{7}{|l|}{ Asia } \\
\hline China & 54 & 23.7 & 54 & 22.6 & & \\
\hline Hong Kong & 54 & 23.2 & 52 & 22.5 & & \\
\hline India & 54 & 25.3 & 53 & 24.4 & 0.86 & 0.10 \\
\hline Indonesia & 54 & 23.9 & 52 & 23.0 & 0.81 & 0.04 \\
\hline Israel & 53 & 21.5 & 51 & 21.3 & 0.73 & 0.21 \\
\hline Japan & 54 & 25.6 & 52 & 25.5 & 0.71 & 0.03 \\
\hline Kazakhstan & 39 & 14.6 & 52 & 18.2 & & \\
\hline Malaysia & 54 & 24.1 & 53 & 23.4 & & \\
\hline Philippines & 54 & 22.1 & 50 & 21.5 & & \\
\hline Saudi Arabia & 50 & 20.1 & 53 & 21.2 & & \\
\hline Singapore & 54 & 24.7 & 51 & 24.0 & & \\
\hline South Korea & 54 & 25.0 & 52 & 24.6 & 0.81 & 0.05 \\
\hline Thailand & 54 & 24.5 & 53 & 24.5 & 0.79 & 0.04 \\
\hline Turkey & 54 & 24.4 & 54 & 23.9 & 0.59 & 0.31 \\
\hline Vietnam & 54 & 19.3 & 49 & 19.0 & & \\
\hline
\end{tabular}

(continued on next page) 


\section{COUNTRY SUMMARY STATISTICS (CONTINUED)}

\begin{tabular}{l|cc|cccc}
\hline \hline & \multicolumn{5}{|c|}{ As exporter } & \multicolumn{4}{c}{ As importer } \\
Country & \#dyads & avg $T$ & \#dyads & avg $T$ & InvS & InvS \\
\hline Europe & & & & & & \\
\hline Austria & 54 & 23.1 & 52 & 23.0 & 0.06 & 0.70 \\
Belgium & 54 & 15.9 & 53 & 15.9 & 0.14 & 0.82 \\
Czech Republic & 54 & 20.6 & 53 & 21.3 & 0.19 & 0.68 \\
Denmark & 54 & 22.3 & 52 & 24.4 & 0.25 & 0.32 \\
Estonia & 47 & 17.9 & 52 & 19.3 & 0.34 & 0.53 \\
Finland & 54 & 25.6 & 52 & 25.0 & 0.42 & 0.38 \\
France & 54 & 23.1 & 54 & 22.7 & 0.21 & 0.75 \\
Germany & 54 & 23.3 & 54 & 23.0 & 0.23 & 0.75 \\
Greece & 54 & 23.0 & 51 & 23.6 & 0.40 & 0.58 \\
Hungary & 54 & 23.6 & 52 & 22.6 & 0.27 & 0.57 \\
Ireland & 54 & 23.4 & 53 & 22.5 & 0.23 & 0.47 \\
Italy & 54 & 23.1 & 54 & 22.5 & 0.29 & 0.67 \\
Lithuania & 53 & 17.3 & 50 & 18.9 & 0.51 & 0.39 \\
Luxembourg & 54 & 15.8 & 51 & 14.0 & 0.16 & 0.78 \\
Netherlands & 54 & 23.7 & 54 & 23.2 & 0.37 & 0.46 \\
Norway & 54 & 23.1 & 52 & 23.0 & 0.21 & 0.29 \\
Poland & 54 & 22.9 & 52 & 22.3 & 0.30 & 0.58 \\
Portugal & 54 & 24.9 & 53 & 24.8 & 0.22 & 0.76 \\
Romania & 54 & 22.6 & 52 & 21.4 & 0.31 & 0.67 \\
Russia & 54 & 21.4 & 52 & 21.0 & & \\
Slovak Republic & 54 & 20.7 & 51 & 20.4 & 0.12 & 0.79 \\
Slovenia & 54 & 21.1 & 52 & 20.7 & 0.20 & 0.75 \\
Spain & 54 & 24.8 & 54 & 24.9 & 0.35 & 0.58 \\
Sweden & 54 & 23.7 & 54 & 23.1 & 0.25 & 0.36 \\
Switzerland & 54 & 25.6 & 54 & 25.1 & 0.13 & 0.53 \\
Ukraine & 53 & 19.3 & 52 & 19.8 & 0.75 & 0.16 \\
United Kingdom & 54 & 23.4 & 54 & 23.3 & 0.47 & 0.15 \\
Oceania & & & & & & \\
Australia & 54 & 25.1 & 52 & 25.2 & 0.53 & 0.08 \\
New Zealand & 22.7 & 50 & 24.0 & & \\
\hline \hline & & & & & \\
\hline
\end{tabular}

Table 4: Summary statistics for countries in the merged Comtrade/WDI sample. \#dyads: number of nonmissing dyads that the country appears in. avg $T$ : average number of years per dyad that the country appears in; a dyad-year observation is counted if at least one UVI or volume observation is reported by the exporter or importer, and exchange rate data exists for both countries. InvS: share of imports invoiced in USD/euro. 
outcome variables $Y_{i j, t}$ are log points, the above priors are highly diffuse. As for the MGLR prior, we assume ${ }^{19}$

$$
\begin{gathered}
\omega_{k} \sim \operatorname{HalfCauchy}(0,2), \quad\left(\begin{array}{l}
\mu_{0, k} \\
\mu_{1, k}
\end{array}\right) \mid \omega_{k} \sim N\left(0,\left(\begin{array}{cc}
\omega_{k}^{2} & 0 \\
0 & \omega_{k}^{2}
\end{array}\right)\right), \quad k=1, \ldots, K, \\
\zeta_{k}(\cdot) \sim G P\left(0, C\left(\cdot ; A_{k}\right)\right), \quad A_{k} \sim \operatorname{Exponential}(1), \quad k=1, \ldots, K-1,
\end{gathered}
$$

independently across $k$. Here $G P(0, C(\cdot ; A))$ denotes a Gaussian process with Gaussian radial covariance kernel

$$
C\left(s_{1}, s_{2} ; A\right)=\exp \left\{-A\left(s_{1}-s_{2}\right)^{2}\right\}+0.0001 \times \mathbb{1}\left(s_{1}=s_{2}\right), \quad s_{1}, s_{2} \in[0,1] .
$$

The second term on the right-hand side above helps avoid numerical issues in the warm-up phase of the MCMC algorithm, but it is small enough to negligibly affect the final output (the dollar invoicing share $S_{j}$ is measured as a fraction between 0 and 1).

\section{A.2.2 Bayesian leave-one-out cross-validation}

The Bayesian Leave-One-Out (LOO) cross-validation criterion of Gelfand et al. (1992) is given by the cross-sectional sum of leave-one-out predictive densities

$$
\begin{aligned}
L O O & =\sum_{i j} \log f\left(Y_{i j} \mid R_{i j}, X_{i j}, Y_{-(i j)}, R_{-(i j)}, X_{-(i j)}\right) \\
& =\sum_{i j} \log \int f\left(Y_{i j} \mid R_{i j}, X_{i j}, \vartheta\right) f\left(\vartheta \mid R_{i j}, X_{i j}, Y_{-(i j)}, R_{-(i j)}, X_{-(i j)}\right) d \vartheta .
\end{aligned}
$$

Here $\vartheta$ collects all model parameters. $Y_{i j}=\left(Y_{i j, 1}, \ldots, Y_{i j, T}\right)$ collects all observed outcomes for dyad $(i, j)$ across time, and similarly for the covariates $R_{i j}$ and $X_{i j} .{ }^{20}$ The notation $Y_{-(i j)}$ means all observed outcomes for dyads other than $(i, j)$, and similarly for $R_{-(i j)}$ and $X_{-(i j)}$. The LOO criterion is large when the model yields good (leave-one-out) out-of-sample fit, given knowledge of the covariates. This is similar in spirit to the well-known non-Bayesian leave-one-out cross-validation criterion. We use a Pareto-smoothed importance sampling estimate of LOO, as developed by Vehtari et al. (2017) and implemented in Stan.

\footnotetext{
${ }^{19}$ Because the mixture component labels are not identified, we additionally impose the normalization $\mu_{0,1}<$ $\mu_{0,2}<\cdots<\mu_{0, K}$. Stan accomplishes this by reparametrizing the vector $\left(\mu_{0,1}, \ldots, \mu_{0, K}\right)^{\prime}$ into an unconstrained parameter, while adjusting for the Jacobian of the transformation in the posterior density.

${ }^{20}$ Since we have an unbalanced panel, the dimension of $Y_{i j}, R_{i j}, X_{i j}$ actually varies across dyads.
} 


\section{References}

Andersen, T. G., Bollerslev, T., Diebold, F. X., and Vega, C. (2003). Micro Effects of Macro Announcements: Real-Time Price Discovery in Foreign Exchange. American Economic Review, 93(1):38-62.

Arellano, M. and Bonhomme, S. (2012). Identifying Distributional Characteristics in Random Coefficients Panel Data Models. Review of Economic Studies, 79(3):987-1020.

Betts, C. and Devereux, M. B. (2000). Exchange Rate Dynamics in a Model of Pricing-to-Market. fournal of International Economics, 50(1):215-244.

Boz, E. and Cerutti, E. (2017). Dissecting the Global Trade Slowdown: A New Database. Forthcoming IMF Working Paper.

Burstein, A. and Gopinath, G. (2014). International Prices and Exchange Rates. In Gopinath, G., Helpman, E., and Rogoff, K., editors, Handbook of International Economics, volume 4, chapter 7, pages 391-451. Elsevier.

Bussière, M., Gaulier, G., and Steingress, W. (2016). Global Trade Flows: Revisiting the Exchange Rate Elasticities. Banque de France Document de Travail no. 608.

Casas, C., Diez, F., Gopinath, G., and Gourinchas, P.-O. (2016). Dominant currency paradigm. Working paper.

Chamberlain, G. (1992). Efficiency Bounds for Semiparametric Regression. Econometrica, 60(3):567-596.

Chernozhukov, V., Fernández-Val, I., Hahn, J., and Newey, W. (2013). Average and Quantile Effects in Nonseparable Panel Models. Econometrica, 81(2):535-580.

Corsetti, G., Dedola, L., and Leduc, S. (2010). Optimal Monetary Policy in Open Economies. In Friedman, B. M. and Woodford, M., editors, Handbook of Monetary Economics, volume 3, chapter 16, pages 861-933. Elsevier.

Corsetti, G. and Pesenti, P. (2001). Welfare and Macroeconomic Interdependence. Quarterly Journal of Economics, 116(2):421-445.

Cravino, J. (2017). Exchange Rates, Aggregate Productivity and the Currency of Invoicing of International Trade. Working paper. 
Devereux, M. B. and Engel, C. (2003). Monetary Policy in the Open Economy Revisited: Price Setting and Exchange Rate Flexibility. Review of Economic Studies, 70(4):765-784.

Engel, C. (2011). Currency Misalignments and Optimal Monetary Policy: A Reexamination. American Economic Review, 101(6):2796-2822.

Evdokimov, K. (2010). Identification and Estimation of a Nonparametric Panel Data Model with Unobserved Heterogeneity. Working paper.

Feenstra, R. C., Lipsey, R. E., Deng, H., Ma, A. C., and Mo, H. (2005). World Trade Flows: 19622000. NBER Working Paper 11040.

Fitzgerald, D. and Haller, S. (2013). Exchange rates and producer prices: Evidence from micro data. Review of Economic Studies, 67(2):761-786.

Galí, J. (2008). Monetary Policy, Inflation and the Business Cycle: An Introduction to the New Keynesian Framework. Princeton University Press.

Gaulier, G., Martin, J., Mejean, I., and Zignago, S. (2008). International Trade Price Indices. CEPII Working Paper No. 2008/10.

Gelfand, A., Dey, D., and Chang, H. (1992). Model determination using predictive distributions with implementation via sampling-based methods. In Bernardo, J., Berger, J., Dawid, A., and Smith, A., editors, Bayesian Statistics 4: Proceedings of the Fourth Valencia International Meeting, pages 147-167. Oxford University Press.

Goldberg, L. S. and Tille, C. (2008). Vehicle currency use in international trade. Fournal of International Economics, 76(2):177-192.

Goldberg, P. K. and Knetter, M. M. (1997). Goods Prices and Exchange Rates: What Have We Learned? fournal of Economic Literature, 35(3):1243-1272.

Gopinath, G. (2015). The International Price System. In Jackson Hole Symposium, volume 27. Kansas City Federal Reserve.

Gopinath, G., Itskhoki, O., and Rigobon, R. (2010). Currency Choice and Exchange Rate PassThrough. American Economic Review, 100(1):304-36.

Gopinath, G. and Rigobon, R. (2008). Sticky Borders. Quarterly fournal of Economics, 123(2):531575. 
Gürkaynak, R. S., Sack, B. P., and Swanson, E. T. (2005). Do Actions Speak Louder Than Words? The Response of Asset Prices to Monetary Policy Actions and Statements. International fournal of Central Banking, 1(1):55-93.

Head, K. and Mayer, T. (2015). Gravity Equations: Workhorse, Toolkit, and Cookbook. In Gopinath, G., Helpman, E., and Rogoff, K., editors, Handbook of International Economics, volume 4, chapter 3, pages 131-195. Elsevier.

Hirano, K. (2002). Semiparametric Bayesian Inference in Autoregressive Panel Data Models. Econometrica, 70(2):781-799.

Hoffman, M. D. and Gelman, A. (2014). The No-U-Turn Sampler: Adaptively Setting Path Lengths in Hamiltonian Monte Carlo. Journal of Machine Learning Research, 15:1593-1623.

Imbens, G. W. and Kolesár, M. (2016). Robust Standard Errors in Small Samples: Some Practical Advice. Review of Economics and Statistics, 98(4):701-712.

IMF (2009). Export and Import Price Index Manual: Theory and Practice. International Monetary Fund, Washington, D.C.

Leigh, D., Lian, W., Poplawski-Ribeiro, M., and Tsyrennikov, V. (2015). Exchange rates and trade flows: Disconnected? In World Economic Outlook: Adjusting to Lower Commodity Prices, chapter 3, pages 105-142. International Monetary Fund.

Liu, L. (2017). Density Forecasts in Panel Data Models: A Semiparametric Bayesian Perspective. Working paper.

Nakamura, E. and Steinsson, J. (2016). High Frequency Identification of Monetary Non-Neutrality: The Information Effect. Working paper.

Neal, R. M. (2011). MCMC Using Hamiltonian Dynamics. In Brooks, S., Gelman, A., Jones, G. L., and Meng, X.-L., editors, Handbook of Markov Chain Monte Carlo, chapter 5, pages 113-162. CRC Press.

Obstfeld, M. and Rogoff, K. (1995). Exchange Rate Dynamics Redux. Fournal of Political Economy, 103(3):624-660.

Pati, D., Dunson, D. B., and Tokdar, S. T. (2013). Posterior consistency in conditional distribution estimation. Journal of Multivariate Analysis, 116:456-472. 
Silver, M. (2007). Do Unit Value Export, Import, and Terms of Trade Indices Represent or Misrepresent Price Indices? IMF Working Paper No. 07/121.

Stan Development Team (2016). Stan Modeling Language Users Guide and Reference Manual, Version 2.14.0. http://mc-stan.org.

Vehtari, A., Gelman, A., and Gabry, J. (2017). Practical Bayesian model evaluation using leaveone-out cross-validation and WAIC. Statistics and Computing, 27(5):1413-1432.

World Bank (2010). Imports, Exports and Mirror Data with UN COMTRADE. World Integrated Trade Solution Online Help. 


\section{B Online Appendix (NOT FOR PUBLICATION)}

\section{B.1 Data: Comparison of Comtrade and BLS price series for the U.S.}

Here we compare our unit value indices to survey price indices from the U.S. Bureau of Labor Statistics. The BLS provides U.S. import price indices by locality of origin for Canada, E.U., France, Germany, U.K, Latin America, Mexico, Pacific Rim, China, Japan, ASEAN, Asia Near East, and Asian Newly Industrialized countries. As these price indices are constructed from surveys, their comparison with our unit value based indices can help gauge the effectiveness of our techniques to deal with the unit value bias and other potential mismeasurement inherent in customs data.

To arrive at comparable series, in this subsection we follow BLS in using Laspeyres indices of total (commodities and non-commodities) goods prices from our data set. For regions with multiple countries, we aggregate country level growth rates using Comtrade import values with a two year lag. Still, the series are not fully comparable because BLS' preferred price basis is f.o.b. (free on board) while import values recorded at customs are c.i.f. (cost, insurance and freight), and not all countries included in BLS regions are in our database.

Our indices constructed from Comtrade unit values track the BLS import price indices fairly well, as shown in Figs. 17 and 18. These figures compare the linearly detrended logged indices, since our regressions use log growth rates and absorb any disparity in average growth rates in the intercept. The growth rates of our indices for Canada, Japan, Mexico, and the aggregated Latin America and Asia Near East match those of BLS remarkably well. The comparison with some Asian countries suggests that a unit value bias may still be present, causing the unit value series to be somewhat more volatile than the BLS price series. Nevertheless, for every country group and individual country except Germany, the correlation coefficient between the Comtrade and BLS growth rates is high. Finally, the match for European countries seems acceptable, with the year 2008 being an exception. A closer inspection of the case of Germany reveals that a couple of products (transport vehicles) with large import shares experienced substantial unit value decreases that year according to Comtrade, leading our indices to decline while the BLS index shows an increase.

\section{B.2 Panel regressions: Supplementary results}

This section provides supplementary panel regression results.

Post-2002 results. Exchange rate pass-through into prices has been stable over our sample period, while trade elasticities may have become larger in absolute value in the latter part of the 
COMTRADE AND BLS IMPORT PRICE INDICES FOR U.S.: COUNTRY GROUPS
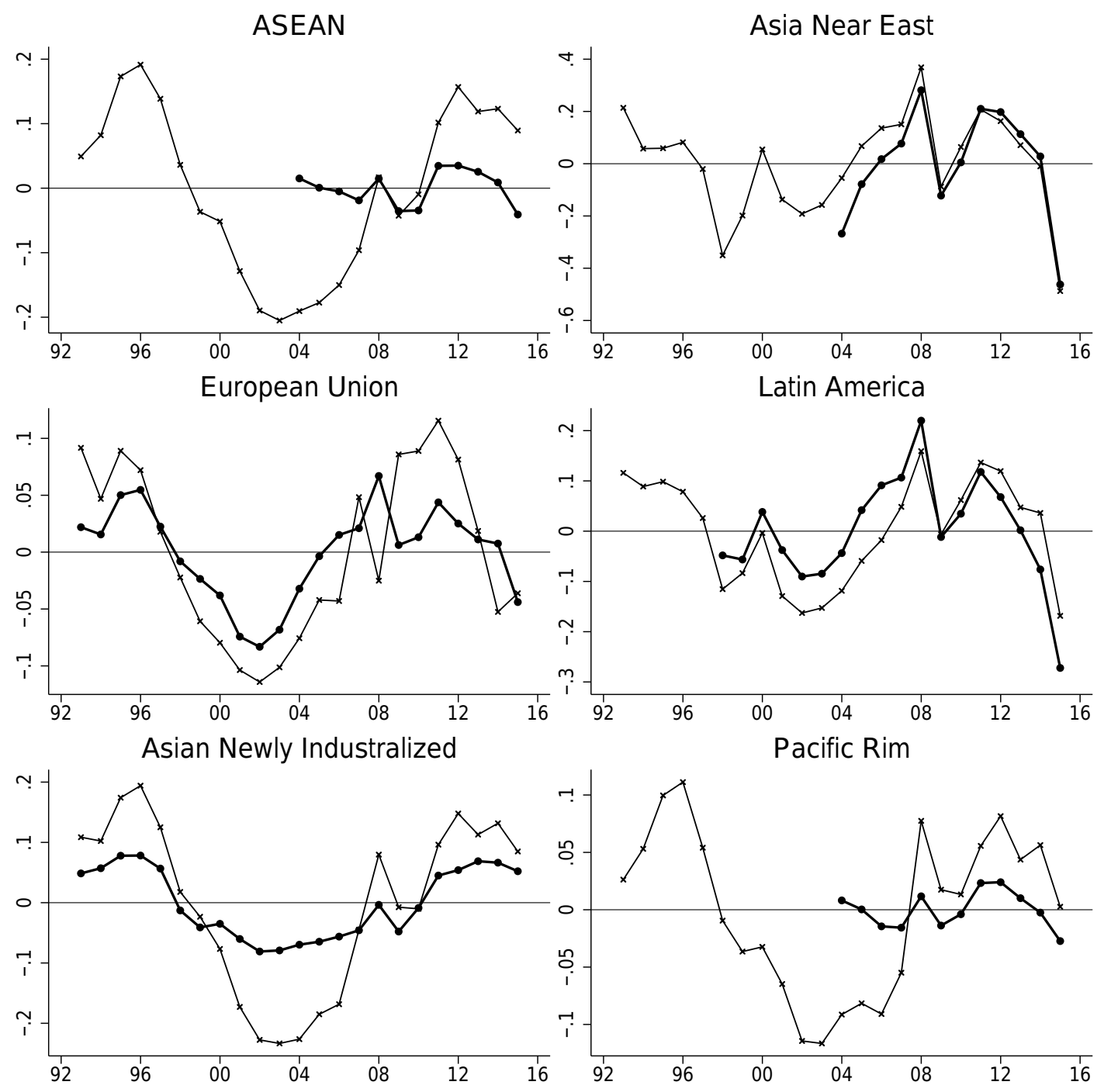

Figure 17: Comparison of BLS Locality of Origin import price indices (thick lines, circles) with our constructed Comtrade analogues (thin lines, crosses). Plotted indices are logged and linearly detrended. The Comtrade sample does not cover all countries in the BLS country groups, cf. Table 5. 
COMTRADE AND BLS IMPORT PRICE INDICES FOR U.S.: INDIVIDUAL COUNTRIES
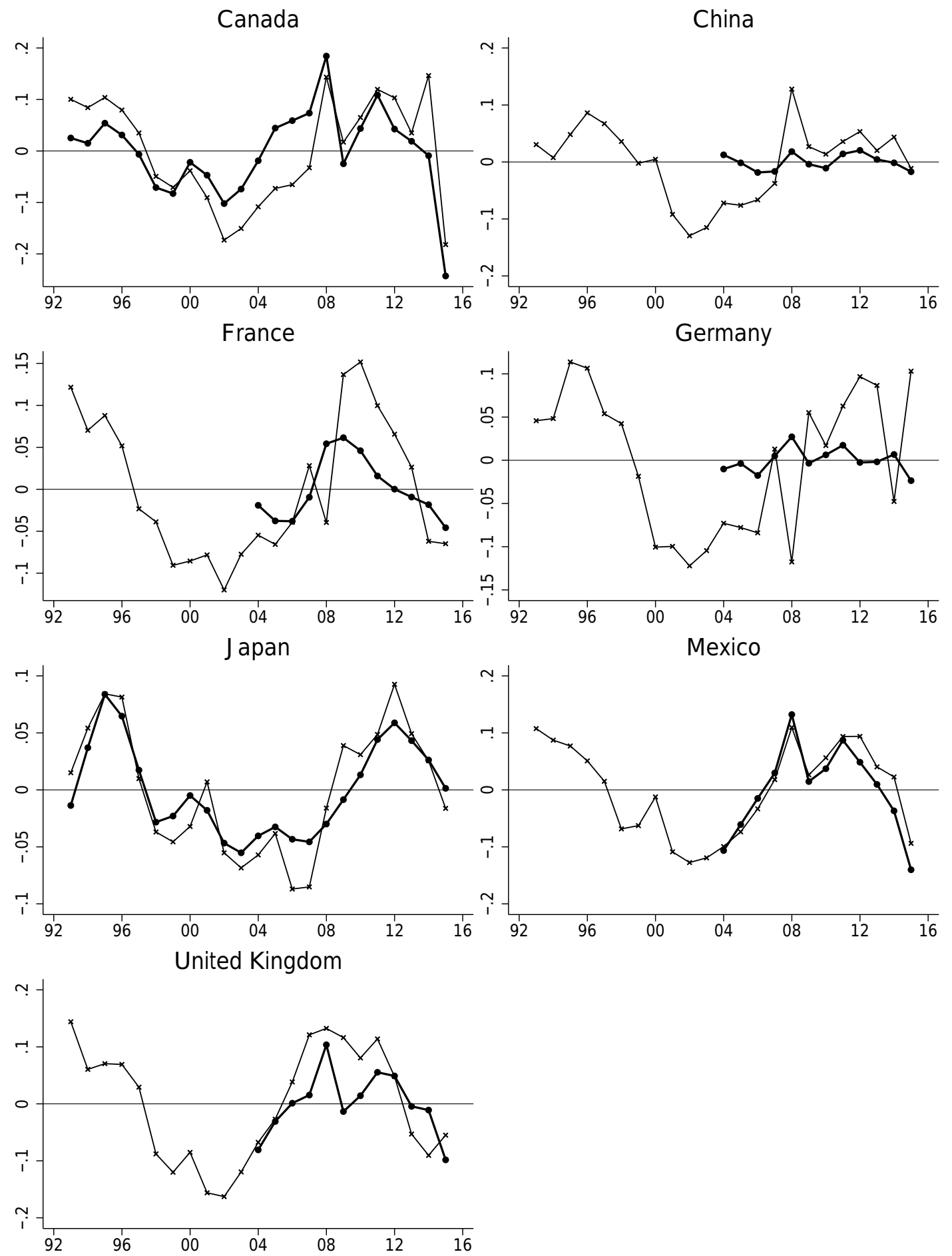

Figure 18: Comparison of BLS Locality of Origin import price indices (thick lines, circles) with our constructed Comtrade analogues (thin lines, crosses). Plotted indices are logged and linearly detrended. 
BLS COUNTRY GROUPS

\begin{tabular}{|c|c|}
\hline BLS group & Country ISO codes \\
\hline ASEAN & BRN $^{*}$ IDN KHM* LAO* MMR* MYS PHL SGP THA VNM* \\
\hline Asia Near East & $\begin{array}{l}\text { ARE }^{*} \text { BHR }^{*} \text { IRN }^{*} \text { IRQ* ISR JOR* KWT* LBN* OMN* QAT* SAU SYR } \\
\text { YEM }^{*}\end{array}$ \\
\hline European Union & $\begin{array}{l}\text { AUT BEL BGR* CYP* CZE DEU DNK ESP EST FIN FRA GBR GRC } \\
\text { HRV }^{*} \text { HUN IRL ITA LTU LUX LVA* } \text { MLT }^{*} \text { NLD POL PRT ROU SVK } \\
\text { SVN SWE }\end{array}$ \\
\hline Latin America & $\begin{array}{l}\text { ARG BRA CHL COL MEX VEN (plus other unspecified Central Amer- } \\
\text { ican, South American, and Caribbean countries*) }\end{array}$ \\
\hline Asian New. Ind. & HKG KOR SGP TWN \\
\hline Pacific Rim & $\begin{array}{l}\text { AUS BRN* CHN HKG IDN JPN KOR MAC* MYS NZL PHL PNG* SGP } \\
\text { TWN }\end{array}$ \\
\hline
\end{tabular}

Table 5: Definition of BLS country groups in Fig. 17. Countries marked with an asterisk $\left.{ }^{*}\right)$ are not available in the Comtrade sample.

sample. We compute results for the subsample 2002-2015, roughly corresponding to the second half of our data set, and also corresponding to the sample used for the euro regressions in Section 4.5. Figs. 19 and 20 show price and volume impulse responses for the 2002-2015 subsample that correspond to the full-sample results in Figs. 1 and 3 in Section 4. The price pass-through impulse responses of bilateral and dollar exchange rates are similar to the full-sample results. However, the post-2002 USD cumulative trade elasticity is substantially negative at lags of 1 and 2 years, whereas the level effect is close to zero at lags 1 and 2 on the full sample.

Euro regressions. Tables 6 and 7 display the results of the price pass-through and trade elasticity regressions in Section 4.5 involving the euro exchange rate. The regressions do not control for time fixed effects but do include the aggregate control variables listed in Section 4.5. Specifications (1) and (4) focus on the bilateral and euro exchange rates, specifications (2) and (5) add the dollar exchange rate, and specifications (3) and (6) include interactions with the dollar and euro import invoicing shares. $S_{j}^{€}$ is the importing country's share of imports invoiced in euros from Gopinath (2015). The interactions are statistically and economically significant and mostly have the expected signs in the price pass-through regressions: A higher share of euro (resp., dollar) invoicing implies a higher pass-through from the euro (resp, dollar) exchange rate. In constrast, the interaction terms are imprecisely estimated in the trade elasticity regressions. 
AverAge PRICE PASS-THROUGH, 2002-2015

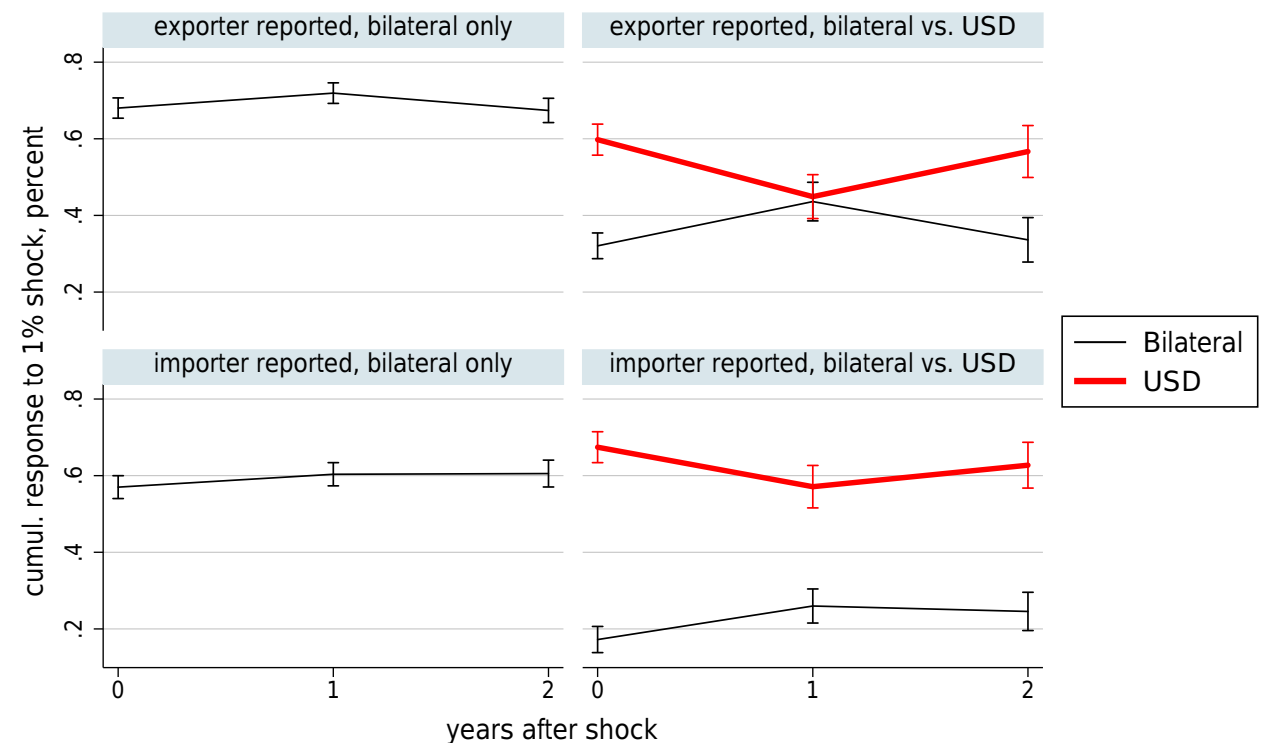

Figure 19: Fig. 1 computed on post-2002 data.

Average trade Elasticity, 2002-2015

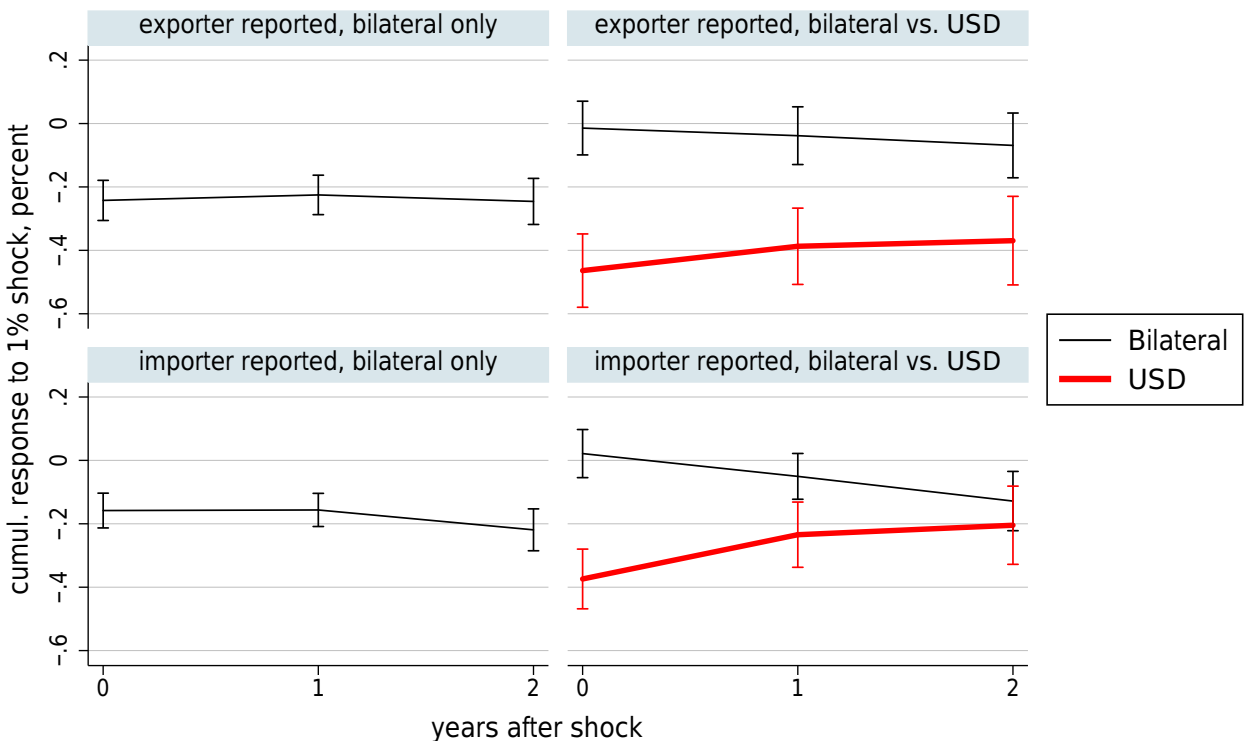

Figure 20: Fig. 3 computed on post-2002 data. 
EURO VS. DOLLAR EXCHANGE RATE PASS-THROUGH INTO PRICES

\begin{tabular}{|c|c|c|c|c|c|c|}
\hline VARIABLES & $\begin{array}{c}(1) \\
\Delta p_{i j, t}\end{array}$ & $\begin{array}{c}(2) \\
\Delta p_{i j, t}\end{array}$ & $\begin{array}{c}(3) \\
\Delta p_{i j, t}\end{array}$ & $\begin{array}{c}(4) \\
\Delta p_{i j, t}\end{array}$ & $\begin{array}{c}(5) \\
\Delta p_{i j, t}\end{array}$ & $\begin{array}{c}(6) \\
\Delta p_{i j, t}\end{array}$ \\
\hline$\Delta e_{i j, t}$ & $\begin{array}{l}0.438^{* * *} \\
(0.0154)\end{array}$ & $\begin{array}{l}0.316^{* * *} \\
(0.0169)\end{array}$ & $\begin{array}{l}0.286^{* * *} \\
(0.0702)\end{array}$ & $\begin{array}{l}0.305^{* * *} \\
(0.0159)\end{array}$ & $\begin{array}{l}0.181^{* * *} \\
(0.0174)\end{array}$ & $\begin{array}{l}0.207^{* * *} \\
(0.0695)\end{array}$ \\
\hline$\Delta e_{i j, t-1}$ & $\begin{array}{l}0.146^{* * *} \\
(0.0151)\end{array}$ & $\begin{array}{l}0.119^{* * *} \\
(0.0157)\end{array}$ & $\begin{array}{l}0.276^{* * *} \\
(0.0821)\end{array}$ & $\begin{array}{l}0.162^{* * *} \\
(0.0133)\end{array}$ & $\begin{array}{l}0.134^{* * *} \\
(0.0140)\end{array}$ & $\begin{array}{c}0.0277 \\
(0.0621)\end{array}$ \\
\hline$\Delta e_{i j, t-2}$ & $\begin{array}{c}-0.101^{* * *} \\
(0.0148)\end{array}$ & $\begin{array}{c}-0.0533^{* * *} \\
(0.0151)\end{array}$ & $\begin{array}{l}-0.0898 \\
(0.0744)\end{array}$ & $\begin{array}{c}-0.0793^{* * *} \\
(0.0123)\end{array}$ & $\begin{array}{c}-0.0389^{* * *} \\
(0.0129)\end{array}$ & $\begin{array}{l}-0.0723 \\
(0.0666)\end{array}$ \\
\hline$\Delta e_{i j, t} \times\left(S_{j}+S_{j}^{€}\right)$ & & & $\begin{array}{c}0.0449 \\
(0.0834)\end{array}$ & & & $\begin{array}{l}-0.0357 \\
(0.0784)\end{array}$ \\
\hline$\Delta e_{i j, t-1} \times\left(S_{j}+S_{j}^{€}\right)$ & & & $\begin{array}{l}-0.178^{*} \\
(0.0919)\end{array}$ & & & $\begin{array}{c}0.0814 \\
(0.0720)\end{array}$ \\
\hline$\Delta e_{i j, t-2} \times\left(S_{j}+S_{j}^{€}\right)$ & & & $\begin{array}{c}0.0311 \\
(0.0827)\end{array}$ & & & $\begin{array}{c}0.0640 \\
(0.0745)\end{array}$ \\
\hline$\Delta e_{\$ j, t}$ & & $\begin{array}{l}0.666^{* * *} \\
(0.0358)\end{array}$ & $\begin{array}{l}0.512^{* * *} \\
(0.0448)\end{array}$ & & $\begin{array}{l}0.754^{* * *} \\
(0.0373)\end{array}$ & $\begin{array}{l}0.614^{* * *} \\
(0.0405)\end{array}$ \\
\hline$\Delta e_{\$ j, t-1}$ & & $\begin{array}{c}-0.0459^{* * *} \\
(0.0161)\end{array}$ & $\begin{array}{l}-0.0121 \\
(0.0311)\end{array}$ & & $\begin{array}{c}-0.0646^{* * *} \\
(0.0161)\end{array}$ & $\begin{array}{l}0.155^{* * *} \\
(0.0252)\end{array}$ \\
\hline$\Delta e_{\$ j, t-2}$ & & $\begin{array}{l}0.00180 \\
(0.0158)\end{array}$ & $\begin{array}{c}0.0456 \\
(0.0299)\end{array}$ & & $\begin{array}{c}0.0576^{* * *} \\
(0.0148)\end{array}$ & $\begin{array}{c}0.0154 \\
(0.0228)\end{array}$ \\
\hline$\Delta e_{\$ j, t} \times S_{j}$ & & & $\begin{array}{l}0.216^{* * *} \\
(0.0470)\end{array}$ & & & $\begin{array}{l}0.510^{* * *} \\
(0.0439)\end{array}$ \\
\hline$\Delta e_{\$ j, t-1} \times S_{j}$ & & & $\begin{array}{l}-0.0841 \\
(0.0613)\end{array}$ & & & $\begin{array}{c}-0.447^{* * *} \\
(0.0555)\end{array}$ \\
\hline$\Delta e_{\$ j, t-2} \times S_{j}$ & & & $\begin{array}{l}-0.0817 \\
(0.0499)\end{array}$ & & & $\begin{array}{c}0.101^{* *} \\
(0.0465)\end{array}$ \\
\hline$\Delta e_{€ j, t}$ & $\begin{array}{l}0.396^{* * *} \\
(0.0179)\end{array}$ & $\begin{array}{c}-0.0688^{* *} \\
(0.0330)\end{array}$ & $\begin{array}{l}-0.108^{* *} \\
(0.0434)\end{array}$ & $\begin{array}{l}0.467^{* * *} \\
(0.0175)\end{array}$ & $\begin{array}{c}-0.0800^{* *} \\
(0.0332)\end{array}$ & $\begin{array}{c}-0.347^{* * *} \\
(0.0430)\end{array}$ \\
\hline$\Delta e_{€ j, t-1}$ & $\begin{array}{l}-0.174^{* * *} \\
(0.0168)\end{array}$ & $\begin{array}{c}-0.109^{* * *} \\
(0.0201)\end{array}$ & $\begin{array}{c}-0.0923^{* * *} \\
(0.0346)\end{array}$ & $\begin{array}{c}-0.187^{* * *} \\
(0.0166)\end{array}$ & $\begin{array}{c}-0.103^{* * *} \\
(0.0209)\end{array}$ & $\begin{array}{c}0.0450 \\
(0.0398)\end{array}$ \\
\hline$\Delta e_{€ j, t-2}$ & $\begin{array}{l}0.119^{* * *} \\
(0.0168)\end{array}$ & $\begin{array}{c}0.0552^{* * *} \\
(0.0204)\end{array}$ & $\begin{array}{c}0.0867^{* * *} \\
(0.0295)\end{array}$ & $\begin{array}{l}0.132^{* * *} \\
(0.0156)\end{array}$ & $\begin{array}{c}0.0294 \\
(0.0188)\end{array}$ & $\begin{array}{c}-0.0982^{* * *} \\
(0.0284)\end{array}$ \\
\hline$\Delta e_{€ j, t} \times S_{j}^{€}$ & & & $\begin{array}{l}0.285^{* * *} \\
(0.0860)\end{array}$ & & & $\begin{array}{l}0.694^{* * *} \\
(0.0821)\end{array}$ \\
\hline$\Delta e_{€ j, t-1} \times S_{j}^{€}$ & & & $\begin{array}{c}0.000 \\
(0.0893)\end{array}$ & & & $\begin{array}{l}-0.203^{* *} \\
(0.0982)\end{array}$ \\
\hline$\Delta e_{€ j, t-2} \times S_{j}^{€}$ & & & $\begin{array}{l}-0.0615 \\
(0.0819)\end{array}$ & & & $\begin{array}{l}0.295^{* * *} \\
(0.0851)\end{array}$ \\
\hline Exp. PPI & yes & yes & yes & yes & yes & yes \\
\hline Agg. controls & yes & yes & yes & yes & yes & yes \\
\hline Time FE & no & no & no & no & no & no \\
\hline R-squared & 0.185 & 0.197 & 0.211 & 0.131 & 0.143 & 0.210 \\
\hline Observations & 32,825 & 32,825 & 23,668 & 33,802 & 33,802 & 24,463 \\
\hline Dyads & 2,611 & 2,611 & 1,867 & 2,647 & 2,647 & 1,900 \\
\hline
\end{tabular}

Table 6: The first (resp., last) three columns use Comtrade data reported by exporting (resp., importing) countries. S.e. clustered by dyad. ${ }^{* * *} \mathrm{p}<0.01,{ }^{* *} \mathrm{p}<0.05,{ }^{*} \mathrm{p}<0.1$. 
EURO VS. DOLLAR TRADE ELASTICITY

\begin{tabular}{|c|c|c|c|c|c|c|}
\hline VARIABLES & $\begin{array}{c}(1) \\
\Delta y_{i j, t}\end{array}$ & $\begin{array}{c}(2) \\
\Delta y_{i j, t}\end{array}$ & $\begin{array}{c}(3) \\
\Delta y_{i j, t}\end{array}$ & $\begin{array}{c}(4) \\
\Delta y_{i j, t}\end{array}$ & $\begin{array}{c}(5) \\
\Delta y_{i j, t}\end{array}$ & $\begin{array}{c}(6) \\
\Delta y_{i j, t}\end{array}$ \\
\hline$\Delta e_{i j, t}$ & $\begin{array}{c}-0.110^{\text {*** }} \\
(0.0418)\end{array}$ & $\begin{array}{l}-0.0234 \\
(0.0432)\end{array}$ & $\begin{array}{c}0.581^{* * *} \\
(0.224)\end{array}$ & $\begin{array}{l}-0.0631^{*} \\
(0.0371)\end{array}$ & $\begin{array}{c}0.0229 \\
(0.0386)\end{array}$ & $\begin{array}{c}0.619^{* * *} \\
(0.229)\end{array}$ \\
\hline$\Delta e_{i j, t-1}$ & $\begin{array}{l}-0.0349 \\
(0.0339)\end{array}$ & $\begin{array}{r}-0.00530 \\
(0.0354)\end{array}$ & $\begin{array}{l}-0.177 \\
(0.184)\end{array}$ & $\begin{array}{c}-0.0827^{* *} \\
(0.0343)\end{array}$ & $\begin{array}{c}-0.0694^{*} \\
(0.0367)\end{array}$ & $\begin{array}{l}-0.366^{*} \\
(0.188)\end{array}$ \\
\hline$\Delta e_{i j, t-2}$ & $\begin{array}{l}-0.0151 \\
(0.0307)\end{array}$ & $\begin{array}{l}-0.0393 \\
(0.0318)\end{array}$ & $\begin{array}{c}0.167 \\
(0.190)\end{array}$ & $\begin{array}{l}-0.0419 \\
(0.0270)\end{array}$ & $\begin{array}{c}-0.0679^{* *} \\
(0.0277)\end{array}$ & $\begin{array}{c}0.121 \\
(0.165)\end{array}$ \\
\hline$\Delta e_{i j, t} \times\left(S_{j}+S_{j}^{€}\right)$ & & & $\begin{array}{c}-0.629^{* *} \\
(0.260)\end{array}$ & & & $\begin{array}{c}-0.668^{* * *} \\
(0.253)\end{array}$ \\
\hline$\Delta e_{i j, t-1} \times\left(S_{j}+S_{j}^{€}\right)$ & & & $\begin{array}{c}0.160 \\
(0.218)\end{array}$ & & & $\begin{array}{l}0.348^{*} \\
(0.207)\end{array}$ \\
\hline$\Delta e_{i j, t-2} \times\left(S_{j}+S_{j}^{€}\right)$ & & & $\begin{array}{l}-0.207 \\
(0.221)\end{array}$ & & & $\begin{array}{l}-0.203 \\
(0.196)\end{array}$ \\
\hline$\Delta e_{\$ j, t}$ & & $\begin{array}{c}-0.703^{* * *} \\
(0.0894)\end{array}$ & $\begin{array}{c}-0.663^{* * *} \\
(0.115)\end{array}$ & & $\begin{array}{c}-0.695^{* * *} \\
(0.0806)\end{array}$ & $\begin{array}{c}-0.316^{* * *} \\
(0.103)\end{array}$ \\
\hline$\Delta e_{\$ j, t-1}$ & & $\begin{array}{l}-0.0615 \\
(0.0441)\end{array}$ & $\begin{array}{c}0.116 \\
(0.0822)\end{array}$ & & $\begin{array}{r}-0.00291 \\
(0.0410)\end{array}$ & $\begin{array}{l}-0.120^{*} \\
(0.0693)\end{array}$ \\
\hline$\Delta e_{\$ j, t-2}$ & & $\begin{array}{l}0.00568 \\
(0.0441)\end{array}$ & $\begin{array}{c}-0.257^{* * *} \\
(0.0797)\end{array}$ & & $\begin{array}{l}0.00554 \\
(0.0400)\end{array}$ & $\begin{array}{c}0.0595 \\
(0.0613)\end{array}$ \\
\hline$\Delta e_{\$ j, t} \times S_{j}$ & & & $\begin{array}{l}-0.243^{*} \\
(0.131)\end{array}$ & & & $\begin{array}{c}-0.760^{* * *} \\
(0.121)\end{array}$ \\
\hline$\Delta e_{\$ j, t-1} \times S_{j}$ & & & $\begin{array}{l}-0.221 \\
(0.159)\end{array}$ & & & $\begin{array}{l}0.357^{* *} \\
(0.145)\end{array}$ \\
\hline$\Delta e_{\$ j, t-2} \times S_{j}$ & & & $\begin{array}{c}0.446^{* * *} \\
(0.131)\end{array}$ & & & $\begin{array}{c}0.00131 \\
(0.108)\end{array}$ \\
\hline$\Delta e_{€ j, t}$ & $\begin{array}{c}-0.244^{* * *} \\
(0.0525)\end{array}$ & $\begin{array}{l}0.264^{* * *} \\
(0.0870)\end{array}$ & $\begin{array}{c}0.302^{* * *} \\
(0.110)\end{array}$ & $\begin{array}{l}-0.179^{* * *} \\
(0.0413)\end{array}$ & $\begin{array}{l}0.320^{* * *} \\
(0.0759)\end{array}$ & $\begin{array}{l}0.427^{* * *} \\
(0.0960)\end{array}$ \\
\hline$\Delta e_{€ j, t-1}$ & $\begin{array}{l}0.117^{* * *} \\
(0.0416)\end{array}$ & $\begin{array}{l}0.119^{* * *} \\
(0.0454)\end{array}$ & $\begin{array}{l}0.218^{* * *} \\
(0.0741)\end{array}$ & $\begin{array}{l}0.170^{* * *} \\
(0.0374)\end{array}$ & $\begin{array}{l}0.145^{* * *} \\
(0.0406)\end{array}$ & $\begin{array}{l}0.00391 \\
(0.0779)\end{array}$ \\
\hline$\Delta e_{€ j, t-2}$ & $\begin{array}{l}-0.0147 \\
(0.0377)\end{array}$ & $\begin{array}{c}0.0161 \\
(0.0460)\end{array}$ & $\begin{array}{l}-0.116^{*} \\
(0.0661)\end{array}$ & $\begin{array}{c}-0.0295 \\
(0.0333)\end{array}$ & $\begin{array}{l}0.00521 \\
(0.0406)\end{array}$ & $\begin{array}{c}0.0250 \\
(0.0639)\end{array}$ \\
\hline$\Delta e_{€ j, t} \times S_{j}^{€}$ & & & $\begin{array}{l}0.0101 \\
(0.214)\end{array}$ & & & $\begin{array}{l}-0.313^{*} \\
(0.185)\end{array}$ \\
\hline$\Delta e_{€ j, t-1} \times S_{j}^{€}$ & & & $\begin{array}{l}-0.115 \\
(0.229)\end{array}$ & & & $\begin{array}{c}0.194 \\
(0.197)\end{array}$ \\
\hline$\Delta e_{€ j, t-2} \times S_{j}^{€}$ & & & $\begin{array}{c}0.560^{* * *} \\
(0.200)\end{array}$ & & & $\begin{array}{l}0.0756 \\
(0.201)\end{array}$ \\
\hline Imp. GDP & yes & yes & yes & yes & yes & yes \\
\hline Agg. controls & yes & yes & yes & yes & yes & yes \\
\hline Time FE & no & no & no & no & no & no \\
\hline R-squared & 0.072 & 0.075 & 0.085 & 0.068 & 0.071 & 0.078 \\
\hline Observations & 36,269 & 36,269 & 26,129 & 37,437 & 37,437 & 27,109 \\
\hline Dyads & 2,773 & 2,773 & 1,982 & 2,807 & 2,807 & 2,014 \\
\hline
\end{tabular}

Table 7: The first (resp., last) three columns use Comtrade data reported by exporting (resp., importing) countries. S.e. clustered by dyad. ${ }^{* * *} \mathrm{p}<0.01,{ }^{* *} \mathrm{p}<0.05,{ }^{*} \mathrm{p}<0.1$. 

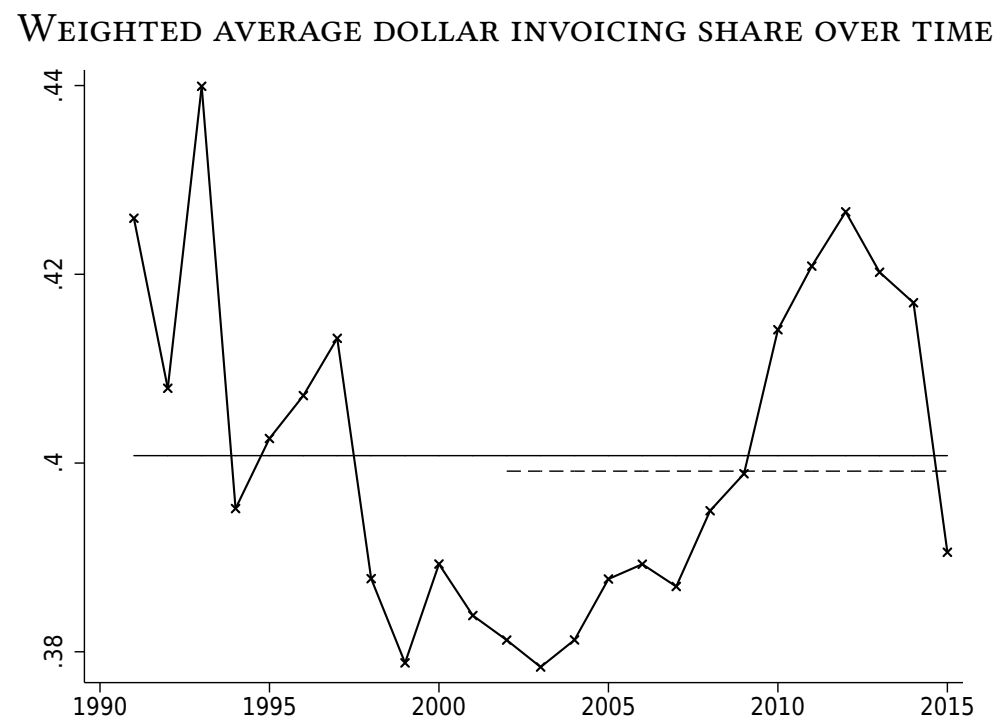

Figure 21: Weighted average dollar import invoicing share $\sum_{j \neq \mathrm{US}} w_{j} S_{j}$, using import value weights $w_{j}$ computed in different reference years (along horizontal axis). Horizontal lines show the mean on the 1992-2015 and 2002-2015 samples.

Weighted average dollar invoicing share. Fig. 21 depicts the weighted average dollar import invoicing share $\sum_{j \neq \mathrm{US}} w_{j} S_{j}$ used in Section 6.1, where the ex-U.S. non-commodity import value weights $w_{j}$ have been computed for each year in our sample. Notice that the weighted average fluctuates tightly around a mean of 0.40 .

CPI and PPI regressions. Table 8 displays the results of the country-level regressions used for constructing the CPI and PPI impulse responses in Fig. 16. The table displays 95\% confidence intervals rather than standard errors because the small number of countries necessitates the use of small-sample corrections. Specifically, we use the bias-reduced "LZ2" clustered variancecovariance matrix estimator, along with Student-t critical values and the "BM" data-dependent degrees of freedom measure, as developed by Imbens and Kolesár (2016). 
Dollar PASS-Through INTO CPI AND PPI, 2002-2015

\begin{tabular}{|c|c|c|c|c|c|c|c|c|}
\hline VARIABLES & $\begin{array}{c}(1) \\
\Delta c p i_{j, t}\end{array}$ & $\begin{array}{c}(2) \\
\Delta c p i_{j, t}\end{array}$ & $\begin{array}{c}(3) \\
\Delta c p i_{j, t}\end{array}$ & $\begin{array}{c}(4) \\
\Delta c p i_{j, t}\end{array}$ & $\begin{array}{c}(5) \\
\Delta p p i_{j, t}\end{array}$ & $\begin{array}{c}(6) \\
\Delta p p i_{j, t}\end{array}$ & $\begin{array}{c}(7) \\
\Delta p p i_{j, t}\end{array}$ & $\begin{array}{c}(8) \\
\Delta p p i_{j, t}\end{array}$ \\
\hline$\Delta e_{\$, t}$ & $\begin{array}{c}0.106^{* *} \\
{[0.04,0.18]}\end{array}$ & $\begin{array}{c}0.0221 \\
{[-0.050 .09]}\end{array}$ & & & $\begin{array}{c}0.284^{* *} \\
{[0.14,0.43]}\end{array}$ & $\begin{array}{c}0.182^{* *} \\
{[0.05,0.32]}\end{array}$ & & \\
\hline$\Delta e_{\$ j, t-1}$ & $\begin{array}{c}0.0862 \\
{[0.00,0.17]}\end{array}$ & $\begin{array}{c}0.108 \\
{[-0.02,0.24]}\end{array}$ & & & $\begin{array}{c}0.115^{* *} \\
{[0.02,0.21]}\end{array}$ & $\begin{array}{c}0.133 \\
{[-0.01,0.28]}\end{array}$ & & \\
\hline$\Delta e_{\$ j, t-2}$ & $\begin{array}{c}0.0353 \\
{[-0.03,0.10]}\end{array}$ & $\begin{array}{c}0.155^{* *} \\
{[0.06,0.25]}\end{array}$ & & & $\begin{array}{c}0.0330 \\
{[-0.04,0.10]}\end{array}$ & $\begin{array}{c}0.129^{* *} \\
{[0.04,0.22]}\end{array}$ & & \\
\hline$\Delta e_{\$ j, t} \times S_{j}$ & & $\begin{array}{c}0.181^{* *} \\
{[0.04,0.33]}\end{array}$ & & & & $\begin{array}{c}0.237 \\
{[-0.03,0.51]}\end{array}$ & & \\
\hline$\Delta e_{\$ j, t-1} \times S_{j}$ & & $\begin{array}{c}0.0306 \\
{[-0.15,0.21]}\end{array}$ & & & & $\begin{array}{c}0.0345 \\
{[-0.15,0.22]}\end{array}$ & & \\
\hline$\Delta e_{\$ j, t-2} \times S_{j}$ & & $\begin{array}{c}-0.151^{* *} \\
{[-0.29,-0.01]}\end{array}$ & & & & $\begin{array}{c}-0.117 \\
{[-0.27,0.04]}\end{array}$ & & \\
\hline$z_{j, t}$ & & & $\begin{array}{c}-0.0768 \\
{[-0.33,0.18]}\end{array}$ & $\begin{array}{c}0.121 \\
{[-0.44,0.68]}\end{array}$ & & & $\begin{array}{c}0.210 \\
{[-0.29,0.71]}\end{array}$ & $\begin{array}{c}-0.261 \\
{[-1.31,0.79]}\end{array}$ \\
\hline$z_{j, t-1}$ & & & $\begin{array}{c}0.0920 \\
{[-0.31,0.49]}\end{array}$ & $\begin{array}{c}0.380 \\
{[-0.39,1.15]}\end{array}$ & & & $\begin{array}{c}0.343 \\
{[-0.16,0.84]}\end{array}$ & $\begin{array}{c}0.236 \\
{[-0.71,1.18]}\end{array}$ \\
\hline $\begin{array}{l}z_{j, t-2} \\
z_{j, t} \times S_{j}\end{array}$ & & & $\begin{array}{c}0.0144 \\
{[-0.24,0.27]}\end{array}$ & $\begin{array}{c}0.310 \\
{[-0.05,0.67]} \\
-0.136 \\
{[-1.64,1.36]}\end{array}$ & & & $\begin{array}{c}-0.0183 \\
{[-0.40,0.37]}\end{array}$ & $\begin{array}{c}0.0275 \\
{[-0.71,0.77]} \\
0.978 \\
{[-2.02,3.98]}\end{array}$ \\
\hline$z_{j, t-1} \times S_{j}$ & & & & $\begin{array}{c}0.241 \\
{[-0.57,1.06]}\end{array}$ & & & & $\begin{array}{c}0.652 \\
{[-0.54,1.84]}\end{array}$ \\
\hline$z_{j, t-2} \times S_{j}$ & & & & $\begin{array}{c}-0.218 \\
{[-0.79,0.35]}\end{array}$ & & & & $\begin{array}{c}0.358 \\
{[-0.77,1.49]}\end{array}$ \\
\hline Time FE & no & no & no & no & no & no & no & no \\
\hline R-squared & 0.283 & 0.453 & 0.066 & 0.183 & 0.532 & 0.675 & 0.256 & 0.378 \\
\hline Observations & 766 & 544 & 768 & 544 & 697 & 525 & 699 & 525 \\
\hline Countries & 55 & 39 & 55 & 39 & 52 & 38 & 52 & 38 \\
\hline
\end{tabular}

Table 8: The first (resp., last) four columns use CPI (resp., PPI) growth as dependent variable. 95\% confidence intervals clustered by country and corrected for small number of clusters using "LZ2-BM" method of Imbens and Kolesár (2016). ** p $<0.05$. 
Robustness to data choices. We now show that our panel regression results are robust to a number of deviations from the baseline specifications in Section 4: using raw data instead of imputed and outlier-adjusted, using total goods indices rather than non-commodities, and changing the price index definition.

Table 9 provides exchange rate price pass-through regression results for three variations of our baseline specification. For brevity, we focus on importer-reported data and the specification with bilateral and USD exchange rates as regressors (but not interactions). The first data column in the table repeats our baseline results from column 5 in Table 1 . The second to fourth data columns vary one of each of the following data choices relative to the baseline: using raw data instead of imputed and outlier-adjusted, using total goods instead of non-commodities, and using Laspeyre price indices instead of Fisher. Across all these variations, the USD exchange rate quantitatively dominates the bilateral exchange rate, and the magnitudes of the contemporaneous and lagged coefficients are similar to the baseline. As expected, the $R^{2}$ of the regression is substantially smaller when outlier product categories are not removed.

Table 10 displays trade elasticity regression results for the same three variations of our baseline specification. We again use importer-reported data and the specification with bilateral and USD exchange rates as regressors (no interactions). The first data column in the table repeats our baseline results from column 5 in Table 3, while data columns two through four consider the same variations around the baseline as in Table 9. Our baseline results are quantitatively robust to these variations, except for the case where we use raw data instead of the imputed and outlieradjusted data. In the raw data, trade volumes appear uncorrelated with the dollar exchange rate, conditional on the bilateral exchange rate. We strongly prefer the cleaned data set used in this paper, since the raw Comtrade data exhibits several extreme outliers in the product category and time dimensions, as well as non-randomly missing data points (Boz and Cerutti, 2017).

\section{B.3 Bayesian analysis: MCMC settings and diagnostics}

We execute Stan through Matlab R2016b using MatlabStan 2.7.0.0, which in turn calls CmdStan 2.14.0. For each model specification, we run Stan's No U-Turn Sampler for 2,500 iterations after discarding 1,000 warm-up iterations, storing every 5th draw. The MCMC routine is initialized at parameter values drawn uniformly at random (after the parameters have been transformed to unconstrained support). We use Stan's default settings for adaptively tuning the MCMC routine in the warm-up phase. Our results are completely insensitive to the initialization.

The sampler robustly delivers near-independent draws from the posterior distribution in reasonable time. The stored posterior draws of most model parameters exhibit essentially zero serial 
RoBUSTNESS: EXCHANGE RATE PASS-THROUGH INTO PRICES

\begin{tabular}{l|cccc}
\hline \hline & $(1)$ & $(2)$ & $(3)$ & $(4)$ \\
VARIABLES & $\Delta p_{i j, t}$ & $\Delta p_{i j, t}$ & $\Delta p_{i j, t}$ & $\Delta p_{i j, t}$ \\
\hline \multirow{4}{*}{$\Delta e_{i j, t}$} & & & & \\
& $0.164^{* * *}$ & $0.192^{* * *}$ & $0.237^{* * *}$ & $0.162^{* * *}$ \\
$\Delta e_{i j, t-1}$ & $(0.0126)$ & $(0.0381)$ & $(0.0144)$ & $(0.0117)$ \\
& $0.0521^{* * *}$ & $-0.148^{* * *}$ & 0.0130 & $0.0739^{* * *}$ \\
$\Delta e_{i j, t-2}$ & $(0.0123)$ & $(0.0417)$ & $(0.0121)$ & $(0.0116)$ \\
& $-0.0727^{* * *}$ & $-0.158^{* * *}$ & $-0.0603^{* * *}$ & -0.0171 \\
$\Delta e_{\$ j, t}$ & $(0.0127)$ & $(0.0460)$ & $(0.0117)$ & $(0.0108)$ \\
& $0.781^{* * *}$ & $0.657^{* * *}$ & $0.708^{* * *}$ & $0.773^{* * *}$ \\
$\Delta e_{\$ j, t-1}$ & $(0.0143)$ & $(0.0456)$ & $(0.0161)$ & $(0.0135)$ \\
& $-0.0737^{* * *}$ & $0.147^{* * *}$ & $-0.0323^{* *}$ & $-0.0771^{* * *}$ \\
$\Delta e_{\$ j, t-2}$ & $(0.0157)$ & $(0.0492)$ & $(0.0151)$ & $(0.0135)$ \\
& $0.104^{* * *}$ & $0.290^{* * *}$ & $0.0890^{* * *}$ & $0.0545^{* * *}$ \\
& $(0.0146)$ & $(0.0528)$ & $(0.0135)$ & $(0.0127)$ \\
Exp. PPI & & & & \\
Time FE & yes & yes & yes & yes \\
R-squared & yes & yes & yes & yes \\
Observations & 0.398 & 0.118 & 0.428 & 0.439 \\
Dyads & 46,820 & 48,081 & 47,473 & 46,820 \\
\hline \hline & 2,647 & 2,680 & 2,661 & 2,647 \\
\hline
\end{tabular}

Table 9: Column 1: same as column 5 in Table 1. Column 2: raw data instead of imputed and outlieradjusted. Column 3: total goods instead of non-commodities. Column 4: Laspeyre price index instead of Fisher. Importer-reported data, full sample. S.e. clustered by dyad. ${ }^{* * *} \mathrm{p}<0.01,{ }^{* *} \mathrm{p}<0.05,{ }^{*} \mathrm{p}<0.1$. 
Robustness: Trade ElASTICITy With RESPECT to EXCHANGE RATE

\begin{tabular}{l|cccc}
\hline \hline & $(1)$ & $(2)$ & $(3)$ & $(4)$ \\
VARIABLES & $\Delta y_{i j, t}$ & $\Delta y_{i j, t}$ & $\Delta y_{i j, t}$ & $\Delta y_{i j, t}$ \\
\hline \multirow{3}{*}{$\Delta e_{i j, t}$} & $-0.0310^{*}$ & $-0.0956^{* * *}$ & $-0.0565^{* * *}$ & -0.0220 \\
& $(0.0160)$ & $(0.0237)$ & $(0.0129)$ & $(0.0158)$ \\
$\Delta e_{i j, t-1}$ & -0.00245 & 0.0410 & 0.00934 & -0.00101 \\
& $(0.0165)$ & $(0.0255)$ & $(0.0143)$ & $(0.0162)$ \\
$\Delta e_{i j, t-2}$ & $0.0235^{* *}$ & $0.0447^{* *}$ & 0.0173 & 0.00731 \\
& $(0.0115)$ & $(0.0192)$ & $(0.0112)$ & $(0.0114)$ \\
$\Delta e_{\$ j, t}$ & $-0.186^{* * *}$ & 0.00364 & $-0.150^{* * *}$ & $-0.187^{* * *}$ \\
& $(0.0250)$ & $(0.0391)$ & $(0.0218)$ & $(0.0245)$ \\
$\Delta e_{\$ j, t-1}$ & $0.168^{* * *}$ & 0.0225 & $0.148^{* * *}$ & $0.151^{* * *}$ \\
& $(0.0248)$ & $(0.0438)$ & $(0.0218)$ & $(0.0242)$ \\
$\Delta e_{\$ j, t-2}$ & $0.0365^{*}$ & -0.0287 & 0.0289 & $0.0409^{* *}$ \\
& $(0.0198)$ & $(0.0350)$ & $(0.0185)$ & $(0.0191)$ \\
Imp. GDP & & & & \\
Time FE & yes & yes & yes & yes \\
R-squared & 0.071 & 0.073 & 0.072 & 0.070 \\
Observations & 52,272 & 53,760 & 53,092 & 52,272 \\
Dyads & 2,807 & 2,845 & 2,822 & 2,807 \\
\hline \hline
\end{tabular}

Table 10: Column 1: same as column 5 in Table 3. Column 2: raw data instead of imputed and outlieradjusted. Column 3: total goods instead of non-commodities. Column 4: Laspeyre price index instead of Fisher. Importer-reported data, full sample. S.e. clustered by dyad. ${ }^{* * *} \mathrm{p}<0.01,{ }^{* *} \mathrm{p}<0.05,{ }^{*} \mathrm{p}<0.1$. 
correlation after a handful of lags. The only parameters that do not exhibit rapid mixing are those MGLR parameters $\mu_{0, k}, \mu_{1, k}, \omega_{k}, A_{k}$ that correspond to mixture components $k$ with low posterior probability $\pi_{k}(\cdot)$ in model specifications with large $K$, but these parameters negligibly influence the features of the posterior that we care about. Depending on $K$ and the random initial parameter draw, it takes 2-60 hours to run the MCMC routine for each specification on a personal laptop with a $2.30 \mathrm{GHz}$ processor and $8 \mathrm{~GB}$ RAM (no parallel computing is involved). In our experience, it is often sufficient to run the algorithm for 2-4 hours to get a sense of the results.

\section{B.4 Bayesian analysis: Supplementary results}

\section{B.4.1 Additional model parameters}

For completeness, we now report posterior summaries of the model parameters that are not of primary interest to us.

First we report results for the price pass-through model with $K=2$. Fig. 22 reports the posterior distribution of the cross-sectionally constant regression coefficients. The results are consistent with the panel regressions in Section 4. In particular, the lagged exchange rate changes are economically insignificant. The posterior for the parameter $\bar{\gamma}$ (the sum of the dollar and bilateral pass-throughs) is concentrated close to 1 , indicating near-complete total pass-through within a year. Fig. 23 reports the posterior of the mean $\alpha$ and standard deviation $\tau$ of the random effects distribution for the dyad-specific effects $\lambda_{i j}$, as well as the idiosyncratic standard error $\sigma$.

Figs. 24 and 25 provide the same posterior summaries for the trade elasticity model with $K=4$. Again, these results are consistent with the panel regressions from Section 4.

\section{B.4.2 Robustness to number of mixture components}

Here we show that the results in Section 5 are robust to varying the number $K$ of components in the MGLR prior for the cross-sectional distribution of dollar pass-through. Specifically, we here report results for $K=8$. Figs. 26 and 27 are the $K=8$ analogues of the price pass-through Figs. 9 and 11 (which had $K=2$ ), while Figs. 28 and 29 are the $K=8$ analogues of the trade elasticity Figs. 12 and 14 (which had $K=4$ ). Clearly, the additional mixture components in the $K=8$ specifications receive very low posterior probability. 
Posterior of CONSTANT REgRESSION COEFFICIENTS, PRICE PASS-THROUgh
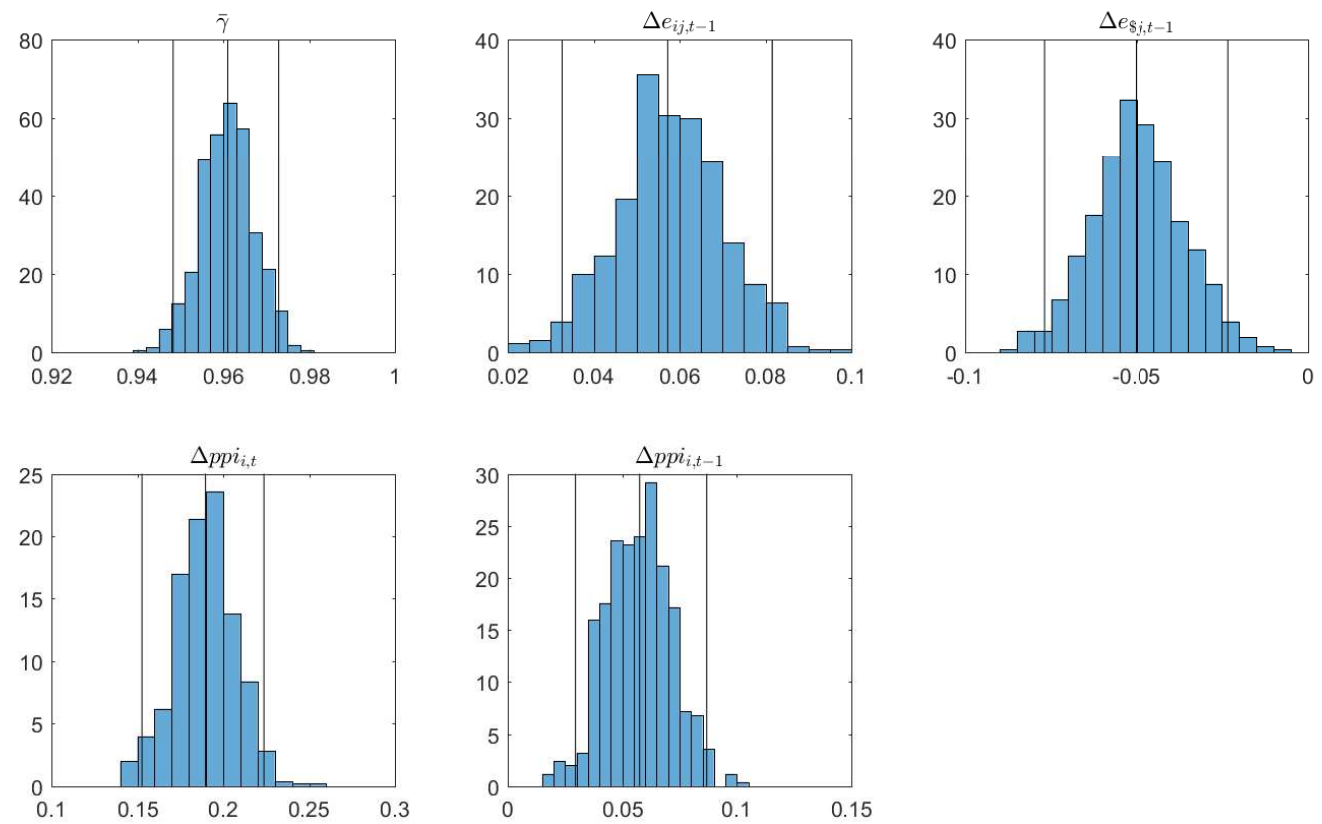

Figure 22: Histogram of posterior draws of elements in $\theta$, the regression coefficients that are assumed constant across dyads. The top left display shows the parameter $\bar{\gamma}$ in Eq. (8). The remaining displays show the coefficients on the indicated exogenous covariates. Vertical lines mark the 2.5, 50, and 97.5 percentiles. For brevity, we do not show the time fixed effects.

POSTERIOR OF OTHER PARAMETERS, PRICE PASS-THROUGH
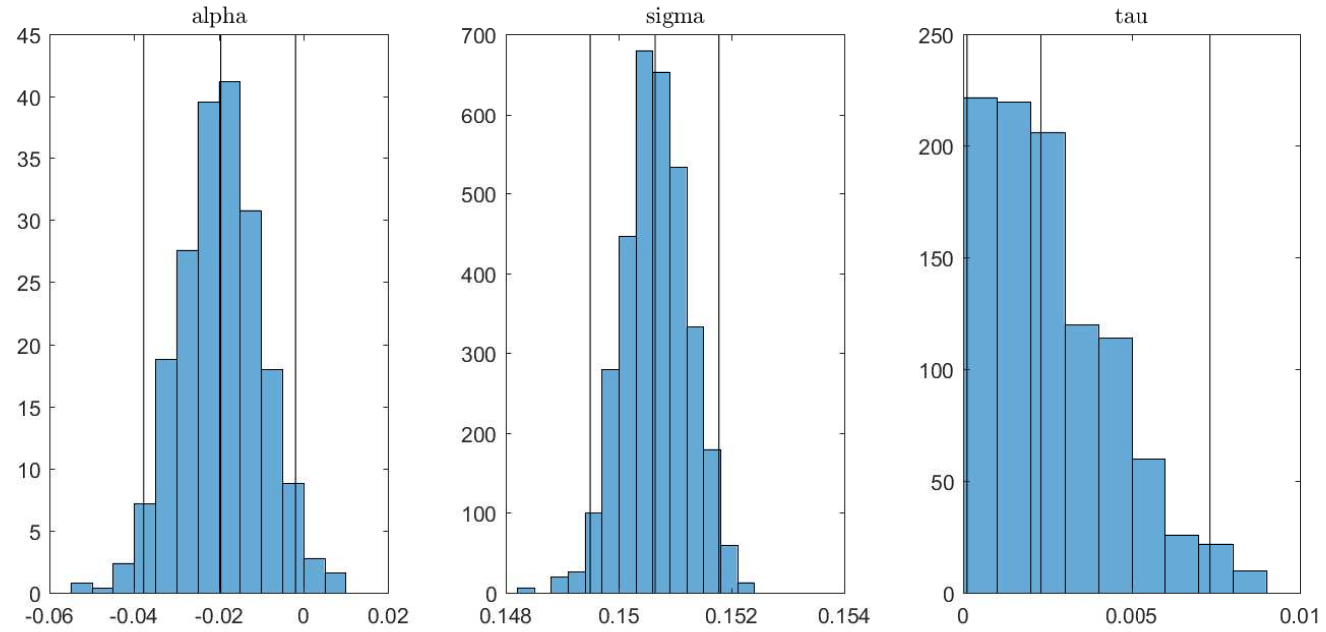

Figure 23: Histogram of posterior draws of $\alpha$ (left), $\sigma$ (middle), and $\tau$ (right). Vertical lines mark the 2.5, 50 , and 97.5 percentiles. 
POSTERIOR OF CONSTANT REGRESSION COEFFICIENTS, TRADE ELASTICITY
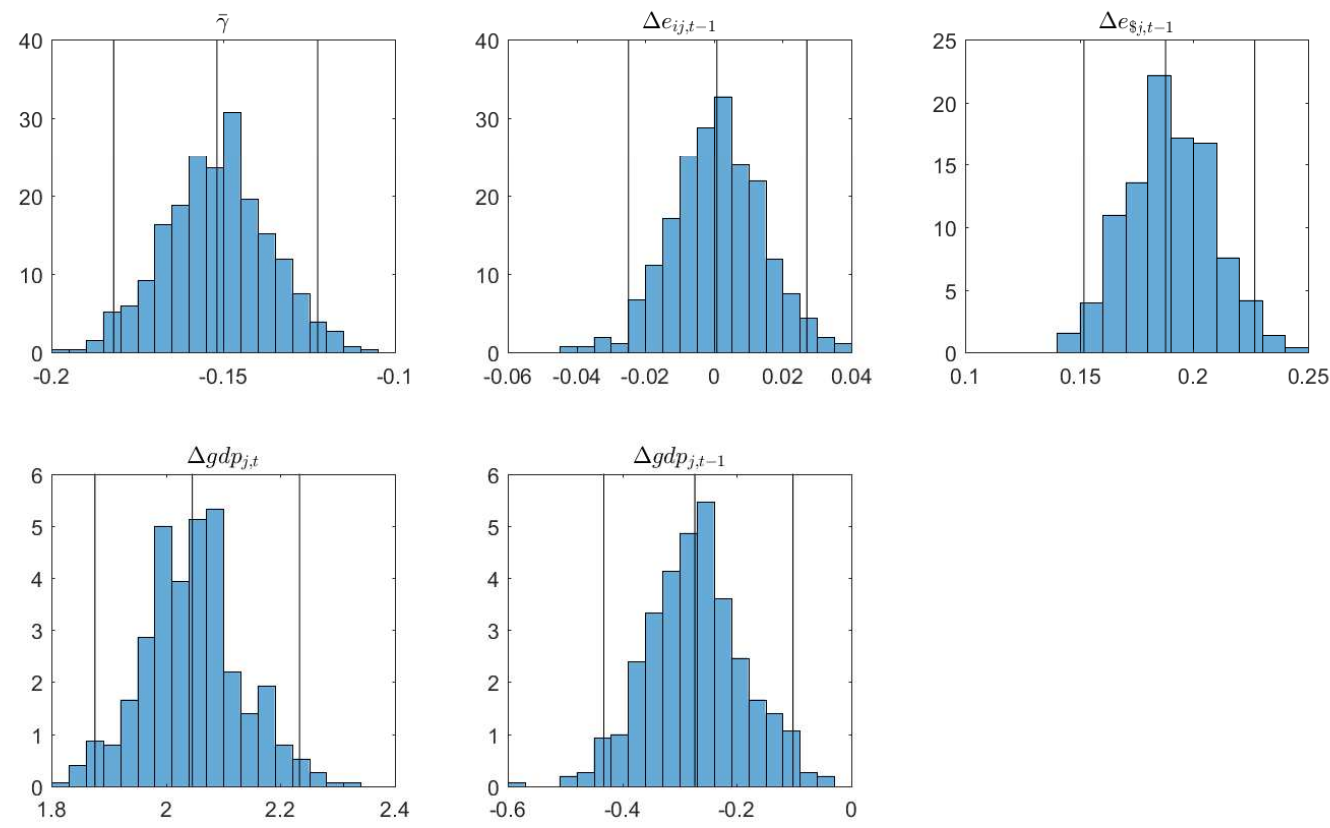

Figure 24: See caption for Fig. 22.

POSTERIOR OF OTHER PARAMETERS, TRADE ELASTICITY
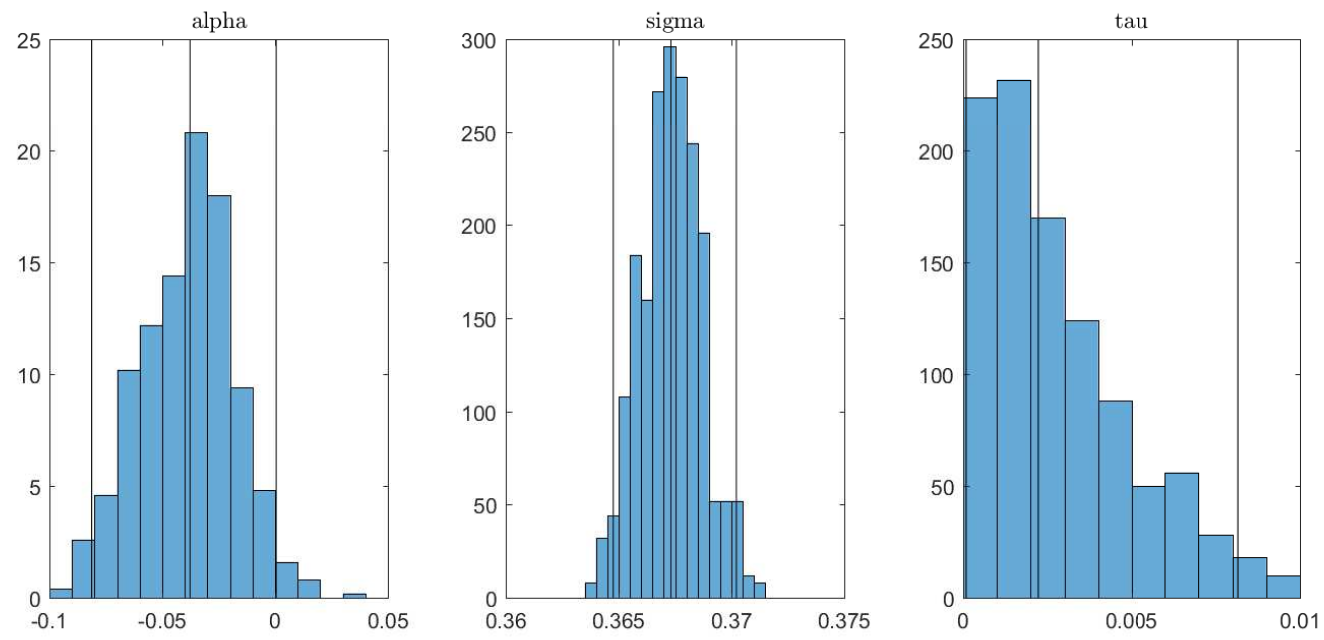

Figure 25: See caption for Fig. 23. 
Density of DOLLAR PRICE PASS-THROUgh GIVEN DOLLAR INVOICING SHARE, $K=8$
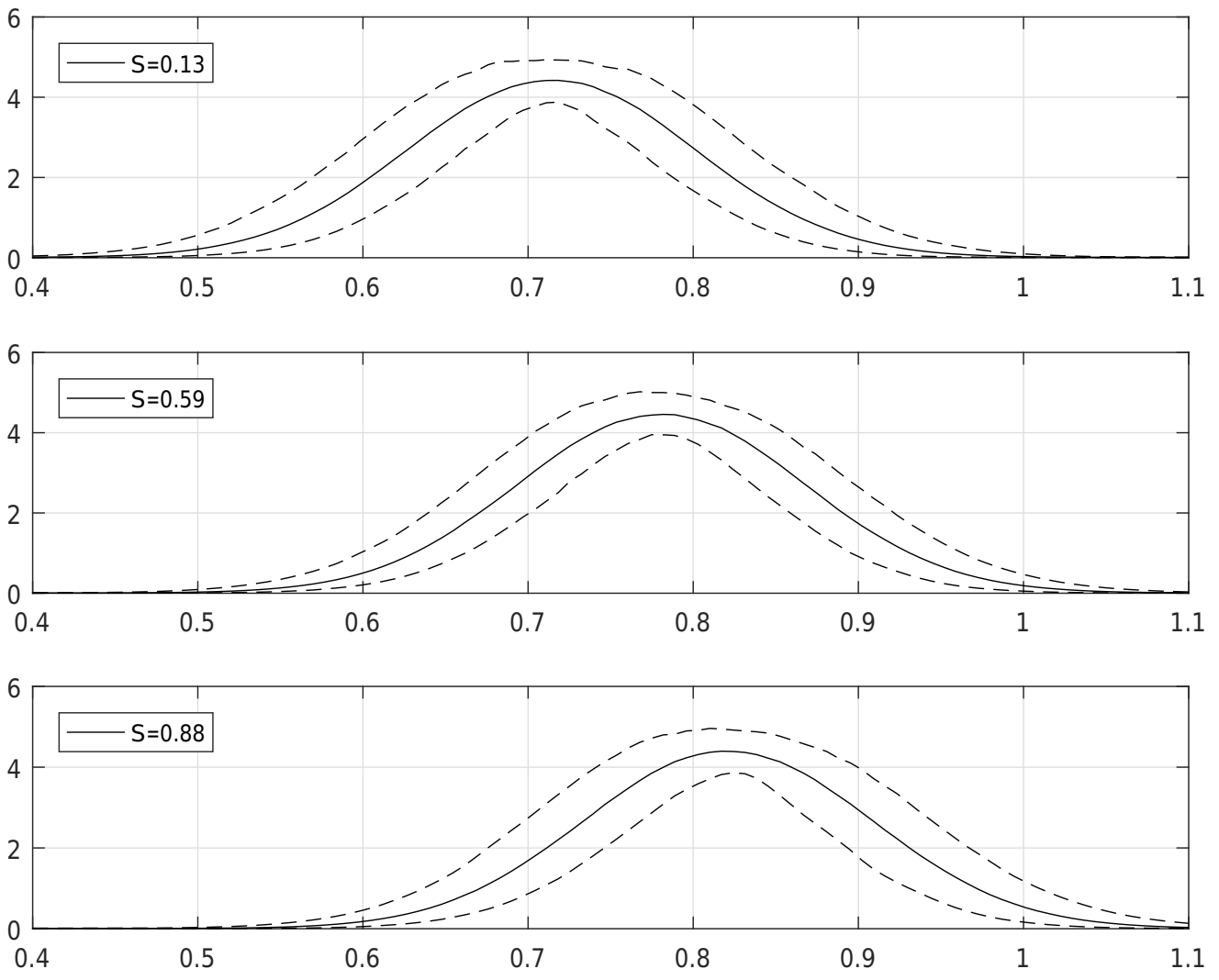

Figure 26: See caption for Fig. 9.

SAMPle Distribution of DOLlar PRICE PASS-THROUGH, $K=8$
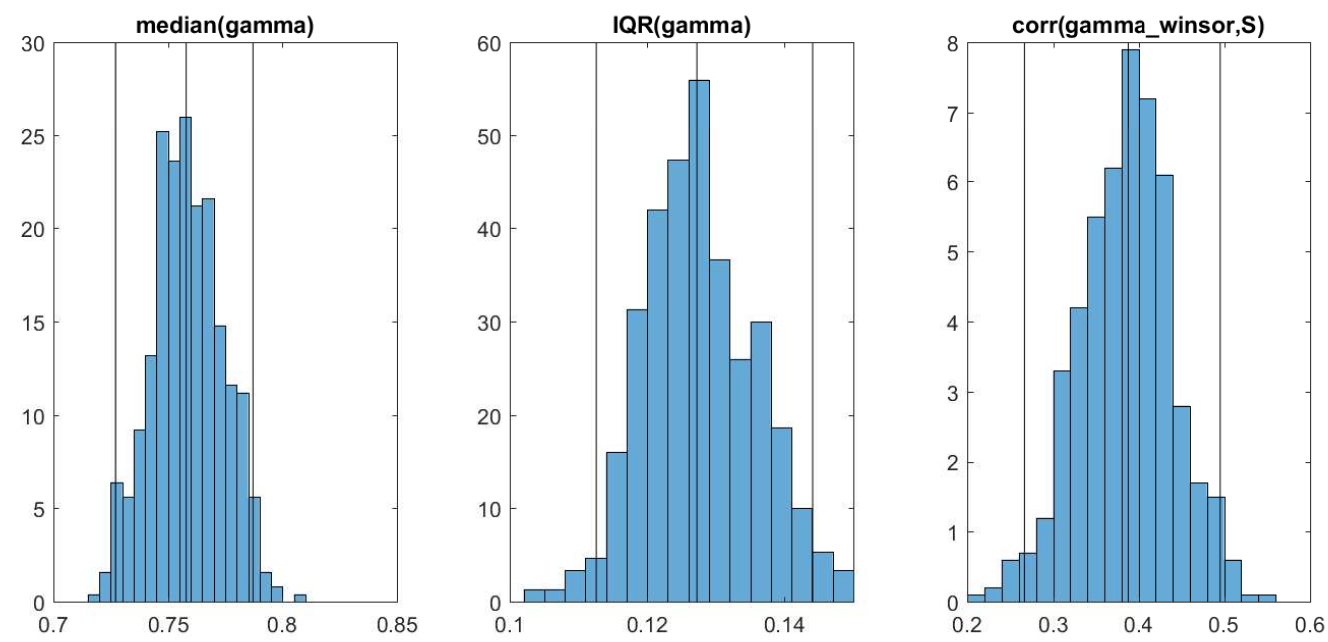

Figure 27: See caption for Fig. 11. 
DENSITY OF DOLLAR TRADE ELASTICITY GIVEN DOLLAR INVOICING SHARE, $K=8$
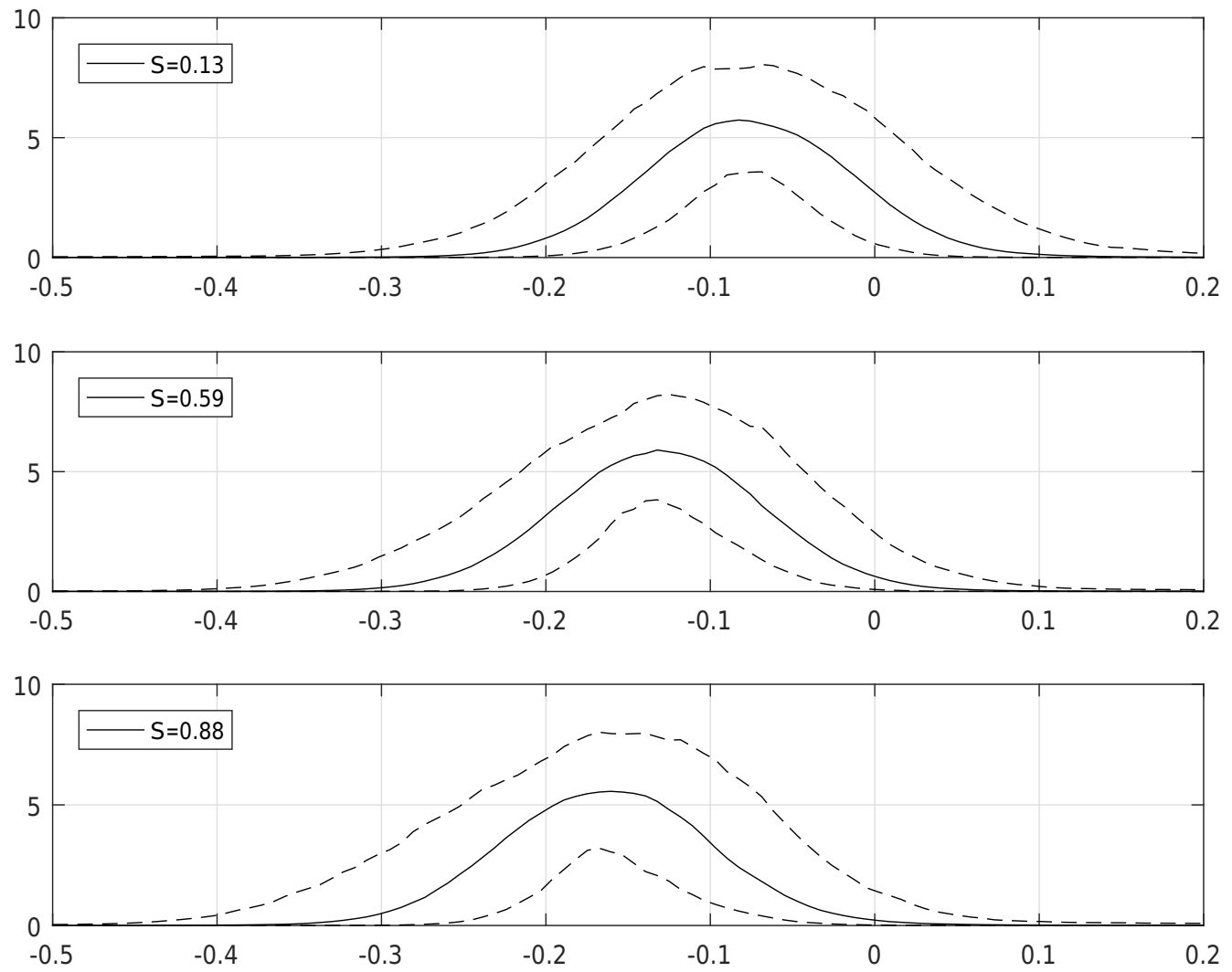

Figure 28: See caption for Fig. 12.

SAMPLE DiSTRIBUTION OF DOLLAR TRADE ELASTICITY, $K=8$
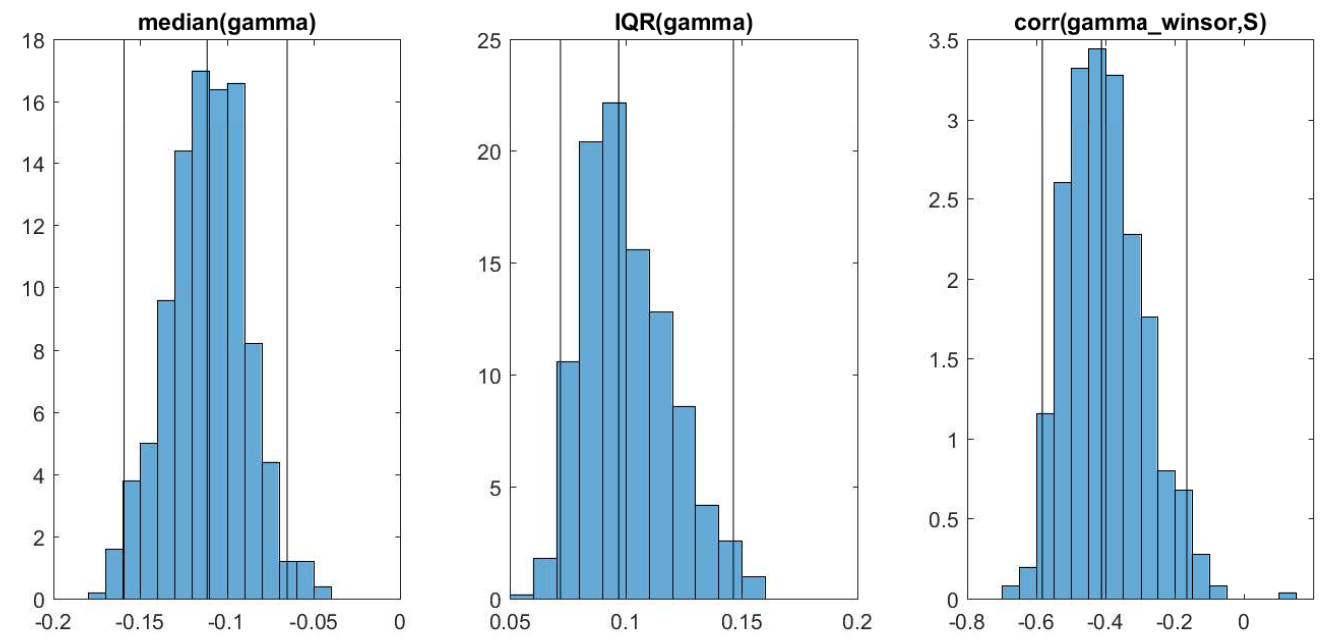

Figure 29: See caption for Fig. 14. 